\title{
Functional architecture of the synaptic transducers at a central
}

\section{glutamatergic synapse}

Marisa M. Brockmann, ${ }^{1, *}$, Estelle Toulme ${ }^{1}$, Andreas T. Grasskamp ${ }^{2}$, Thorsten Trimbuch ${ }^{1}$, Thomas C. Südhof $^{3}$, Alexander M. Walter ${ }^{2}$, Christian Rosenmund ${ }^{1, *}$

$8{ }^{1}$ Institute of Neurophysiology, Charité - Universitätsmedizin, 10117 Berlin, Germany

$9 \quad{ }^{2}$ Leibniz-Forschungsinstitut für Molekulare Pharmakologie (FMP), 13125, Berlin, Germany

$10{ }^{3}$ Department of Cellular and Molecular Physiology and Howard Hughes Medical Institute, Stanford University

11 School of Medicine, Stanford, CA 94305, USA

$12 *$ corresponding authors

\section{Summary:}

Neuronal synapses transduce information via the consecutive action of three transducers: voltage-gated $\mathrm{Ca}^{2+}$-channels, fusion-competent synaptic vesicles, and postsynaptic receptors. Their physical distance is thought to influence the speed and efficiency of neurotransmission. However, technical limitations have hampered resolving their nanoscale arrangement. Here, we developed a new method for live-labeling proteins for electron microscopy (EM), revealing that release-competent vesicles preferentially align with $\mathrm{Ca}^{2+}$-channels and postsynaptic AMPA receptors within $20-30 \mathrm{~nm}$ and thereby forming a transsynaptic tripartite nanocomplex. Using functional EM, we show that single action potentials cause vesicles within the nanocomplex to fuse with a $50 \%$ probability. The loss of the presynaptic scaffold disrupts the formation of the tripartite transducers. Strikingly, the forced transsynaptic alignment of the $\mathrm{Ca}^{2+}$-channel subunit $\alpha 2 \delta 1$ and AMPA receptors suffice to restore neurotransmission in a scaffold lacking synapse. Our results demonstrate a synaptic transducer nanocomplex that actively contributes to the organization of central synapses.

32 Keywords: electron microscopy; live-gold labeling; stim-and-freeze; high-pressure freezing; calcium 33 channels; $\alpha 2 \delta 1$; AMPA receptor; calcium-secretion coupling; release probability transsynaptic nanocolumns synapse assembly; synaptic transmission 


\section{Introduction}

37 Synapses are highly specialized structures that orchestrate the activity-dependent information transfer 38 between neurons. At the presynapse, an incoming action potential opens voltage-gated $\mathrm{Ca}^{2+}$-channels (VGCC) that triggers the fusion of release competent synaptic vesicles (SVs) and neurotransmitter release into the synaptic cleft (Sudhof, 2014). At the postsynapse, the neurotransmitter is sensed by its respective receptors and elicits an amplitude-coded response. Therefore, $\mathrm{Ca}^{2+}$-channels, fusioncompetent SVs, and postsynaptic receptors represent the key transducers of synaptic transmission. While this basic concept is well-accepted, a clearer picture of the nanoscale arrangement of pre- and postsynaptic proteins is only now starting to emerge.

The nanoscale arrangement of $\mathrm{Ca}^{2+}$-channels and fusion-competent SVs is thought to be critical in determining the speed and efficiency of neurotransmission. Initial experiments, performed at the frog neuromuscular junction (Harlow et al., 2001) and the squid giant synapse (Adler et al., 1991), already suggested tight coupling distances between $\mathrm{Ca}^{2+}$-channels and fusion-competent $\mathrm{SVs}$ that favor efficient $\mathrm{Ca}^{2+}$ secretion coupling. Measuring the sensitivity of neurotransmitter release in the presence of exogenous calcium chelators indicates a wide range $(10 \mathrm{~nm}$ and $100 \mathrm{~nm})$ of functional coupling distances at mammalian central synapses (Arai and Jonas, 2014; Bohme et al., 2016; Bucurenciu et al., 2008; Eggermann et al., 2011; Keller et al., 2015; Nakamura et al., 2015; Rebola et al., 2019; Vyleta and Jonas, 2014). However, the physical distance between fusion-competent SVs and $\mathrm{Ca}^{2+}$-channels in small mammalian central synapses has not yet been measured.

Distinct coupling distances between $\mathrm{Ca}^{2+}$-channels and release-competent SVs may contribute to the striking diversity of release probability and short-term plasticity characteristics among synapses (Nusser, 2018; Rosenmund et al., 1993). RIM proteins (Rab3-interacting molecule) and RIM-binding proteins (RBPs) are particularly good candidates to control the $\mathrm{Ca}^{2+}$-secretion coupling distance in synapses. They directly interact with $\mathrm{Ca}^{2+}$-channels, and their loss of function leads to disruption of $\mathrm{Ca}^{2+}$-secretion coupling in both vertebrates and invertebrates (Acuna et al., 2015; Brockmann et al., 2019; Davydova et al., 2014; Graf et al., 2012; Grauel et al., 2016; Kaeser et al., 2011; Liu et al., 2011). Therefore, by controlling the precise distances between fusion-competent SVs and voltage-gated $\mathrm{Ca}^{2+}$-channels, these presynaptic scaffolding proteins could contribute to the heterogeneity of release properties between synapses.

The positional arrangement of central postsynaptic glutamate receptors also shapes synaptic function. AMPA receptors are organized in nanodomains (MacGillavry et al., 2013), and super-resolution microscopy revealed a transsynaptic organization of nanocolumns, including the association of the presynaptic scaffold RIM with the postsynaptic scaffold PSD-95 and AMPA receptors (Tang et al., 
69 2016). These findings raise the hypothesis that synapses comprise functional units at the pre- and

70 postsynapse that must be transsynaptically aligned to ensure successful neurotransmission. Therefore,

71 it is not only important to determine the spatial arrangement of functional units, but also to uncover

72 the underlying molecular mechanism that drives their assembly. Although multiple transsynaptic

73 interactions by diverse adhesion molecules contribute to the assembly of pre- and postsynaptic 74 assemblies (Sudhof, 2018), we still lack information about which and how those interactions control 75 the position of the key transducers.

76 In this study, we aimed to address the relative localization of the three key transducers of efficient neurotransmission - fusion-competent $\mathrm{SVs}, \mathrm{Ca}^{2+}$-channels, and AMPA receptors - in the synapse. To determine the transducers' spatial arrangement on a nanometer scale, we developed a live-goldlabeling, EM compatible tagging approach for synaptic proteins to reveal the spatial arrangement of docked SVs in the active zone relative to proteins, such as $\mathrm{Ca}^{2+}$-channels. We could detect $\mathrm{Ca}^{2+}$ - and AMPA channels within the narrow confines of the synaptic cleft and found that they both align with a distance of 20-30 nm to docked SVs to form a nanocomplex in small excitatory synapses. Moreover, we combined the live-labeling of $\mathrm{Ca}^{2+}$-channels with functional EM, allowing us to arrest the synaptic ultrastructure milliseconds after action-potential induced SV fusion and defined the vesicle fusion probability as a function of $\mathrm{Ca}^{2+}$-channel distance. Synaptic vesicles within the nanocomplex fused with a $50 \%$ probability upon action potential stimulation. Furthermore, genetically induced the loss of synaptic scaffold led to loss of the alignment of the three transducers and synaptic transmission, but by forcing the transsynaptic alignment of the presynaptic voltage-gated $\mathrm{Ca}^{2+}$-channel auxiliary subunit $\alpha 2 \delta 1$ and postsynaptic AMPAR receptor subunit GluA2, synaptic transmission was restored. Thus, $\alpha 2 \delta 1$ can act as a nucleation factor to recruit the $\mathrm{Ca}^{2+}$-channels $\alpha$-subunit and docked SVs to enable neurotransmission in the absence of a presynaptic scaffold. Therefore, our findings support a model of self-organizing synaptic units and close physical $\mathrm{Ca}^{2+}$-channel-fusion-competent-SV coupling as means by which central mammalian synapses ensure efficient synaptic transmission.

Results

96 We first sought to localize voltage-gated $\mathrm{Ca}^{2+}$-channels within the presynaptic active zone (AZ). We tagged the mouse $\mathrm{Ca}^{2+}$-channel auxiliary subunit $\alpha 2 \delta 1$ (Dolphin, 2013) with a $10 \mathrm{x}$ His-Tag and induced its exogenous expression using lentivirus (Figure 1A). Using nickel nitrilotriacetic acid 99 (NiNTA) coupled to $5 \mathrm{~nm}$ gold particles, we were able to detect $\alpha 2 \delta 1$-His with a coupling distance of 
Because of their synaptogenic function, strong overexpression of $\alpha 2 \delta 1$ in neurons potentiates synaptic responses (Eroglu et al., 2009; Hoppa et al., 2012). To prevent alterations in synaptic localization of $\alpha 2 \delta 1$-His due to its overexpression, we transduced $\alpha 2 \delta 1$-His in primary neurons and assessed synaptic responses. The concentrations of $\alpha 2 \delta 1$-His reached in our experiments did not affect synaptic amplitudes or release probability (Figure S1). Moreover, ultrastructural parameters of the synapse, such as the number and distribution of docked SV at the AZ and the length of the postsynaptic density (PSD), were also unchanged upon $\alpha 2 \delta 1$-His expression (Figure S2A-E). Pre-incubation of synapses expressing $\alpha 2 \delta 1$-His with the NiNTA-gold resulted in an 8-fold enrichment of gold particles in the synaptic cleft (Figure 1B,C), and their position was significantly skewed towards the presynaptic membrane within the synaptic cleft width (Figure 1D), indicating specific labeling. The gold particles were equally allocated across the length of the synaptic profile, suggesting a uniform distribution of the $\mathrm{Ca}^{2+}$-channel subunit $\alpha 2 \delta 1$, similar to the positions of docked SVs (Figure S2E, I).

\section{$\mathrm{Ca}^{2+}$-channels associate with docked SVs in $20 \mathrm{~nm}$}

115 While physiological recordings, super-resolution imaging, and computational studies inferred the 116 coupling distance in various vertebrate and invertebrate synapses (Arai and Jonas, 2014; Bucurenciu 117 et al., 2008; Eggermann et al., 2011; Keller et al., 2015; Nakamura et al., 2015; Schmidt et al., 2013; 118 Vyleta and Jonas, 2014; Wadel et al., 2007), the distance of $\mathrm{Ca}^{2+}$-channels to fusion-competent, docked 119 SVs has never been directly determined. We assessed each gold particle's shortest distance, labeling $\alpha 2 \delta 1$, to the next docked SV. The cumulative distribution, as well as the mean-nearest neighbor analysis, revealed that the distance between the $\mathrm{Ca}^{2+}$-channel subunit $\alpha 2 \delta 1$ and the next docked SV is non-random and significantly different from the control, skewing the distribution towards shorter distances (Figure 1E, and Figure S2J). In the first $60 \mathrm{~nm}$ of the next docked SV, the abundance of $\alpha 2 \delta 1$-His increased by $23 \%$ compared to simulations of uniform SV and gold particle placement (Figure S2L), with a median distance of $46 \mathrm{~nm}$ (Figure 1E). To gain further insight into the $\mathrm{Ca}^{2+}$-channel-docked SV relationship at the AZ, we obtained tomograms and analyzed the distance of $\alpha 2 \delta 1$-His to the center of the next docked SV in 3D (Figure 1F, G, Figure S3, and Figure S4A). Strikingly, as with the $2 \mathrm{D}$ analysis, the $3 \mathrm{D}$ analysis revealed an accumulation of $\alpha 2 \delta 1$ within a median distance of $22 \mathrm{~nm}$ of the closest docked SV compared to random uniform SV and gold particle placement (Figure 1G, and Figure S4B). Fitting the minimal distances, using an integrated Rayleigh function, revealed a $\sigma$ value of $20.3 \mathrm{~nm}$ (Figure 1H), demonstrating a close association of 


\section{The vesicle release probability as a function of $\mathrm{Ca}^{2+}$-channels to fusion-competent $\mathrm{SV}$ distance}

135 In theory, the tight association of $\mathrm{Ca}^{2+}$-channel and fusion competent SVs should promote the high 136 probability of action potential triggered SV fusion (Augustine et al., 2003; Bucurenciu et al., 2008; 137 Neher, 1998). However, how this translates into absolute release probabilities as a function of the 138 distance of two key presynaptic transducers and how release probabilities of docked SVs decay with 139 increasing distances has only been modeled. We set out to define the probability of SVs fusion as a 140 function of $\mathrm{Ca}^{2}$-channel distance by comparing the distances of $\mathrm{Ca}^{2+}$-channels and fusion-competent 141 SVs between unstimulated samples and samples arrested milliseconds after action potential induced 142 vesicle fusion (Figure 2A). This precise timing was now possible by combining our novel anatomical 143 approach with stim-and-freeze technology, in which a single action potential is triggered in neurons 144 by field stimulation, followed by rapid cryofixation with a delay of $5 \mathrm{~ms}$ using a high-pressure freezing 145 device. The number of docked SVs in stimulated sections decreased by $30 \%$, demonstrating successful 146 fusion events across the whole AZ length (Figure 2B and Figure S2C, E) (Kusick et al., 2020). As 147 predicted, the median distance of $\alpha 2 \delta 1$-His to the next remaining docked SV increased from $46 \mathrm{~nm}$ to $148126 \mathrm{~nm}$ since docked SVs close to $\mathrm{Ca}^{2+}$-channels had been depleted. These findings strongly support 149 our assumption that synaptic $\alpha 2 \delta 1$ labeling is a proxy for functional $\mathrm{Ca}^{2+}$-channels (Figure 2C). 150 Therefore, we were now able to define the vesicular release probability as a function of distances to $151 \mathrm{Ca}^{2+}$-channels. By comparing the minimal distances between gold particles and SVs without 152 stimulation to the ones observed $5 \mathrm{~ms}$ after stimulation, we found a $50 \%$ vesicular release probability 153 at a distance of $20 \mathrm{~nm}$ (Figure 2D). The likelihood of SV fusion as a function of distance was 154 determined by fitting with a single exponential decay function and revealed a peak release probability 155 of $86 \%$ for minimal distances while release probability decayed with a length constant of $39 \mathrm{~nm}$. This 156 value represents an upper limit of the $\mathrm{Ca}^{2+}$-secretion coupling distance as live labeling of $157 \mathrm{Ca}^{2+}$-channels by gold particles was likely not saturated.

\section{AMPA receptors transsynaptically align with docked SVs}

160 The magnitude of the postsynaptic response to presynaptic neurotransmitter release is defined both by 161 the number of postsynaptic receptors (Nusser et al., 1998) and the fraction of receptor binding sites 162 occupied by glutamate; the latter of which increases with close apposition to the site of presynaptic 163 release (Savtchenko and Rusakov, 2014). Therefore, we tested whether AMPA receptors are also 164 associated with docked SVs by labeling exogenously expressed His-tagged AMPA receptor GluA2 subunits in living neurons (Figure 3A, B). As with $\alpha 2 \delta 1$-His expression, GluA2-His expression did not affect the number and distribution of docked SVs at the AZ or the PSD length (Figure S5A-E). We 
detected a $\sim 5$-fold enrichment of gold particles in the synaptic cleft upon GluA2-His expression, with localization skewed towards the postsynaptic membrane within the width of the synaptic cleft (Figure S5F-H). Interestingly, the synaptic distribution of GluA2 showed a preference towards the edge of the AZ (Figure 3C). To determine whether GluA2 is preferentially localized near release sites, we measured each gold particle's distance to the nearest presynaptic docked SV. Again, we found a non-random distribution with a $57 \%$ higher probability of GluA2-His within $60 \mathrm{~nm}$ of docked SVs compared to randomized data (Figure 3D, E). Strikingly, in the first $90 \mathrm{~nm}$, the cumulative distribution of GluA2-His to docked SVs is equal to the distribution of $\alpha 2 \delta 1-\mathrm{His}$ (Figure 3D). These data compellingly suggest that the three main transducers of synaptic transmission constitute an anatomical unit.

\section{Neurexin1 and neuroligin 1 are localized at the edge of the $\mathrm{AZ}$}

At mammalian hippocampal synapses, pre- and postsynaptic scaffold proteins align in nanocolumns across the synapse, possibly mediated by cell-adhesion molecules (Biederer et al., 2017; Sudhof, 2017). Transsynaptic alignment of pre- and postsynaptic scaffold proteins has been linked to adhesion molecules (Sudhof, 2018). To test for their putative role in positioning $\mathrm{Ca}^{2+}$-channels, release competent SVs, and postsynaptic receptors, we expressed His-tagged neurexin1 and neuroligin1 in neurons and probed their synaptic distribution. Neurexin1-His and neuroligin1-His expression did not alter synaptic ultrastructure (Figure S5A-E) and resulted in an $~ 5$-fold enrichment of gold particles in the synaptic cleft. Gold particles were closer to the presynapse for neurexin1 and closer to the postsynapse for neuroligin1 (Figure S5F-H), consistent with their predicted pre- and postsynaptic localization, respectively (Sudhof, 2017). Along the surface of the AZ, neuroligin1, and to a greater extent, neurexin1 show a non-randomized distribution, with a strong enrichment towards the edge of the AZ (Figure 3F and Figure S5I). When assessing their relative position to docked SVs, neurexin1 and neuroligin1 showed an increased distance to docked SV compared to randomized placement (Figure 3G, H and Figure S5J, K). Therefore, neurexin1 and neuroligin1 are not closely positioned to docked SVs and are unlikely to drive the tripartite synaptic transducer complex assembly.

\section{The presynaptic scaffold orchestrates the transducers' alignment}

So far, our EM data show that $\mathrm{Ca}^{2+}$-channels, release competent SVs, and postsynaptic AMPA receptors form an anatomical unit. The main mechanisms proposed how the transducers align at the $\mathrm{AZ}$ is via synaptic scaffold proteins that align in nanocolumns and subsequently recruit and stabilize them. We addressed the synaptic scaffold's requirement by examining synapses from the RIM/RBP 
quadruple $\mathrm{KO}$ (qKO) mouse. In qKO neurons, the presynaptic scaffold is drastically disrupted, docked

201 SVs, and presynaptic $\mathrm{Ca}^{2+}$-channels are substantially reduced, the PSD length is increased, and consequently, synaptic transmission nearly abolished (Figure S6) (Acuna et al., 2016; Brockmann et al., 2020). Our live-gold-labeling protocol showed that in qKO synapses, His-tagged $\alpha 2 \delta 1$ and GluA2 were significantly reduced (Figure 4A-D). Consistent with the electron microscopy data, dSTORM analysis revealed a severe, synapse-specific loss of endogenous Cav2.1, Cav2.2, and GluA1 and GluA2 protein clusters (Figure 4F-H, and Figure S6F-O). The reduction in postsynaptic AMPA receptors was confirmed by electrophysiological recordings detecting a $60 \%$ reduction in the mEPSC amplitude (Figure 4I, J). Interestingly, mEPSC rise time in qKO neurons was significantly increased, perhaps caused by the broadening of the synaptic cleft width or the aberrant alignment of fusing SVs to postsynaptic receptors (Figure 4E, K). The mEPSC amplitude and rise time were obtained from the reanalysis of previously published data (Brockmann et al., 2020). These findings strongly support that the synaptic scaffold is necessary for the efficient alignment of the tripartite transducer complex. However, there is emerging evidence that the transducers transsynaptically align by direct or indirect interactions (Watson et al., 2017), and it is possible that the transducers autonomously promote their coupling and therefore promote synaptic transmission. To test this, we bypassed scaffold function by the forced alignment of two transducers, $\alpha 2 \delta 1$ and GluA2, in a scaffold lacking synapse and tested for their independent role in synaptic organization and function.

\section{Artificial alignment of the transducers' rescues neurotransmission in a scaffold lacking synapse}

We reconstituted $\mathrm{Ca}^{2+}$-channel and AMPA receptor alignment in qKO synapses by artificially enforcing the extracellular interaction of $\alpha 2 \delta 1$ - and GluA2 through a transsynaptic biotin-minimal streptavidin (mSA) link (Penn et al., 2017). We then tested whether this link would, in turn, restore some synaptic architecture and function. To our surprise, transfecting $\alpha 2 \delta 1$-acceptor protein (AP), GluA2-mSA, and the biotin ligase BirA in qKO synapses (Figure 5A) rescued synaptic transmission (Figure 5B, C). Multiple functions are required for synaptic transmission. First, to test for the reassembly of release sites, we probed for the formation of plasma membrane docked, fusioncompetent SVs using EM. We found that SV docking, and its electrophysiology equivalent, SV priming, were robustly rescued (Figure 5D-G), likely due to partial relocalization of the essential SV priming factor Munc13-1 that was lost in qKO synapses (Figure S7H, J) (Acuna et al., 2016; Brockmann et al., 2020). Second, voltage-gated $\mathrm{Ca}^{2+}$-channel function returned in the presynaptic terminals of qKOs neurons (Figure 5H, I), indicative for the recruitment of pore-forming $\mathrm{Ca}^{2+}$-channel $\alpha$-subunits to release sites. The absence of neurotransmission in synapses, only expressing $\alpha 2 \delta 1-\mathrm{AP}$ 
233 and GluA2-mSA without BirA, where no interaction between the two components was forced, shows

234 that not the re-expression itself but specifically their alignment in the synapse is mandatory for neurotransmission. Overall, these data suggest that the stable alignment of $\mathrm{Ca}^{2+}$-channels, AMPA receptors, and docked SV is both necessary and sufficient to achieve neurotransmission. Additionally, anchoring $\alpha 2 \delta 1$ at the presynapse is a key step in organizing the presynaptic release function. However, not all functions lost in qKO synapses were restored by the artificial alignment of $\alpha 2 \delta 1$ and GluA2: the increase in PSD length and synaptic cleft width remained, and also mEPSC amplitude and rise time were not significantly rescued (Figure S7A-G). These data suggest that the transsynaptic

$241 \mathrm{Ca}^{2+}$-channel-GluA2 alignment restored presynaptic release, it did not recruit endogenous AMPA

242 channels across functional release sites.

\section{Discussion}

245 We developed a novel live labeling EM based protein technique and utilized this technique to quantify 246 -with single-digit $\mathrm{nm}$ resolution- the spatial arrangement of the three transducers for 247 neurotransmission: release competent SVs, voltage-gated $\mathrm{Ca}^{2+}$-channels, and postsynaptic AMPA 248 receptors at central hippocampal synapses. Interestingly, we found that $\mathrm{Ca}^{2+}$-channels are located at a 249 preferred distance of $20 \mathrm{~nm}$ to docked SVs and that action potential induced $\mathrm{Ca}^{2+}$-influx through $250 \mathrm{Ca}^{2+}$-channels triggers the fusion of these SVs with a release probability of $50 \%$. Furthermore, we 251 found that the three transducers form a transsynaptic nanocomplex. By artificially reconstituting a 252 transsynaptic interaction between the $\mathrm{Ca}^{2+}$-channel auxiliary subunit $\alpha 2 \delta 1$ and the AMPA subunit 253 GluA2, we provide the first evidence that $\alpha 2 \delta 1$ can serve as a nucleation point in the presynapse to 254 align the transducers for neurotransmission, independent from the presynaptic scaffold. This finding 255 proposes a novel mechanism on how individual synaptic units self-organize to orchestrate 256 neurotransmission.

257 The finding that pre- and postsynaptic scaffold proteins align in nanocolumns (Tang et al., 2016) 258 strongly suggested a transsynaptic association of the transducers for neurotransmission. Indeed, by 259 utilizing our live-gold-labeling of synaptic proteins, we showed for the first time that the pre- and 260 postsynaptic transducers transsynaptically align at a spatial scale equivalent to that of the SV radius.

261 Using the efficacy of slow intracellular $\mathrm{Ca}^{2+}$-buffers and diffusion models, previously published works 262 suggest varying coupling distances at mammalian synapses, e.g., 10-20 nm for basket cells, 30-60 nm 263 for the Calyx of Held, and 65-90 nm for mossy fiber synapses (Bohme et al., 2018). Since the key 264 parameter - the distance of fusion-competent vesicles to $\mathrm{Ca}^{2+}$-channels - was lacking, the release 265 probability of SVs was simulated. Simulations established that vesicular release is sensitive to their 
distance to $\mathrm{Ca}^{2+}$-channels in a range of 5-10 nm (Bennett et al., 2000; Scimemi and Diamond, 2012), that $\mathrm{SV}$ s close to $\mathrm{Ca}^{2+}$-channels have a higher release probability than distant once (Meinrenken et al., 2002; Neher, 2015) and that coupling-distances above $100 \mathrm{~nm}$ do not contribute to synaptic release (Nakamura et al., 2015). Our study used functional anatomy at small hippocampal synapses, which enabled us to directly determine the spatial coupling and release function of fusion competent SVs and $\mathrm{Ca}^{2+}$-channels. Compared to simulated data from other synapses (Nakamura et al., 2015; Rebola et al., 2019), the estimated release probability for small hippocampal synapses is rather high, but detailed modeling and consideration of the fraction and mobility of fusion competent SVs that are not associated with $\mathrm{Ca}^{2+}$-channels will likely provide a better understanding how overall release properties and short-term plasticity characteristics are defined by the anatomical state of the synapse.

Deploying our functional anatomy approach, it is now possible to also measure fusion probability as a function of $\mathrm{Ca}^{2+}$-channel distance for other synapse types, such as the hippocampal mossy fiber bouton, and compare the physical arrangement of synaptic transducers with the resulting function in synaptic transmission. Comparing the measured distance between docked SVs and $\mathrm{Ca}^{2+}$-channels in synapse types with different release probabilities and short-term plasticity characteristics will address whether diversity in coupling distances indeed contributes to varying release efficacies, thus uncovering an underlying mechanism for synaptic diversity. These approaches will not only teach us about the function of individual synapses, but they will also help to add significant new understanding for computation in neural networks when the approach is applied to large scale connectome analysis, as individual connections may be decoded for their release probability.

Our live-gold-labeling technique, paired with high-pressure-freezing EM, revealed the spatial arrangement between membranous structures and pre- and postsynaptic proteins. A previous study, using super-resolution light microscopy, demonstrated the transsynaptic nanocolumn arrangement of synaptic scaffold proteins (Tang et al., 2016). However, visualization of the SV, a crucial component in the neurotransmitter release process, was lacking. By combining EM with efficient protein labeling, we have proven that docked SVs align with $\mathrm{Ca}^{2+}$-channels and AMPA receptors. Strikingly, the adhesion molecules neurexin1 and neuroligin1 are not associated with docked SVs and are primarily found at the active zone's edge, rendering them an unlikely candidate for stabilizing the transducer complex.

What are possible candidates for stabilizing the transducers' complex, and what drives its assembly? To gain mechanistic insight, we made use of synapses lacking the presynaptic scaffold. The deletion of RIM and RBP results in synaptic loss and disruption of the transducers, shown by a substantial reduction in gold particles labeling $\mathrm{Ca}^{2+}$-channels and AMPA receptors. The disruption of the 
299 transducers' alignment results in major synaptic changes, including the loss of docked SVs and

300 neurotransmission. Strikingly, we found that the stabilization of the $\mathrm{Ca}^{2+}$-channel subunit $\alpha 2 \delta 1$ at the

301 presynapse in scaffold lacking synapses restores primary presynaptic functions such as the rescue of

$302 \mathrm{SV}$ docking and priming, $\mathrm{Ca}^{2+}$-influx, and $\mathrm{Ca}^{2+}$-triggered release, suggesting that the $\alpha 2 \delta 1$ subunit,

303 rather than the $\alpha$-subunit (Held et al., 2020), plays a key organizing role in the synapse. These results

304 imply that the $\mathrm{Ca}^{2+}$-channel $\alpha$-subunit that mediates the voltage-dependent $\mathrm{Ca}^{2+}$-influx is stabilized by

$305 \alpha 2 \delta 1$. Therefore, the RIM and RBP scaffold that interacts intracellularly with the $\alpha$-subunit may

306 perform fine-tuning of the voltage-dependent $\mathrm{Ca}^{2+}$-channel localization rather than the initial

307 stabilization. So far, we still do not understand the molecular mechanism that stabilizes $\alpha 2 \delta$ at the

308 synapse. The most noteworthy candidates are cis or trans-interacting adhesion molecules, which

309 orchestrate pre- and postsynaptic scaffolds to form nanocolumns (Chen et al., 2017; Sudhof, 2017).

310 How critical is the presynaptic scaffold in the organization of synapses? While its loss causes severe

311 impairments in synaptic structure and function, synaptic contacts still form, SVs accumulate, and the

312 postsynapse differentiates to some degree (Acuna et al., 2016; Brockmann et al., 2020). Our finding

313 that the artificial alignment of $\alpha 2 \delta 1$ and AMPA receptors suffices to restore synaptic transmission in

314 the absence of the presynaptic scaffold not only suggests that the scaffold is not essential for

315 neurotransmission, it also places $\alpha 2 \delta 1$ as a key component of the presynaptic module that governs

316 presynaptic release. However, the presynaptic scaffold, especially RIM and RBP2, has been proven to

317 fine-tune the coupling distance between $\mathrm{Ca}^{2+}$-channels and docked SVs. Therefore, the coupling

318 distances of $20 \mathrm{~nm}$ between $\mathrm{Ca}^{2+}$-channels and docked SVs and their high release probability of $50 \%$

319 that we revealed for hippocampal synapses are likely mediated by the unique organization of the

320 presynaptic scaffold in that synapse. All in all, our results suggest a molecular model in which a

321 synapse contains autonomous building blocks that govern synaptic structure and -function and a

322 presynaptic scaffold modulating that fine-tunes vesicular release probability. 


\section{Acknowledgements:}

324 This research was supported by an Einstein BIH Visiting Fellow grant (EVFBOJ2017-369) and 325 German Research Council grants (RO 1296/8-1; Reinhardt Koselleck project; CRG958A5; C.R.). We 326 would like to thank Melissa Herman for valuable comments on the manuscript. We thank Diana 327 Steinkampf for data analysis. We are grateful to Berit Söhl-Kielczynski, Bettina Brokowski, Katja 328 Pötschke, Heike Lerch, Rike Dannenberg and Sabine Lenz for technical assistance. We also thank for 329 the services of the Charité viral core facility for virus production and the electron microscopy core 330 facility for technical support. We would also like to thank Jan Schmoranzer and the Charite AMBIO 331 facility for the training and use of the STORM setup.

\section{Author contributions:}

334 M.M.B. performed electron microscopy and electrophysiological experiments

335 E.T. performed super-resolution microscopy experiments

336 M.M.B., T.C. S., and C.R. designed experiments

337 A.T.G., A.M.W. performed computational analysis

338 T.T. designed lentiviral constructs

339 M.M.B. and C.R. wrote, and A.M.W. edited the manuscript

\section{Declaration of interests}

342 The authors declare no competing interests.

\section{Material and Methods}

\section{Animals maintenance and mouse lines}

346 All mouse experiments were in accordance with the regulation of the animal welfare committee of the 347 Charité Universitätsmedizin and the Landesamt für Gesundheit und Soziales Berlin under license 348 number T0220/09. The qKO mouse line contains floxed RIM1, RIM2, RBP1, and RBP2 genes, as 349 published previously(Acuna et al., 2016). The gene deletion is induced by lentiviral transduction of 350 cre-recombinase. Wildtype neurons were obtained from C57B1/6 mice. 


\section{Primary hippocampal cultures}

353 Hippocampal neurons were dissected from postnatal day (P) 0-2 mice of either sex, as described 354 previously (Arancillo et al., 2013). Briefly, hippocampi were dissected, and neurons dissociated by an 355 enzymatic treatment using 25 units per $\mathrm{ml}$ of papain for $45 \mathrm{~min}$ at $37^{\circ} \mathrm{C}$. For electron microscopy 356 experiments, $100 \times 10^{3}$ neurons/well (22 mm diameter) were plated on astrocyte feeder layers as high357 density culture (Chang et al., 2018). Low-density cultures of $3 \times 10^{3}$ neurons/well were seeded on 358 astrocyte micro-islands (35 mm diameter) for autaptic cultures (Arancillo et al., 2013). For dSTORM

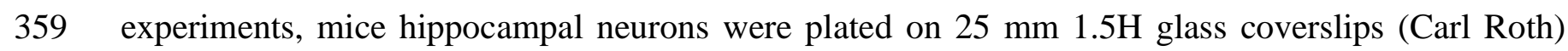
360 following an adapted Banker culture protocol (Kaech and Banker, 2006). Astrocyte feeder layers were 361 prepared 1-2 weeks before neuronal seeding, as described previously (Arancillo et al., 2013). After plating, neurons were incubated in Neurobasal-A media medium supplemented with $50 \mu \mathrm{g} / \mathrm{ml}$ streptomycin and $50 \mathrm{IU} / \mathrm{ml}$ penicillin at $37^{\circ} \mathrm{C}$, before electrophysiological, imaging, or electronmicroscopy experiments were performed at DIV 14-20.

\section{Lentiviral constructs}

All lentiviral constructs were generated through the Gibson assembly method (NEB) with the corresponding cDNAs and with a human synapsin-1 promoter-driven lentiviral shuttle vector (f(syn), based on FUGW (Lois et al., 2002)) that could contain either nuclear-localized (NLS) GFP or RFP that was fused C-terminally to a self-cleaving P2A peptide (Kim et al., 2011) to allow polycistronic translation.

To perform Ni-NTA-Nanogold labeling for electron microscopy, the sequence of 10 Histidine residues (His) was incorporated in the corresponding cDNAs. For the postsynaptic AMPA receptor GluA2, SEP-GluA2 (Addgene \#24001) was used by exchanging the pHluorin cDNA with His and Gibson assembling into f(syn)NLS-GFP-P2A (BL-984). Postsynaptic mouse neuroligin-1 was PCR amplified from Addgene \#15260. Here, the His sequence was fused after the N-terminal signaling peptide of neuroligin, and the resulting neuroligin-His was assembled in the $\mathrm{f}(\mathrm{syn}) \mathrm{NLS}-\mathrm{RFP}-\mathrm{P} 2 \mathrm{~A}$ shuttle vector (BL-1045). Presynaptic rat neurexin1a was obtained from Addgene \#58266. The His-sequence was also fused after the $\mathrm{N}$ terminal signaling peptide. neurexin-1-His was cloned in the shuttle vector f(syn)NLS-GFP-P2A (BL-1047). Presynaptic Cacna2d1 was PCR amplified from mouse brain cDNA P0. After sequence verification, the His-tag was inserted after the signaling peptide sequence by Gibson assembly and fused in the empty shuttle vector to form f(syn)Cacna2d1-His (BL-744).

383 For super-resolution microscopy, the cDNA of mEOS3.2 (from Addgene \#54696) was fused within 
corresponding pHluorin cDNA within these Addgene clones. GluA1-mEOS3.2 and GluA2-mEOS3.2 were subcloned into the f(syn)NLS-GFP-P2A shuttle vector (BL-1038, BL-1054). From the same Addgene plasmid \#57461 Homer1 cDNA was PCR amplified from the Addgene plasmid \#57461 and fused at its C-terminus with tdTomato into the shuttle vector $f(s y n)$ to produce $f(s y n) H o m e r 1$ tdTomato (BL-1034). The cDNA of presynaptic mouse synaptophysin (Sampathkumar et al., 2016) was fused at its C-terminus with tdTomato into the shuttle vector $\mathrm{f}(\mathrm{syn})$ to form $\mathrm{f}(\mathrm{syn})$ SynaptopysintdTomato (BL-1039).

In order to perform site-specific biotinylation and streptavidin interaction studies, bacterial biotin ligase BirA-ER from Addgene \#20856 was subcloned into a CFP-P2A expressing shuttle vector to form f(syn)CFP-P2A-BirA-ER. A 15 amino acid biotin acceptor peptide (AP) (Howarth et al., 2005), was inserted in the Cacna2d1 cDNA by exchanging the His-tag and subsequent assembling in the NLS-GFP-P2A containing shuttle vector to form f(syn)NLS-GFP-P2A-Cacna2d1-AP. As counterpart, the sequence of monomeric streptavidin (mSA) was amplified from Addgene \#39860, fused after to the GluA2 sequence (Addgene clone \#24001, GluA2-pH) by replacing the pHluorin sequence. Subsequently, this fragment was assembled into an NLS-RFP-P2A containing shuttle vector to form f(syn)NLS-RFP-P2A-GluA2-mSA.

401

\section{Ni-NTA gold labelling}

For the Nickel Nitrilotriacetic acid (Ni-NTA) labeling, primary hippocampal neurons were grown on sapphire disks for 14 days. Before high-pressure freezing, neurons were incubated in $10 \mathrm{nM} 5 \mathrm{~nm} \mathrm{Ni}$ NTA-Nanogold (Nanoprobes) (Chang et al., 2013) for $15-20 \mathrm{~min}$ in the $\mathrm{CO}^{2}$ incubator at $37^{\circ} \mathrm{C}$. To remove unbound gold particles, cells were washed ten times in $\mathrm{Base}^{+}$solution at RT that contained the following (in $\mathrm{mM}$ ): $140 \mathrm{NaCl}, 2.4 \mathrm{KCl}, 10 \mathrm{HEPES}$ (Merck, NJ, USA), 10 glucose (Carl Roth, Karlsruhe, Germany), $2 \mathrm{CaCl}_{2}$ (Sigma-Aldrich, St. Louis, USA), and $4 \mathrm{MgCl}_{2}$ (Carl Roth) ( 300mOsm; pH7.4). Primary neurons were high-pressure fixed $\sim 2$ min after finishing the washing

\section{High-pressure freezing with electrical stimulation}

413 For high-pressure freezing experiments, hippocampal neurons were plated on $6 \mathrm{~mm}$ sapphire disks. 414 Neurons were high-pressure fixed (2100 bar, ICE, Leica Microsystems) between DIV 14-16 in 415 extracellular solution containing the following (in $\mathrm{mM}$ ): $140 \mathrm{NaCl}, 2.4 \mathrm{KCl}, 10 \mathrm{HEPES}, 10$ glucose, $4162 \mathrm{CaCl}_{2}$, and $4 \mathrm{MgCl}_{2}(\sim 300 \mathrm{mOsm}$; $\mathrm{pH} 7.4)$. For the gold labeling, neurons were incubated with the 
temperature. For electrical stimulation $3 \mu \mathrm{M}$ NBQX and $30 \mu \mathrm{M}$ bicuculine were added to the

419 extracellular. To induce vesicle fusion, the ICE applies an electrical field for $1 \mathrm{~ms}$, and cells were

420 frozen $5 \mathrm{~ms}$ after stimulation at $37^{\circ} \mathrm{C}$.

421 After freezing, samples were transferred from liquid nitrogen to cryovials containing the freeze 422 substituent (1\% glutaraldehyde, $1 \%$ osmium tetroxide, and $1 \% \mathrm{H}_{2} \mathrm{O}$ in anhydrous acetone). The 423 freeze-substitution was performed in an automated freeze-substitution (Leica EM AFS2) with the 424 following protocol: $-90^{\circ} \mathrm{C}$ for $5-7 \mathrm{~h}, 5^{\circ} \mathrm{C}$ per hour to $-20^{\circ} \mathrm{C} .12$ hours at $-20^{\circ} \mathrm{C}$, and $10^{\circ} \mathrm{C}$ per hour to $42520^{\circ} \mathrm{C}$. Following en bloc staining with $0.1 \%$ uranyl acetate for 1 hour, the samples were epon 426 embedded and cured for 48 hours at $60^{\circ} \mathrm{C}$. Afterward, $40 \mathrm{~nm}$ sections were cut using a microtome 427 (Leica UCT). The sections were collected on formvar-coated single-slot grids and stained before 428 imaging with $2.5 \%$ uranyl acetate and lead citrate. Pictures were collected blindly in an FEI Tecnai 429 G20 TEM operating at $200 \mathrm{keV}$ and digital images taken with a Veleta $2 \mathrm{~K} \times 2 \mathrm{~K}$ CCD camera 430 (Olympus). For Tomograms, $200 \mathrm{~nm}$ sections were obtained and imaged with an FEI Tecnai G20. 431 Tomograms were obtained from synapses with at least 1 gold particle detected and reconstructed and 432 analyzed using IMOD (University of Colorado, Boulder; http://bio3d.colorado.edu/imod/).

433 For all experiments, the images were obtained from at least 3 independent hippocampal cultures. 434 Synapses for imaging were chosen by the presence of a prominent PSD, presynaptic vesicles, and a 435 visible synaptic cleft in low magnification. The images were collected and scored blind by using an 436 analysis program for ImageJ and Scala. Active Zones were defined as the membrane stretch directly 437 juxtaposed to the postsynaptic density (PSD). Docked SVs were defined as those contacting the active 438 zone plasma membrane.

\section{D electron microscopy data analysis}

441 Synaptic Parameters analyzed: Morphological analysis of EM images performed manually in ImageJ. 442 Micrographs were blinded for the experimenter to prevent biased analysis. In Fiji, the post-synaptic 443 density (PSD) was defined as the electron-dense structure at the postsynapse and the active zone as 444 the membrane stretch opposed to the PSD at the presynaptic side. Vesicles were defined as docked 445 when the vesicular membrane directly contacted the presynaptic plasma membrane. Gold particles 446 were marked in the synaptic cleft when found in the confines of the active zone. After detecting all 447 relevant structures, localization parameters were exported as a text file.

448 Distance calculation: To determine the distances between gold particles and docked SV, coordinates 449 of all structures were loaded from each text file into a self-written analysis program. As the image files 450 contain only points, we transformed the data in the following way in order to be able to compute 
distances: the AZ and the PSD were approximated using a $3^{\text {rd }}$-degree polynomial and fitted with the least error squares. Subsequently, the polynomial was divided into straight line segments by computing the respective values on the highest resolution available from the data (once per pixel). We projected the docked SVs and the gold particles onto the line segments by using the point which has the minimal distance across all line segments.

We then calculated the following distances on the line segments: 1) The length of the PSD. 2) The position of the gold particle along the AZ length. 3) The number of gold particles in the confines of the synaptic cleft. 4) Number of docked SV. 5) Location of docked SV along the AZ length. 6) Distance between docked SVs. 7) Distance between each gold particle and the nearest docked SV. 8) Distance of each gold particle to all docked SVs.

Randomized placement of SVs and gold particles for 2D data: To analyze gold and docked SVs distribution, measured data were compared to simulations of randomly equally distributed SVs and gold particles. For randomized conditions, the measured number of SVs and gold particles were randomly placed on the given AZ length.

Residual value calculation: To obtain the residual value (\%), frequency distribution histograms (bin $20 \mathrm{~nm}$ ) for were utilized and calculated as the percent of increase distance of docked SVs to $\mathrm{Ca}^{2+}$ channels.

\section{Image analysis tomograms}

Randomized placement of SVs and gold particles: If a guided process determined SV placement in relation to $\mathrm{Ca}^{2+}$-channels, then the distribution of distances between docked $\mathrm{SVs}$ and $\mathrm{Ca}^{2+}$ channels should differ from a random uniform distribution. To test this hypothesis, we first quantified the shortest distance of each immunogold particle ("au", as observed in 3D EM tomographs) to the closest observed docked SV, yielding one distance value per observed au ( $\mathrm{n}=19$ in $10 \mathrm{AZ}$ tomographs). We then simulated randomly placed positions of docked SVs and au by randomly drawing AZ coordinates for their uniform placement, as described below. All following procedures were performed in MATLAB (R2016b). The custom scripts written for this analysis are available upon request.

Data handling and distance calculations: AZ coordinates were loaded from .xlsx-files containing one AZ per sheet (in this case 10 sheets for 10 analyzed AZs), with data being described by 5 columns. In the first column, all AZ coordinates were classified as "1", all docked SV positions were classified as "2", and all au positions were classified as " 3 ". The second column contained information about the tomograph slice identity but was not used in this analysis. The third to fifth column contained $\mathrm{x}, \mathrm{y}$ and $\mathrm{z}$ coordinates of the respective AZ, SV or au position. Each sheet was then loaded into a MATLAB 
cell array using $x l s r e a d$ and the $3^{\text {rd }}$ to $5^{\text {th }}$ columns were converted to a 3-column matrix using cell2mat. Then, going through each AZ individually, the following information was stored: the index of AZ coordinates ("1"), the index of docked SV positions ("2"), and the index of au positions ("3"), yielding three cell arrays containing either AZ, docked SV or au coordinates. Then, for each docked SV and au, we projected its position onto the $\mathrm{AZ}$ surface by finding the $\mathrm{AZ} \mathrm{x}, \mathrm{y}, \mathrm{Z}$-coordinate closest to the $\mathrm{x}, \mathrm{y}, \mathrm{z}$-coordinates of the docked SV or au. The distances between SV/au and AZ coordinates were determined using pdist 2 , which calculates Euclidean distances between given sets of points, and taking the smallest value from this list, as shown in equations (1) and (2).

(1) $\operatorname{mindist}\left(S V_{\text {curr }}, A Z_{x y z}\right)=\min \left(\operatorname{vector}\left\{\begin{array}{c}c=1 \\ \ldots \\ n\end{array}\right\}\right)$ where vector $(\mathrm{c})=$

$$
\sqrt{\left(d_{x}\left(S V_{c u r r}, A Z_{x y z}(c)\right)\right)^{2}+\left(d_{y}\left(S V_{c u r r}, A Z_{x y z}(c)\right)\right)^{2}+\left(d_{z}\left(S V_{c u r r}, A Z_{-} x y z(c)\right)\right)^{2}}
$$

(2) $\operatorname{mindist}\left(a u_{c u r r}, A Z_{x y z}\right)=\min \left(\operatorname{vector}\left\{\begin{array}{c}c=1 \\ \cdots \\ n\end{array}\right\}\right)$ where vector $(\mathrm{c})=$

$$
\sqrt{\left(d_{x}\left(a u_{c u r r}, A Z_{x y z}(c)\right)\right)^{2}+\left(d_{y}\left(a u_{c u r r}, A Z_{x y z}(c)\right)\right)^{2}+\left(d_{z}\left(a u_{c u r r}, A Z_{-} x y z(c)\right)\right)^{2}}
$$

In equations (1) and (2), $\mathrm{SV}_{\text {curr }}$ and aucurr are the docked $\mathrm{SV}$ or au being considered, and $\mathrm{AZ}_{\mathrm{xyz}}$ is the set of all AZ x,y,z-coordinates. For each single $x, y, z$-coordinate $A Z_{x y z}(c), d_{x}, d_{y}$ and $d_{z}$ are the difference (or "shift") between SV or au and the currently considered $A Z_{x y z}(c)$ along either spatial dimension ( $\mathrm{x}, \mathrm{y}$ or $\mathrm{z})$ ). The counter $\mathrm{c}$ increases from 1 to $\mathrm{n}$, where $\mathrm{n}$ is the amount of observed $\mathrm{AZ}$ coordinates. The $\mathrm{x}, \mathrm{y}, \mathrm{z}$-coordinate $\mathrm{AZ}_{\mathrm{xyz}}$ corresponding to the shortest distance is then taken as the projected position of the docked SV or au.

Having determined the projected coordinates of all au particles and docked SVs, we calculated the distances between each au particle and the closest docked SV, resulting in as many distance measurements per $\mathrm{AZ}$ as there were observed au particles $(\mathrm{n}=19)$. Because a possible curvature of the AZ surface is not easily quantified, exact distance measurement along the 3D surface coordinates poses a non-trivial problem. However, AZs were generally rather flat in shape. We therefore approximated the actual surface distance by taking the shortest Euclidean distance in space, analogous to equations (1) and (2) and as schematically depicted in Figure S4. This was done for both the experimental and simulated data.

Simulated random placement and bootstrapping: To generate a distribution with randomly placed components, we proceeded as follows. For each observed AZ, we placed as many docked SVs and au 
513 particles as had been observed in that AZ in EM tomography. Placement happened by choosing a 514 random position of their projection on the AZ surface (using the MATLAB function randi) to 515 randomly determine an integer number that corresponded to a position in the list of all observed AZ $516 \mathrm{x}, \mathrm{y}, \mathrm{z}-\mathrm{coordinates}$ from a uniform distribution. We further excluded unrealistic cases by excluding 517 placements where SVs were positioned less than $40 \mathrm{~nm}$ apart (because docked SVs cannot physically 518 overlap, assuming an SV diameter of $40 \mathrm{~nm}$ ) by randomly redrawing positions until all SVs were 519 sufficiently far apart. This procedure was performed analogously for randomly placed au particles, but no minimum distance between au particles, or between au particles and SVs, was enforced.

521 Next, we wanted to compare the distribution of observed minimal distances between au and docked 522 SVs with the distribution of randomly uniformly placed au and docked SVs. To account for effects of 523 variability within the experiment on the outcome, we furthermore performed bootstrapping (using the MATLAB function bootstrp) on both experimental and simulated datasets. For the experimental data, this was done from the original dataset of 10 AZs by drawing 100 subsets from the 10 AZs and generating an average histogram of the derived distances in $20 \mathrm{~nm}$ bins. This was done by first binning the distances in $20 \mathrm{~nm}$ bins and then averaging over all 100 bootstrapping runs. Calculating the cumulative sum over distance bins resulted in the plot shown in Figure $1 \mathrm{G}(\alpha 2 \delta$-His).

The random drawing of simulated random positions in $10 \mathrm{AZs}$ was then performed 100 times, using the same bootstrapped AZs as in the above procedure, where au particles and SVs were randomly uniformly placed in each bootstrap run and the observed positions quantified. For each random drawing of positions in $10 \mathrm{AZs}$, we binned the observed minimal distances between au and docked SVs. After repeating this 100 times, we then generated the average histogram we could compare to the distribution of observed distances. The cumulative distribution of this random drawing is shown in shown in Figure 1G (simulated).

\section{Fitting the minimal distance distribution for EM tomograms}

538 We utilized an integrated Rayleigh function that describes the distribution of distances between docked $539 \mathrm{SVs}$ and gold-labelled $\alpha 2 \delta$ (Figure $1 \mathrm{H}$ ) with a single parameter, $\sigma$, similar to analysis done previously 540 at the NMJ active zone of L3 stage drosophila ${ }^{39}$. A maximum likelihood estimation using the Matlab 541 function mle was used to estimate $\sigma$. For comparison, $\sigma$ was 3.8 times larger at the Drosophila NMJ 542 (using light microscopy; $\sigma=76.52 \mathrm{~nm}^{39}$ ) than our estimates at the central mammalian synapse, arguing 543 for an overall shorter coupling between voltage gated calcium channels and docked SVs.

$$
g(x)=\frac{\sqrt{2}}{\sqrt{\pi} \sigma^{3}} x^{2} e^{-\frac{x^{2}}{2 \sigma^{2}}}
$$




\section{Calculation of the vesicular release probability as a function of distances to $\alpha 2 \delta$ gold label}

547 The profiles depicting the distance-dependence of the vesicular release probability ( $\mathrm{pV}$, Figure 2D)

548 were calculated by comparing the measured minimal distances between gold particles and SVs without 549 stimulation to the ones observed $5 \mathrm{~ms}$ after stimulation that triggered SV fusion. For the quantification 550 depicted in Figure 2D, the analysis was performed on EM profiles containing a single gold particle 551 only. This simplifies the assignment of SVs to the respective particles and alleviates the concern that 552 the number of gold particles may influence the observation frequency of distances (as the average 553 number of gold particles observed in the two groups were different). The observation frequency of 554 distances between gold particles and docked SVs were quantified in the control dataset in 6 bins whose 555 sizes were chosen such that a same/similar number of observations fell into those bins. The probability 556 density of observations was then calculated by dividing the number of observations per bin by the respective bin-width. The same bins were then used to calculate the probability density of distance observations between gold particles and docked SVs in the profiles obtained $5 \mathrm{~ms}$ after stimulation. In the latter the overall number of observations was reduced, consistent with the loss/triggered membrane fusion of docked SVs following the stimulus. To investigate the variability within the datasets, bootstrapping of the observed distances was performed in both cases with 10000 bootstrap runs by drawing samples of distances using the second output of the Matlab function bootstrap. The respective numbers of observations were then counted using the using the Matlab (release Matlab2017b, Mathworks, MA, USA) function histcounts in the 6 bins and this number divided by the respective bin width to obtain the observation density. This number was furthermore divided by the number of profiles analyzed in the respective groups (57/196 profiles in the case of the control dataset and 62/204 profiles following stimulation for the analysis of profiles containing a single /at least one gold particle). The vesicular release probability $\left(\mathrm{pV}_{\mathrm{r}}\right)$ for all 10000 bootstrap runs in each bin was then calculated by subtracting the probability density of observed distances after stimulation from the ones without stimulation and then dividing by the probability density of observations without stimulation. In some cases, also depending on the bootstrap sample, negative values were calculated when a higher observation density is observed in the group following stimulation than in the control group. Because negative probabilities are not defined, the $\mathrm{pV}_{\mathrm{r}}$ value was then forced to zero (the smallest defined value). This typically occurred for larger distances, where overall fewer docked SVs were observed in the control condition. Figure 2D depicts the mean $\mathrm{pV}_{\mathrm{r}}$ profile plotted against the bin center values plus and minus the standard deviation from the bootstrapped data. The mean $\mathrm{pV}_{\mathrm{r}}$ profile was fit (using the 


$$
p V_{r}(x)=\text { Amplitude } * e^{-\frac{x}{\text { Lambda }}}
$$

where Amplitude denotes the (maximal) $\mathrm{pV}_{\mathrm{r}}$ value at the position of the gold particle, $x$ denotes distance from the gold particle and Lambda is a length constant. The values of the parameters Amplitude and Lambda were found by optimization (from starting values 1 and $30 \mathrm{~nm}$ ) by the fitting routine.

\section{Electrophysiology}

585 Whole-cell patch-clamp recordings were performed on autaptic cultures at room temperature at days in vitro 15-20. Synaptic currents were recorded using a Multiclamp 700B amplifier (Axon Instruments) controlled by Clampex 9.2 software (Molecular Devices). A fast perfusion system (SF77B; Warner Instruments) continuously perfused the neurons with the extracellular solution contained the following (in $\mathrm{mM}$ ): $140 \mathrm{NaCl}, 2.4 \mathrm{KCl}, 10$ HEPES (Merck, NJ, USA), 10 glucose (Carl Roth, Karlsruhe, Germany), $2 \mathrm{CaCl}_{2}$ (Sigma-Aldrich, St. Louis, USA), and $4 \mathrm{MgCl}_{2}$ (Carl Roth) ( 300mOsm; pH7.4). Somatic whole cell recordings were obtained using borosilicate glass pipettes, yielding a tip resistance of 2-3.5 $\mathrm{M} \Omega$ and filled with the following internal solution (in $\mathrm{mM}$ ): $136 \mathrm{KCl}$, 17.8 HEPES, 1 EGTA, 4.6 $\mathrm{MgCl}_{2}$, 4 Na2ATP, 0.3 Na2GTP, 12 creatine phosphate, and $50 \mathrm{U} / \mathrm{ml}$ phosphocreatine kinase ( 300 mOsm; pH7.4). Membrane capacitance and series resistance were compensated by $70 \%$ und data filtered by low-pass Bessel filter at $3 \mathrm{kHz}$ and sampled at $10 \mathrm{kHz}$ using an Axon Digidata 1322A digitizer (Molecular Devices).

Neurons were held at $-70 \mathrm{mV}$, and action potentials triggered by a $2 \mathrm{~ms}$ depolarization to $0 \mathrm{mV}$ to measure EPSCs (excitatory postsynaptic currents). Afterward, EPSCs were induced in the presence of the competitive AMPA receptor antagonist NBQX (3 $\mu \mathrm{M}$, Tocris Bioscience). Paired-Pulse 600 stimulation for excitatory autapses was assessed by the induction of 2 action potentials with an 601 interstimulus interval of $25 \mathrm{~ms}$. Spontaneous events (mEPSCs) were detected for $60 \mathrm{~s}$, and false positive mEPSC events obtained in NBQX were subtracted to calculate the frequency of spontaneous events. The readily-releasable pool (RRP) was determined by $5 \mathrm{~s}$ application of external solution made hypertonic by adding $500 \mathrm{mM}$ and integrating the transient inward response component (Rosenmund and Stevens, 1996). The $\mathrm{P}_{\mathrm{vr}}$ was calculated by dividing the average charge of the EPSC by the RRP charge. Data were analyzed using AxoGraph software. 


\section{Sample preparation and immuno-labeling for dSTORM}

609 For dSTORM imaging of $\mathrm{Ca}^{2+}$-channels, neuronal cultures were fixed by incubating cells with a 610 solution of $4 \%$ PFA and $4 \%$ sucrose for 10 minutes at room temperature before incubation with 611 primary antibody (Abcam, ab6556). In another set of experiments, to ensure labeling of surface 612 expressed GluA1-SEP or GluA2-SEP receptors prior to fixation with 4\% PFA and 4\% sucrose, 613 primary cultures were live labeled by incubating them with rabbit anti-GFP antibody (Abcam, ab6556) 614 diluted in Ringer solution at 1:2000 for 10 minutes at $37^{\circ} \mathrm{C}$. After fixation, PFA autofluorescence was 615 quenched with $\mathrm{NH}_{4} \mathrm{Cl}(50 \mathrm{mM})$ for 5 minutes. Next, cells were permeabilized with $0.3 \%$ Triton-X100 616 for 5 minutes. After 3 washes of each 5 minutes with PBS, nonspecific staining was blocked by 617 incubating coverslips in $2 \%$ BSA solution for 45 minutes at room temperature. Primary antibodies 618 were revealed with goat anti-rabbit Alexa 647 (dSTORM) secondary antibodies (1:1000, 619 ThermoFisher). Incubation with secondary antibody was followed by a second fixation step with $2 \%$ 620 PFA and 2\% sucrose for 10 minutes, and by an extra step of PFA quenching with the incubation of $621 \mathrm{NH}_{4} \mathrm{Cl}$ for 5 minutes. Fixed neuronal cultures were kept for up to 2 weeks in PBS prior to imaging.

\section{Imaging buffer and sample mounting}

624 The STORM imaging buffer was prepared with $10 \mathrm{mM}$ cysteamine (Sigma-Aldrich), 10\% w/v Dglucose (Sigma-Aldrich), $0.5 \mathrm{mg} / \mathrm{ml}$ glucose oxidase (Sigma-Aldrich), and $40 \mu \mathrm{g} / \mathrm{ml}$ catalase (SigmaAldrich) in Tris buffer. $100 \mu \mathrm{l}$ imaging buffer was dropped onto a spherical void (Carl Roth) before the coverslip containing sample was inverted over the chamber and gently pressed down into a central position. Excess imaging buffer was removed, and the coverslip was sealed in place using picodent twinsil ${ }^{\circledR}$ to minimize oxygen exchange during acquisition.

\section{direct STochastic Optical Reconstruction Microscopy (dSTORM)}

632 dSTORM experiments were done on fixed immunolabeled neurons. dSTORM imaging experiments 633 were conducted on a Nikon Eclipse-Ti inverted microscope using a Nikon 100x 1.49 NA oil immersion 634 TIRF objective. The perfect focus system (PFS) was used to minimize focal drift during long acquisitions. Excitation light was provided by a fiber-coupled laser launch $(405 \mathrm{~nm}, 488 \mathrm{~nm}, 561 \mathrm{~nm}$, and $647 \mathrm{~nm}$ ). The fluorescent signal was collected with an EMCCD camera (Andor iXon Ultra, Oxford Instruments, USA). Image acquisition and control of the microscope were driven by NIS-Elements imaging software (Nikon, USA). Each image stack contained typically 30,000-80,000 frames. Selected ROI (region of interest) had a dimension of 256x256 pixels (one pixel edge was $107 \mathrm{~nm}$ ). The power of the $647 \mathrm{~nm}$ laser was kept constant at 100\% during the entire acquisition. 


\section{Cluster analysis}

643 Localization of Alexa-647 signals and Single-Molecule Localization (SML) image reconstruction with 644 a pixel size of $21 \mathrm{~nm}$ was performed using the ImageJ plugin Thunderstorm (DOI: 645 10.1093/bioinformatics/btu202). GluA receptor and $\mathrm{Ca}^{2+}$-channel receptor localizations were 646 extracted from super- resolved images corrected for lateral drift. GluA and $\mathrm{Ca}^{2+}$-channel clusters were 647 then identified using SR-Tesseler software (doi: 10.1038/nmeth.3579). Clusters were extracted in three 648 sequential steps for each image. First, the tessellation of the image creates a Voronoi diagram, which 649 consists of polygons based on the density of localizations. Then a region with a density factor (DF) 650 greater than 2 is defined as an object. Finally, an automatic threshold of normalized density DF $=2$ 651 was used to extract clusters of proteins (cluster of level 2) having an enrichment factor higher than the 652 average localization density. For cluster determination, we added 2 extra parameters, specifying a 653 minimum area of $0.002 \mu \mathrm{m}^{2}$ and a minimum localization number per cluster of 5 . The extraction of 654 clusters was performed on the SML image, and the synaptic regions were pre-determined by low655 resolution imaging of synaptophysin-tdTomato or Homer-tdTomato according to the particular experiment.

\section{SynGCaMP6f Imaging}

659 Hippocampal autapses were transduced at DIV 1-2 with lentiviral constructs of synGCamp6f 660 (Brockmann et al., 2020; Grauel et al., 2016). Live imaging at room temperature was performed at an inverted microscope, and samples were continuously perfused with external solution containing 662 NBQX/bicuculline. Neuronal stimulation was achieved by field stimulation (Warner Instruments, CT, 663 USA). Imaging experiments were performed at DIV 15-20 of autapses in response to single stimuli 664 and stimuli trains of $10 \mathrm{~Hz}$. Images were acquired using a 490-nm LED system (pE2; CoolLED) at a $6652 \mathrm{~Hz}$ sampling rate with $50 \mathrm{~ms}$ of exposure time.

\section{Immunostaining and quantification}

668 Primary hippocampal mass cultures were fixed for $10 \mathrm{~min}$ in $4 \%$ paraformaldehyde (PFA), 669 permeabilized with $0.1 \%$ Phosphate Buffered Saline (PBS)-Tween-20 solution and blocked with $5 \%$ 670 normal donkey serum. Primary antibodies were used to immune stain Munc13-1 (sysy 126104) and 671 synaptophysin1 (sysy 101002). Subsequently, secondary antibodies labeled with Alexa Fluor 647 anti672 guinea pig IgG, and Alexa Fluor 488 anti-rabbit both in donkey (Jackson ImmunoResearch) serum 
673

were applied, respectively. Glass coverslips were mounted on glass slides and images acquired with an Olympus IX81 epifluorescent microscope with MicroMax 1300YHS camera using MetaMorph software (Molecular Device). The analysis was performed offline with ImageJ.

\section{Statistical Analysis}

Statistical tests were performed with Prism 8 (Graphpad). For bar plots data are represented as mean \pm SEM and for violin plots data were presented as median (solid lines) and quartiles (dashed lines). First, all data were tested for normality using the D'Agostino \& Pearson test. If they did not pass the parametric assumption, for bar graphs the Mann-Whitney U-test for the comparison of two unpaired data sets. For cumulative distribution plots the Kruskal-Wallis test followed by Dunn's test was performed. In case data passed the parametric assumption, for data sets including two experimental groups we applied the Student's t-test and for analysis an Ordinary One-way ANOVA followed by Turkey's test. For detail see Supplementary Table 1.

All experiments in the manuscript are repeated at least three times.

\section{Data and materials availability:}

Data and Materials of this study are available from the corresponding authors upon reasonable request.

\section{Code availability:}

Custom codes used in this study are available from the corresponding authors upon reasonable request.

\section{References:}

Acuna, C., Liu, X., Gonzalez, A., and Sudhof, T.C. (2015). RIM-BPs Mediate Tight Coupling of Action Potentials to $\mathrm{Ca}(2+)$-Triggered Neurotransmitter Release. Neuron 87, 1234-1247.

Acuna, C., Liu, X., and Sudhof, T.C. (2016). How to Make an Active Zone: Unexpected Universal Functional Redundancy between RIMs and RIM-BPs. Neuron 91, 792-807.

Adler, E.M., Augustine, G.J., Duffy, S.N., and Charlton, M.P. (1991). Alien intracellular calcium chelators attenuate neurotransmitter release at the squid giant synapse. The Journal of neuroscience : the official journal of the Society for Neuroscience 11, 1496-1507.

Arai, I., and Jonas, P. (2014). Nanodomain coupling explains $\mathrm{Ca}(2)(+)$ independence of transmitter release time course at a fast central synapse. elife 3.

Arancillo, M., Min, S.W., Gerber, S., Munster-Wandowski, A., Wu, Y.J., Herman, M., Trimbuch, T., Rah, J.C., Ahnert-Hilger, G., Riedel, D., et al. (2013). Titration of Syntaxin1 in mammalian synapses reveals multiple roles in vesicle docking, priming, and release probability. J Neurosci 33, 16698-16714.

Augustine, G.J., Santamaria, F., and Tanaka, K. (2003). Local calcium signaling in neurons. Neuron 40, 331-346. 
Bennett, M.R., Farnell, L., and Gibson, W.G. (2000). The probability of quantal secretion within an array of calcium channels of an active zone. Biophys J 78, 2222-2240.

Biederer, T., Kaeser, P.S., and Blanpied, T.A. (2017). Transcellular Nanoalignment of Synaptic Function. Neuron 96, 680-696.

Bohme, M.A., Beis, C., Reddy-Alla, S., Reynolds, E., Mampell, M.M., Grasskamp, A.T., Lutzkendorf, J., Bergeron, D.D., Driller, J.H., Babikir, H., et al. (2016). Active zone scaffolds differentially accumulate Unc13 isoforms to tune $\mathrm{Ca}(2+)$ channel-vesicle coupling. Nat Neurosci 19, 1311-1320.

Bohme, M.A., Grasskamp, A.T., and Walter, A.M. (2018). Regulation of synaptic release-site Ca(2+) channel coupling as a mechanism to control release probability and short-term plasticity. FEBS letters 592, 3516-3531.

Brockmann, M.M., Maglione, M., Willmes, C.G., Stumpf, A., Bouazza, B.A., Velasquez, L.M., Grauel, M.K., Beed, P., Lehmann, M., Gimber, N., et al. (2019). RIM-BP2 primes synaptic vesicles via recruitment of Munc13-1 at hippocampal mossy fiber synapses. eLife 8.

Brockmann, M.M., Zarebidaki, F., Camacho, M., Grauel, M.K., Trimbuch, T., Sudhof, T.C., and Rosenmund, C. (2020). A Trio of Active Zone Proteins Comprised of RIM-BPs, RIMs, and Munc13s Governs Neurotransmitter Release. Cell reports 32, 107960.

Bucurenciu, I., Kulik, A., Schwaller, B., Frotscher, M., and Jonas, P. (2008). Nanodomain coupling between $\mathrm{Ca} 2+$ channels and $\mathrm{Ca} 2+$ sensors promotes fast and efficient transmitter release at a cortical GABAergic synapse. Neuron 57, 536-545.

Chang, J.W., Wu, Y.M., Chen, Z.Y., Huang, S.H., Wang, C.H., Wu, P.L., Weng, Y.P., You, C., Piehler, J., and Chang, W.H. (2013). Hybrid electron microscopy-FRET imaging localizes the dynamical Cterminus of Tfg2 in RNA polymerase II-TFIIF with nanometer precision. J Struct Biol 184, 52-62.

Chang, S., Trimbuch, T., and Rosenmund, C. (2018). Synaptotagmin-1 drives synchronous Ca(2+)triggered fusion by $\mathrm{C} 2 \mathrm{~B}$-domain-mediated synaptic-vesicle-membrane attachment. Nature neuroscience $21,33-40$.

Chen, L.Y., Jiang, M., Zhang, B., Gokce, O., and Sudhof, T.C. (2017). Conditional Deletion of All Neurexins Defines Diversity of Essential Synaptic Organizer Functions for Neurexins. Neuron 94, 611625 e614.

Davydova, D., Marini, C., King, C., Klueva, J., Bischof, F., Romorini, S., Montenegro-Venegas, C., Heine, M., Schneider, R., Schroder, M.S., et al. (2014). Bassoon specifically controls presynaptic P/Q-type $\mathrm{Ca}(2+)$ channels via RIM-binding protein. Neuron 82, 181-194.

Dolphin, A.C. (2013). The alpha2delta subunits of voltage-gated calcium channels. Biochim Biophys Acta 1828, 1541-1549.

Eggermann, E., Bucurenciu, I., Goswami, S.P., and Jonas, P. (2011). Nanodomain coupling between $\mathrm{Ca}(2)(+)$ channels and sensors of exocytosis at fast mammalian synapses. Nature reviews Neuroscience 13, 7-21.

Eroglu, C., Allen, N.J., Susman, M.W., O'Rourke, N.A., Park, C.Y., Ozkan, E., Chakraborty, C., Mulinyawe, S.B., Annis, D.S., Huberman, A.D., et al. (2009). Gabapentin receptor alpha2delta-1 is a neuronal thrombospondin receptor responsible for excitatory CNS synaptogenesis. Cell 139, 380392.

Graf, E.R., Valakh, V., Wright, C.M., Wu, C., Liu, Z., Zhang, Y.Q., and DiAntonio, A. (2012). RIM promotes calcium channel accumulation at active zones of the Drosophila neuromuscular junction. The Journal of neuroscience : the official journal of the Society for Neuroscience 32, 16586-16596. 
Grauel, M.K., Maglione, M., Reddy-Alla, S., Willmes, C.G., Brockmann, M.M., Trimbuch, T., Rosenmund, T., Pangalos, M., Vardar, G., Stumpf, A., et al. (2016). RIM-binding protein 2 regulates release probability by fine-tuning calcium channel localization at murine hippocampal synapses. Proceedings of the National Academy of Sciences of the United States of America 113, 11615-11620. Harlow, M.L., Ress, D., Stoschek, A., Marshall, R.M., and McMahan, U.J. (2001). The architecture of active zone material at the frog's neuromuscular junction. Nature 409, 479-484.

Held, R.G., Liu, C., Ma, K., Ramsey, A.M., Tarr, T.B., De Nola, G., Wang, S.S.H., Wang, J., van den Maagdenberg, A., Schneider, T., et al. (2020). Synapse and Active Zone Assembly in the Absence of Presynaptic $\mathrm{Ca}(2+)$ Channels and $\mathrm{Ca}(2+)$ Entry. Neuron 107, 667-683 e669.

Hoppa, M.B., Lana, B., Margas, W., Dolphin, A.C., and Ryan, T.A. (2012). alpha2delta expression sets presynaptic calcium channel abundance and release probability. Nature 486, 122-125.

Howarth, M., Takao, K., Hayashi, Y., and Ting, A.Y. (2005). Targeting quantum dots to surface proteins in living cells with biotin ligase. Proc Natl Acad Sci U S A 102, 7583-7588.

Kaech, S., and Banker, G. (2006). Culturing hippocampal neurons. Nat Protoc 1, 2406-2415.

Kaeser, P.S., Deng, L., Wang, Y., Dulubova, I., Liu, X., Rizo, J., and Sudhof, T.C. (2011). RIM proteins tether Ca2+ channels to presynaptic active zones via a direct PDZ-domain interaction. Cell 144, 282295.

Keller, D., Babai, N., Kochubey, O., Han, Y., Markram, H., Schurmann, F., and Schneggenburger, R. (2015). An Exclusion Zone for Ca2+ Channels around Docked Vesicles Explains Release Control by Multiple Channels at a CNS Synapse. PLoS Comput Biol 11, e1004253.

Kim, J.H., Lee, S.R., Li, L.H., Park, H.J., Park, J.H., Lee, K.Y., Kim, M.K., Shin, B.A., and Choi, S.Y. (2011). High cleavage efficiency of a $2 A$ peptide derived from porcine teschovirus-1 in human cell lines, zebrafish and mice. PLoS One 6, e18556.

Kusick, G.F., Chin, M., Raychaudhuri, S., Lippmann, K., Adula, K.P., Hujber, E.J., Vu, T., Davis, M.W., Jorgensen, E.M., and Watanabe, S. (2020). Synaptic vesicles transiently dock to refill release sites. Nat Neurosci.

Liu, K.S., Siebert, M., Mertel, S., Knoche, E., Wegener, S., Wichmann, C., Matkovic, T., Muhammad, K., Depner, H., Mettke, C., et al. (2011). RIM-binding protein, a central part of the active zone, is essential for neurotransmitter release. Science 334, 1565-1569.

Lois, C., Hong, E.J., Pease, S., Brown, E.J., and Baltimore, D. (2002). Germline transmission and tissuespecific expression of transgenes delivered by lentiviral vectors. Science 295, 868-872.

MacGillavry, H.D., Song, Y., Raghavachari, S., and Blanpied, T.A. (2013). Nanoscale scaffolding domains within the postsynaptic density concentrate synaptic AMPA receptors. Neuron 78, 615-622.

Meinrenken, C.J., Borst, J.G., and Sakmann, B. (2002). Calcium secretion coupling at calyx of Held governed by nonuniform channel-vesicle topography. The Journal of neuroscience : the official journal of the Society for Neuroscience 22, 1648-1667.

Nakamura, Y., Harada, H., Kamasawa, N., Matsui, K., Rothman, J.S., Shigemoto, R., Silver, R.A., DiGregorio, D.A., and Takahashi, T. (2015). Nanoscale distribution of presynaptic $\mathrm{Ca}(2+)$ channels and its impact on vesicular release during development. Neuron 85, 145-158.

Neher, E. (1998). Usefulness and limitations of linear approximations to the understanding of $\mathrm{Ca}++$ signals. Cell Calcium 24, 345-357.

Neher, E. (2015). Merits and Limitations of Vesicle Pool Models in View of Heterogeneous Populations of Synaptic Vesicles. Neuron 87, 1131-1142. 
Nusser, Z. (2018). Creating diverse synapses from the same molecules. Current opinion in neurobiology 51, 8-15.

Nusser, Z., Lujan, R., Laube, G., Roberts, J.D., Molnar, E., and Somogyi, P. (1998). Cell type and pathway dependence of synaptic AMPA receptor number and variability in the hippocampus. Neuron 21, 545-559.

Penn, A.C., Zhang, C.L., Georges, F., Royer, L., Breillat, C., Hosy, E., Petersen, J.D., Humeau, Y., and Choquet, D. (2017). Hippocampal LTP and contextual learning require surface diffusion of AMPA receptors. Nature 549, 384-388.

Rebola, N., Reva, M., Kirizs, T., Szoboszlay, M., Lorincz, A., Moneron, G., Nusser, Z., and DiGregorio, D.A. (2019). Distinct Nanoscale Calcium Channel and Synaptic Vesicle Topographies Contribute to the Diversity of Synaptic Function. Neuron 104, 693-710 e699.

Rosenmund, C., Clements, J.D., and Westbrook, G.L. (1993). Nonuniform probability of glutamate release at a hippocampal synapse. Science 262, 754-757.

Rosenmund, C., and Stevens, C.F. (1996). Definition of the readily releasable pool of vesicles at hippocampal synapses. Neuron 16, 1197-1207.

Sampathkumar, C., Wu, Y.J., Vadhvani, M., Trimbuch, T., Eickholt, B., and Rosenmund, C. (2016). Loss of MeCP2 disrupts cell autonomous and autocrine BDNF signaling in mouse glutamatergic neurons. eLife 5.

Savtchenko, L.P., and Rusakov, D.A. (2014). Moderate AMPA receptor clustering on the nanoscale can efficiently potentiate synaptic current. Philos Trans R Soc Lond B Biol Sci 369, 20130167.

Schmidt, H., Brachtendorf, S., Arendt, O., Hallermann, S., Ishiyama, S., Bornschein, G., Gall, D., Schiffmann, S.N., Heckmann, M., and Eilers, J. (2013). Nanodomain coupling at an excitatory cortical synapse. Curr Biol 23, 244-249.

Scimemi, A., and Diamond, J.S. (2012). The number and organization of Ca2+ channels in the active zone shapes neurotransmitter release from Schaffer collateral synapses. The Journal of neuroscience : the official journal of the Society for Neuroscience 32, 18157-18176.

Sudhof, T.C. (2014). The molecular machinery of neurotransmitter release (nobel lecture). Angewandte Chemie 53, 12696-12717.

Sudhof, T.C. (2017). Synaptic Neurexin Complexes: A Molecular Code for the Logic of Neural Circuits. Cell 171, 745-769.

Sudhof, T.C. (2018). Towards an Understanding of Synapse Formation. Neuron 100, 276-293.

Tang, A.H., Chen, H., Li, T.P., Metzbower, S.R., MacGillavry, H.D., and Blanpied, T.A. (2016). A transsynaptic nanocolumn aligns neurotransmitter release to receptors. Nature 536, 210-214.

Vyleta, N.P., and Jonas, P. (2014). Loose coupling between Ca2+ channels and release sensors at a plastic hippocampal synapse. Science 343, 665-670.

Wadel, K., Neher, E., and Sakaba, T. (2007). The coupling between synaptic vesicles and Ca2+ channels determines fast neurotransmitter release. Neuron 53, 563-575.

Watson, J.F., Ho, H., and Greger, I.H. (2017). Synaptic transmission and plasticity require AMPA receptor anchoring via its $\mathrm{N}$-terminal domain. Elife 6. 
A Live gold-labeling strategy

B
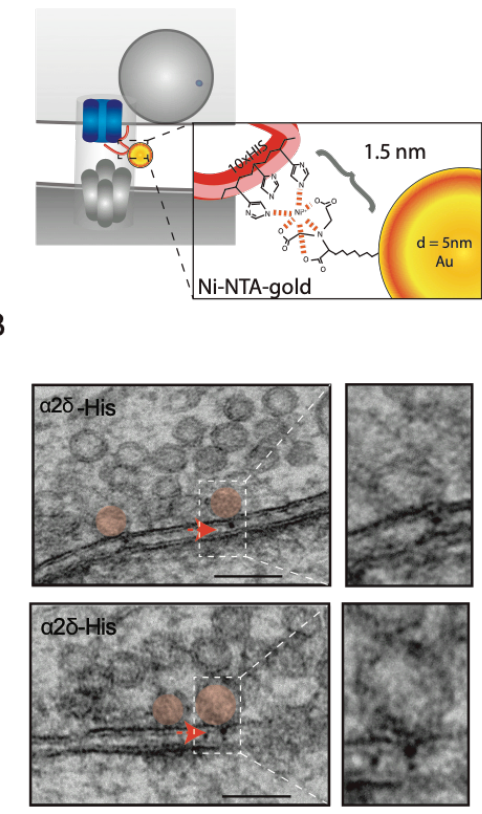
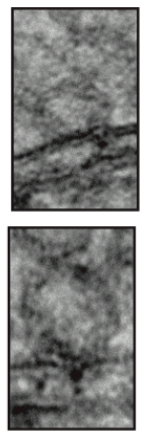

Verification of the gold-labeling protocol using $\alpha 2 \delta 1-$ HIS
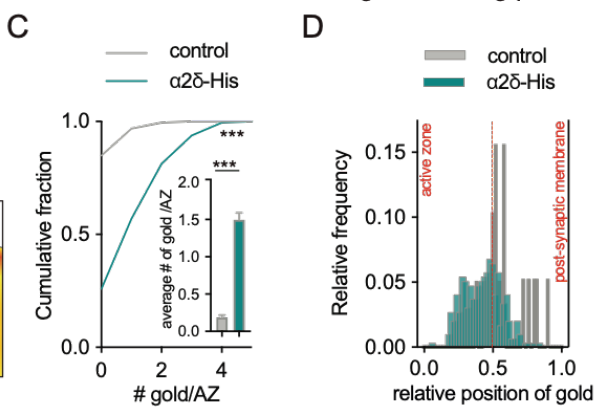

$\mathrm{E}$

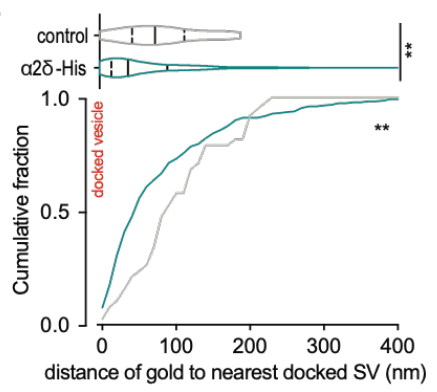

$3 \mathrm{D}$ analysis of $\alpha 2 \delta 1$ distribution at hippocampal synapses
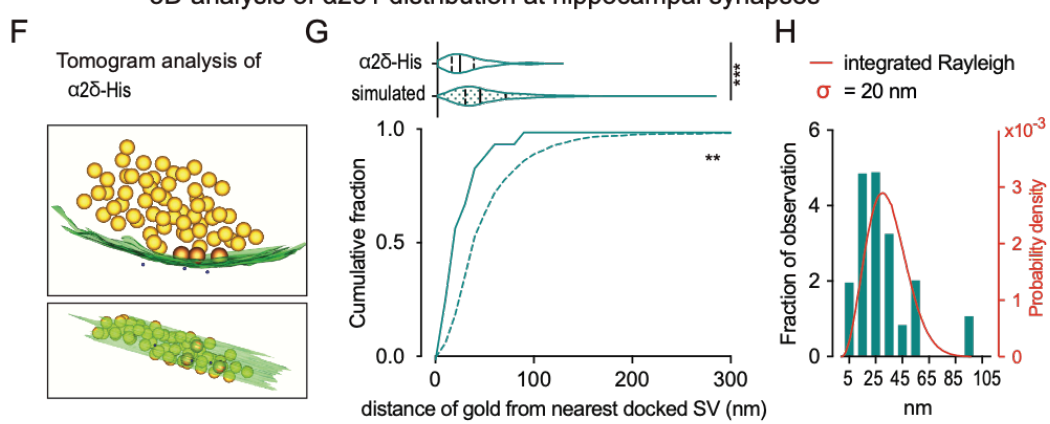

Figure 1: A novel tool to gold-label synaptic proteins reveal the tight association of docked SVs with $\mathrm{Ca}^{2+}$-channels.

(A) Live gold-labeling strategy of the $\mathrm{Ca}^{2+}$-channel subunit $\alpha 2 \delta$ using polyhistidine-tagging and incubation with $5 \mathrm{~nm}$ NiNTA- gold particles; coupling $1.5 \mathrm{~nm}$. (B) Representative electron micrographs of cryofixed primary hippocampal neurons expressing $\alpha 2 \delta 1-H i s$. Scale bars, $100 \mathrm{~nm}$ (docked SV = red circle, arrows point to gold particles). (C) Number of gold particles per AZ. (D) Gold particles distribution throughout the synaptic cleft width $(0=$ active zone membrane; $1=$ postsynaptic membrane). (E) Distance from each gold particle to the nearest docked SV in a synaptic profile from control and $\alpha 2 \delta 1$-His transfected neurons. (F) Tomogram of a cryofixed excitatory hippocampal synapse transfected with $\alpha 2 \delta 1$-His (docked SV = orange, gold particle = blue, active zone $=$ green $).(G)$ Distance of each gold particle to the nearest docked SV in tomograms in $\alpha 2 \delta 1$-His expressing neurons, compared to random placement. (H) Histogram of the distance of each gold particle to the nearest docked SV. Integrated Rayleigh distribution (red line).

Data for bar graphs are means \pm SEM. Data for violin plots are medians (solid lines) and quartiles (dashed lines). Statistical significance for $\mathrm{C}$ was assessed by unpaired t-test, the violin plots for $\mathrm{E}$ and G by Mann-Whitney test, and the cumulative distribution plots in C, E, and G by KolmogorovSmirnov test. $* \mathrm{p}<0.05, * * \mathrm{p}<0.01, * * * \mathrm{p}<0.001$. 
A

a2ס - SV distance

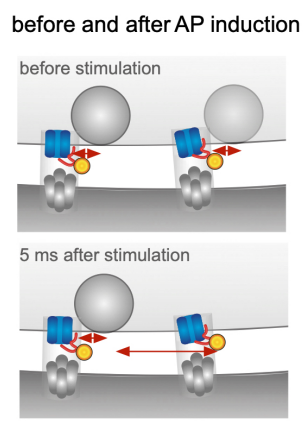

B

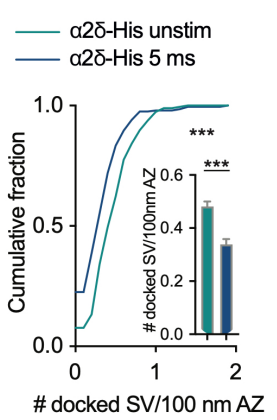

C

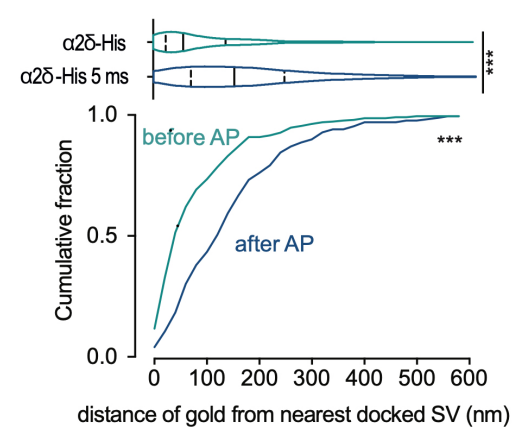

D

peak release probability $=86 \%$

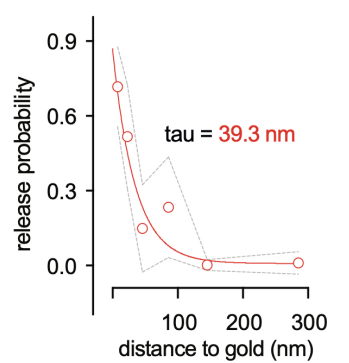

Figure 2: Deriving SV release probability from $\mathrm{Ca}^{2+}$ channel distance.

(A) Experimental design to determine the distance of $\mathrm{Ca}^{2+}$-channels to docked SVs before and after the induction of an action potential. To obtain SVs' distribution after action potential stimulation, the synaptic ultrastructure was arrested $5 \mathrm{~ms}$ after stimulation. (B) Docked SVs per synaptic profile in $\alpha 2 \delta 1$-His transfected neurons cryo-fixed before (green lines, bars) and after (blue lines, bars) stimulation. (C) Distance of each gold particle to the nearest docked SV in a synaptic profile, comparing unstimulated and stimulated conditions. (D) Calculation of the vesicular release probability as a function of distances to $\alpha 2 \delta 1$ gold label.

Data for bar graphs are means \pm SEM. Data for violin plots are medians (solid lines) and quartiles (dashed lines). Statistical significance for B was assessed by unpaired $\mathrm{t}$-test, the violin plot for $\mathrm{C}$ by Mann-Whitney test, and the cumulative distribution plots in $\mathrm{B}$ and $\mathrm{C}$ by Kolmogorov-Smirnov test. $* * * \mathrm{p}<0.001$ 
A
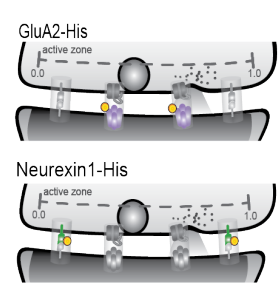

C

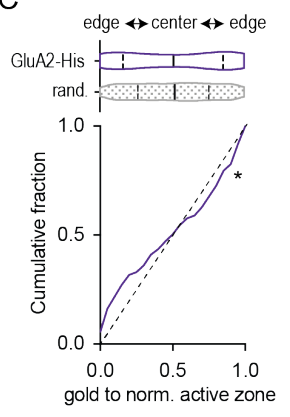

$\mathrm{F}$
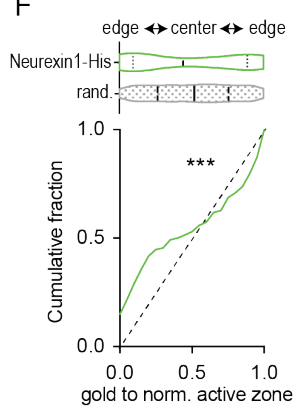

B

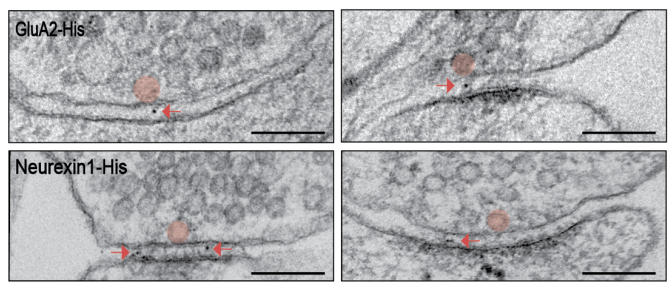

$\mathrm{E}$
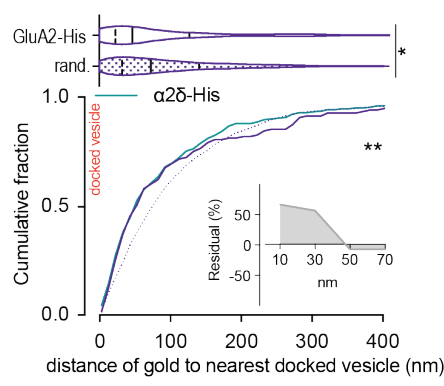

Null model - *
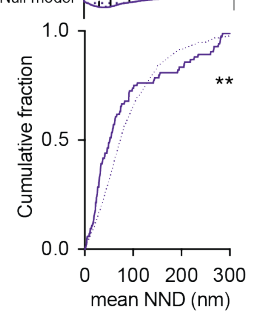

$\mathrm{H}$

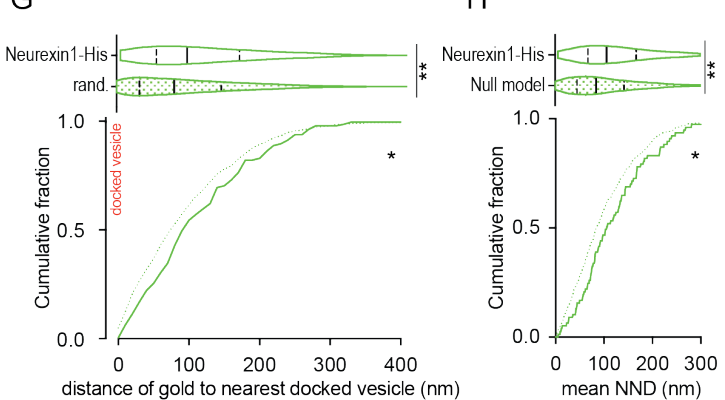

Figure 3: GluA2, but not neurexin1, is associated with docked SVs.

(A) Graphic for the ultrastructural parameters analyzed in electron micrographs for GluA2-His and neurexin1-His expressing neurons. (B) Representative electron micrographs of cryofixed primary hippocampal neurons expressing GluA2-His or neurexin1-His. (C and E) Violin, and cumulative probability plots of gold particle distribution at the normalized AZ. (D and G) Violin, and cumulative probability plots of the nearest distance between gold participles and the next docked SV compared to randomized distances (dashed line). Insert depicts the residual percentage of the distance of gold particles to the next docked SV compared to their randomized distribution. (E and $\mathbf{H}$ ) Violin, and cumulative probability plots of the measured data and null model data of mean nearest neighbor distance (NND) to docked SVs.

Data for violin plots are medians (solid lines) and quartiles (dashed lines). Statistical significance for violin plots in $\mathrm{C}, \mathrm{D}, \mathrm{E}, \mathrm{F}, \mathrm{G}$, and $\mathrm{H}$ was assessed by the Mann-Whitney test and for the cumulative distribution plots $\mathrm{C}, \mathrm{D}, \mathrm{E}, \mathrm{F}, \mathrm{G}$, and $\mathrm{H}$ by Kolmogorov-Smirnov test. $* \mathrm{p}<0.05, * * \mathrm{p}<0.01, * * *$ $\mathrm{p}<0.001$. 

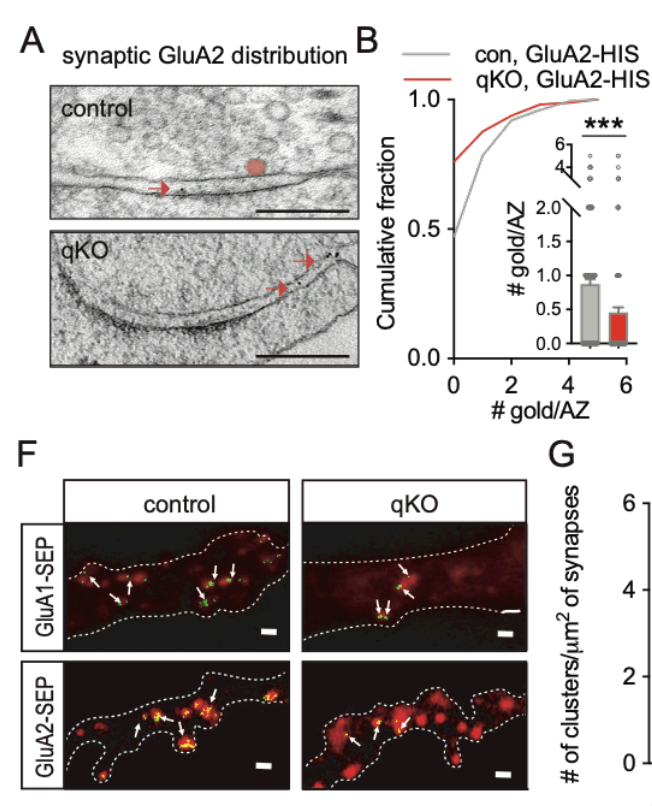
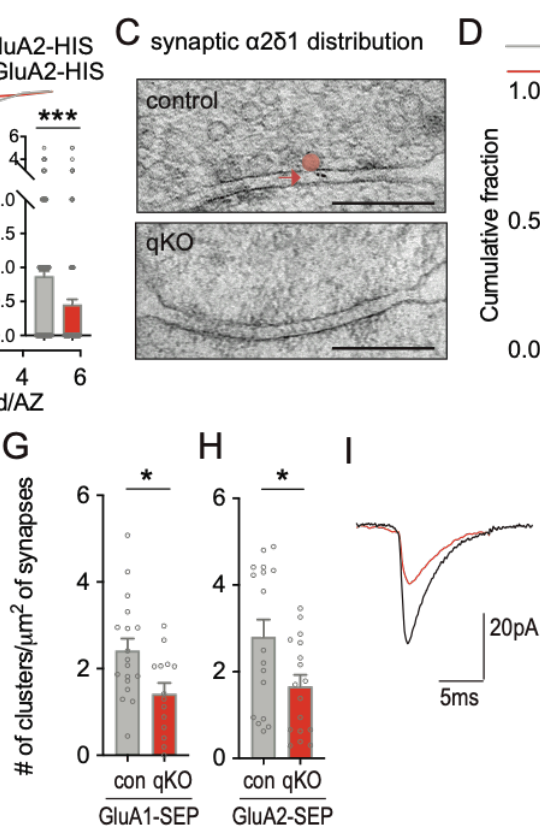
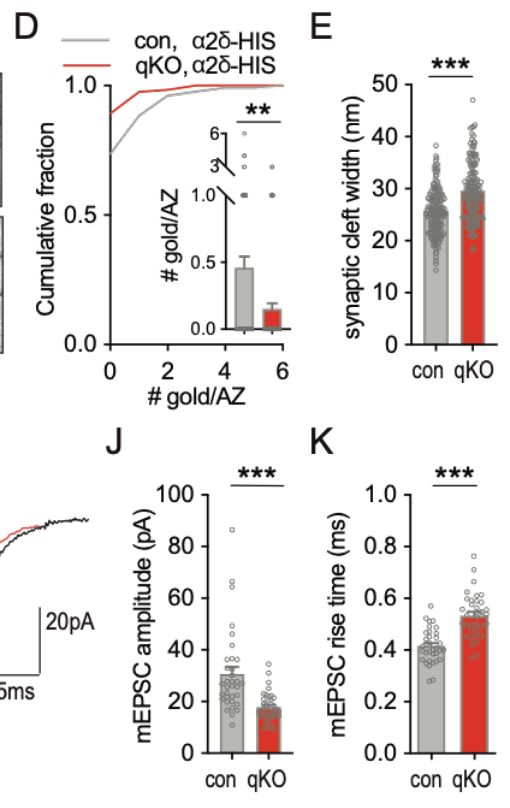

Figure 4: Loss of transducer-coupling in RIM/RBP deficient synapses.

(A-H), Experiments were conducted in RIM/RBP deficient synapses (qKO) and their respective control $(\Delta \mathrm{cre}$ ). (A and C) Representative electron micrographs of cryo-fixed control and qKO primary hippocampal neurons expressing either GluA2-His or $\alpha 2 \delta 1$-His. Scale bar, $200 \mathrm{~nm}$. (B and D) Number of gold particles per AZ. (E) Synaptic cleft width. (F) Representative dSTORM images of GluA1 and GluA2 (green) and Homer (red) expressed in control and qKO neurons. Scale bars $1 \mu \mathrm{m}$. (G) Number of GluA1 clusters per synapse area. (H) Number of GluA2 clusters per synapse area. (I) Sample traces of mEPSC events in control (grey) and qKO (red) derived from autaptic neurons. (J) Miniature excitatory postsynaptic current (mEPSC) amplitude. (K) mEPSC rise time.

Data are individual values and means \pm SEM. Statistical significance for B, D, E, J, K, G, and H was assessed by unpaired t-test and cumulative distribution plots in B and D by Kolmogorov-Smirnov test. $* \mathrm{p}<0.05, * * * \mathrm{p}<0.001$ 
bioRxiv preprint doi: https://doi.org/10.1101/2020.12.25.424391; this version posted December $25,2020$. The copyright holder for this

preprint (which was not certified by peer review) is the author/funder, who has granted bioRxiv a license to display the preprint in perpetuity. It is made available under aCC-BY-NC-ND 4.0 International license.

A

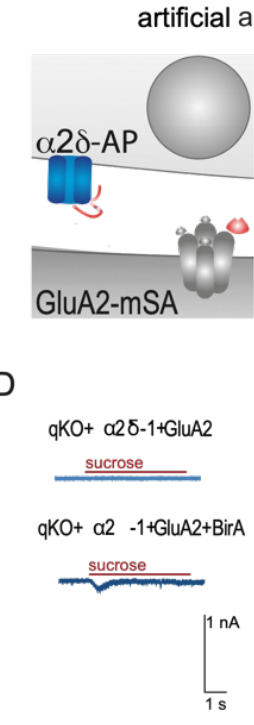

$\mathrm{H}$

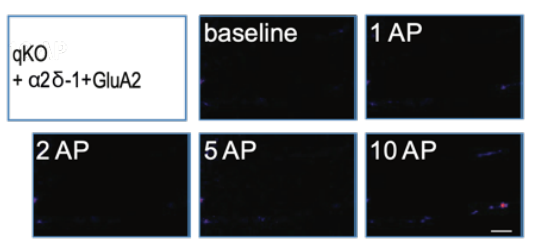

E
B

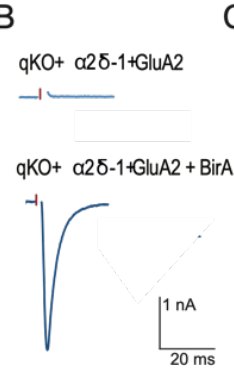

$\mathrm{F}$
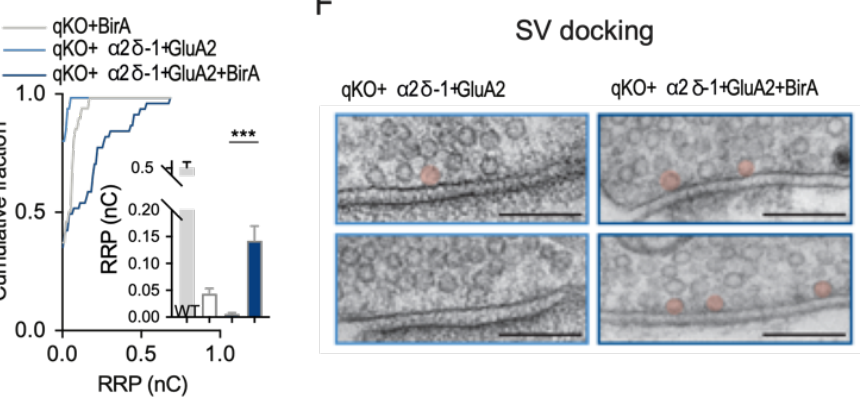

$G$

qKO+BirA

$-\mathrm{qKO}+$ a2 $\delta-1+\mathrm{GluA}$

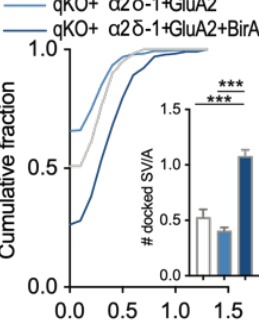

\# docked SVs/100nm AZ

I

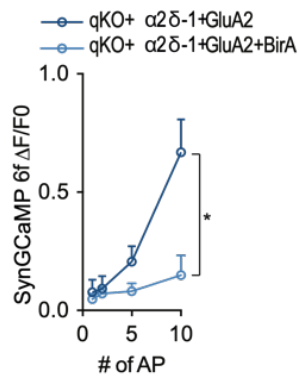

Figure 5: The artificial alignment of $\alpha 2 \delta 1$ and GluA2 rescues neurotransmission in RIM/RBP deficient synapses.

(A) Model of transsynaptic alignment of $\alpha 2 \delta 1-\mathrm{AP}$ and GluA2-mSA by BirA co-expression in qKO synapses. (B) Example traces of excitatory postsynaptic currents (EPSC). (C) Excitatory postsynaptic current (EPSC) amplitudes. (D) Example traces of synaptic responses to a $5 \mathrm{~s}$ application of hypertonic sucrose. (E) Readily releasable pool (RRP) charge. (F) Representative electron micrographs of cryofixed primary hippocampal neurons from qKO mice. (G) Absolute number of docked SV and docked SV per $100 \mathrm{~nm} \mathrm{AZ.} \mathrm{(H)} \mathrm{Example} \mathrm{images} \mathrm{of} \mathrm{SynGCaMP6f} \mathrm{fluorescence} \mathrm{in}$ qKO neurons, obtained during trains of AP stimulation. Scale bars $5 \mu \mathrm{m}$ (I) Fluorescence changes $(\triangle \mathrm{F} / \mathrm{F})$ upon single $\mathrm{AP}$ and APs trains.

Data are individual values and means \pm SEM. Statistical significance for C, E, and G was assessed by Kruskal-Wallis test and I by Two-way ANOVA. ${ }^{*} \mathrm{p}<0.05,{ }^{*} \mathrm{p}<0.01, * * * \mathrm{p}<0.001$. 
A

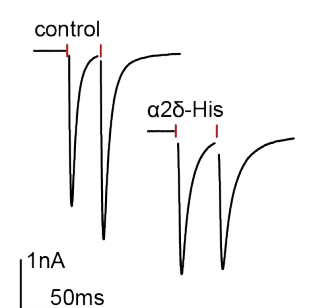

B

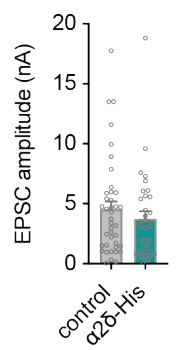

C

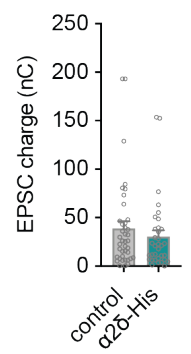

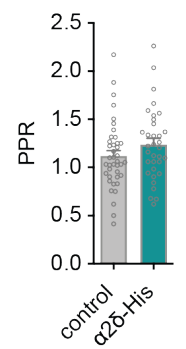

$\mathrm{D}$

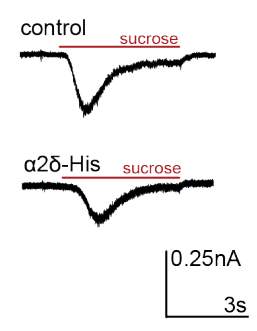

E

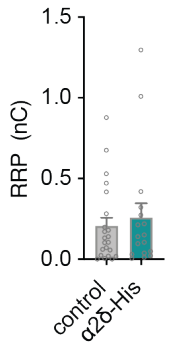

$\mathrm{F}$

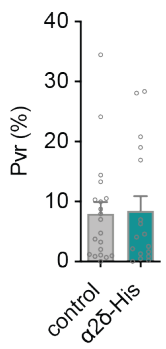

Figure S1: The lentiviral expression of $\alpha 2 \delta 1-\mathrm{His}$ does not impact excitatory synaptic transmission.

(A) Example traces of two EPSCs evoked by a $2 \mathrm{~ms}$ depolarization with an interstimulus interval of $25 \mathrm{~ms}$ from control and $\alpha 2 \delta 1$-His expressing hippocampal autapses. (B) Summary graphs of excitatory postsynaptic current (EPSC) amplitude, and charge. (C) Summary graph of the PairedPulse-ratio (PPR) calculated as the fraction of the second EPSC and the first EPSC at an interstimulus interval of $25 \mathrm{~ms}$. (D) Example traces of synaptic responses to a $5 \mathrm{~s}$ application of hypertonic sucrose $(500 \mathrm{mM})$ solution probing the readily releasable pool (RRP). (E) Summary graph of the RRP. (F) Summary graph of the vesicular release probability $\left(\mathrm{P}_{\mathrm{vr}}\right)$ calculated as the ratio of the EPSC and the RRP charge.

Data are individual values and means \pm SEM. Statistical significance for B, C, E, and F was assessed by unpaired t-test. 
A
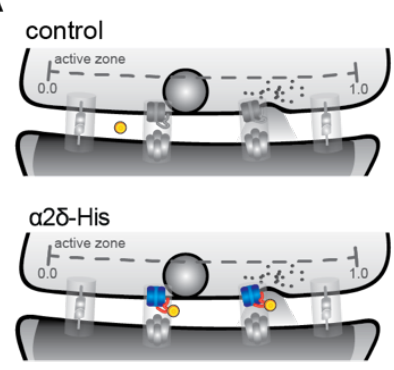

$\mathrm{B}$
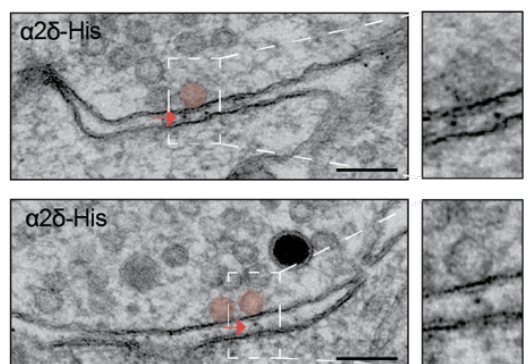

$\mathrm{E}$

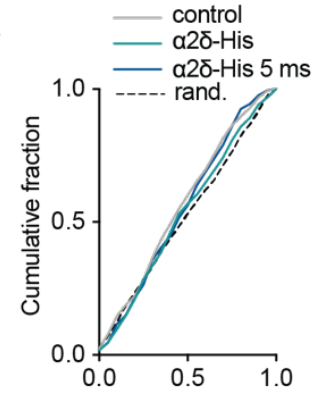

dockedSVs/norm. AZ size
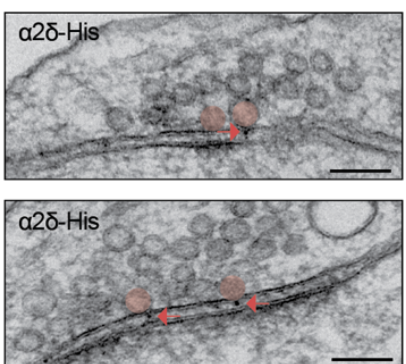

$\mathrm{F}$

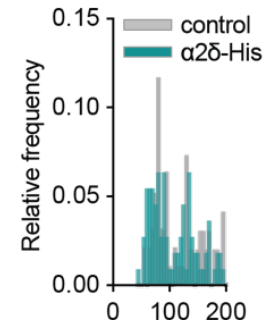

dist. betw. dockedSVs (nm)
G

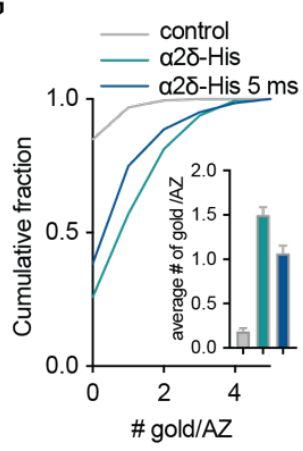

$J$
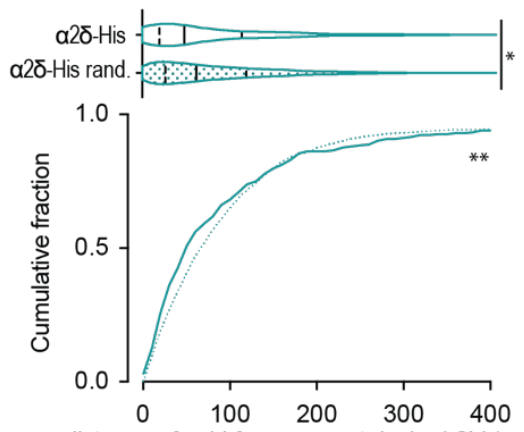

distance of gold from nearest docked SV $(\mathrm{nm})$

L

$\alpha 2 \delta$-His vs. $\alpha 2 \delta$-His rand

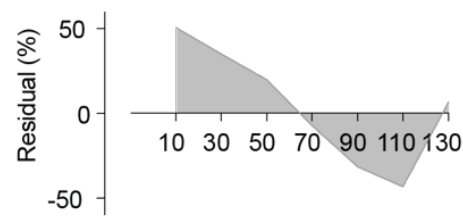

distance of gold from nearest docked SV (nm) (t)

80

$\mathrm{H}$

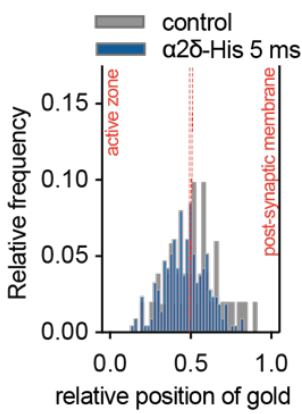

I

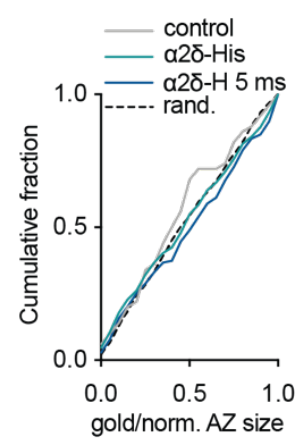

$\mathrm{K}$
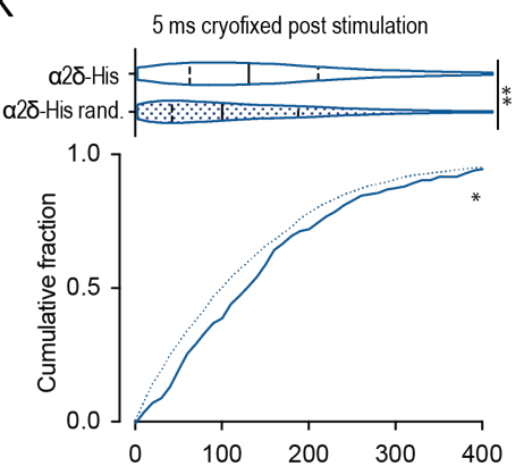

distance of gold from nearest docked SV $(\mathrm{nm})$

M

$\alpha 2 \delta-H i s$ vs. $\alpha 2 \delta$-His rand. $5 \mathrm{~ms}$ post stimulation

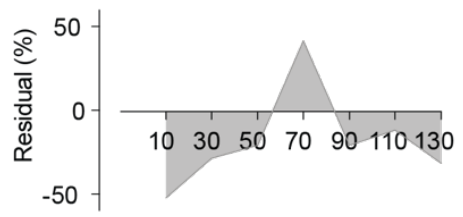

distance of gold from nearest docked SV $(\mathrm{nm})$ 
Figure S2: The lentiviral expression of $\alpha 2 \delta 1-\mathrm{His}$ does not impact the ultrastructure of excitatory synapses.

(A) Scheme of the ultrastructural parameters analyzed in electron micrographs for control (nontransfected) and $\alpha 2 \delta 1$-His expressing neurons. The active zone (AZ) is defined as the membrane stretch opposed to the postsynaptic density (PSD). Synaptic vesicles (SV) are docked when their membrane is directly attached to the AZ membrane. For some analysis, the AZ length is normalized to 1 with the center at 0.5 . (B) Representative electron micrographs of primary hippocampal neurons expressing the tagged $\mathrm{Ca}^{2+}$-channel subunit $\alpha 2 \delta 1$-His. Boxed docked vesicle enlarged together with the respective gold particle. Scale bars, $100 \mathrm{~nm}$. (C and D) Summary graphs show the number of docked SVs (c) and the PSD length (d) for control, $\alpha 2 \delta 1$-His expressing neurons, and $\alpha 2 \delta 1$-His expressing neurons cryofixed $5 \mathrm{~ms}$ after action potential induction. (E) Cumulative probability plot of docked SVs distribution at the normalized AZ. (F) Frequency plot of the distance between neighboring docked SVs at the AZ. (G) Cumulative probability plot and bar graph of the number of gold particles in the synaptic cleft in control, $\alpha 2 \delta 1$-His expressing neurons without stimulation, and $\alpha 2 \delta 1$-His expressing neurons cryofixed $5 \mathrm{~ms}$ after action potential induction. (H) Frequency plot of the gold particle position in the synaptic cleft $(0=\mathrm{AZ} ; 1=\mathrm{PSD})$. (I Cumulative probability plot of gold particle distribution throughout the normalized AZ length. (J) Violin, and cumulative probability plot of the nearest distance of a gold particle to the next docked SV in $\alpha 2 \delta 1$-His expressing neurons compared to random placement of SVs and $\alpha 2 \delta 1$-His. (K) Violin, and cumulative probability plot of a gold particle's shortest distance to the next docked SV in $\alpha 2 \delta 1$-His expressing neurons cryofixed $5 \mathrm{~ms}$ after action potential induction compared to random placement of SVs and $\alpha 2 \delta 1$-His. (L) Enrichment of a2d1-His localization to docked SVs in $20 \mathrm{~nm}$ bins compared to the simulated distribution of random docked SVs and a2d1-His placement. The residual percentage is calculated as the percentage of the measured distances of gold particles to docked SVs to their randomized distribution distances. (M) Residual percentage of a2d1-His localization to docked SVs $5 \mathrm{~ms}$ after action potential induction in $20 \mathrm{~nm}$ bins, measured as the percentage of the measured distances of gold particles to docked SVs to the distances of their randomized distribution.

Data for bar graphs are individual values and means \pm SEM. Data for violin plots are medians (solid lines) and quartiles (dashed lines). Statistical significance for C, D and G was assessed by KruskalWallis test for the violin plots in $\mathrm{J}$ and $\mathrm{K}$ by Mann-Whitney test, and for the cumulative distribution plots in $\mathrm{E}, \mathrm{I}, \mathrm{J}$, and $\mathrm{K}$ by the Kolmogorov-Smirnov test. $* \mathrm{p}<0.05, * * * \mathrm{p}<0.001$. 
A
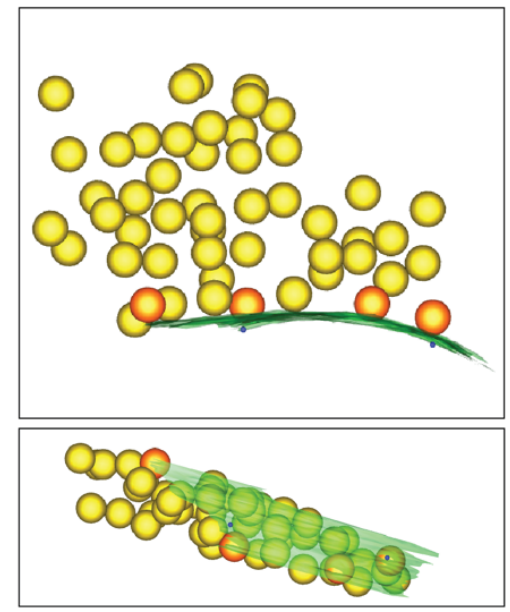

D

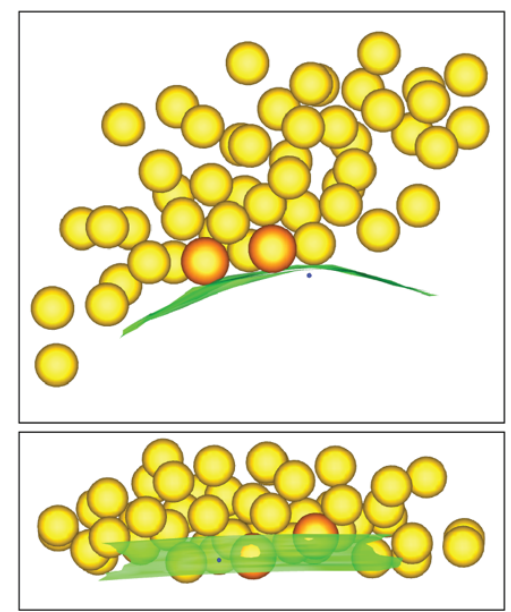

B

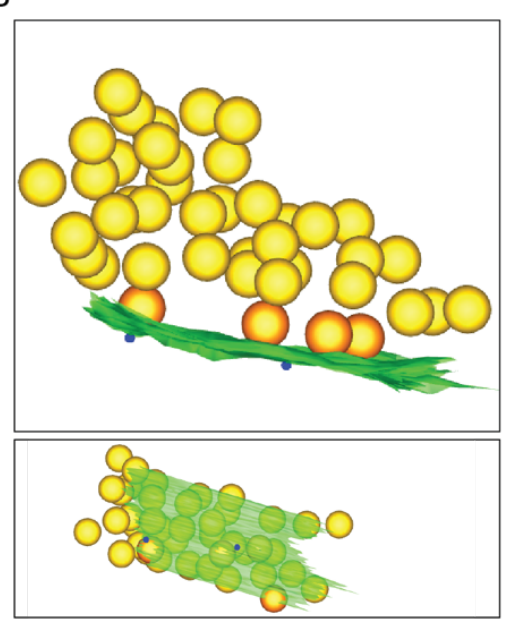

E

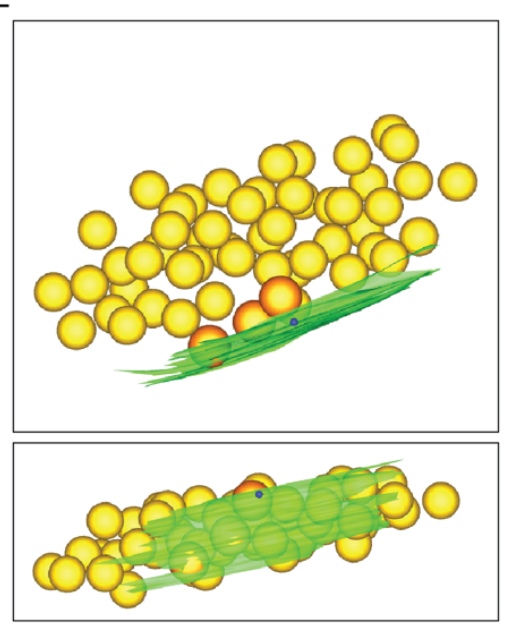

C

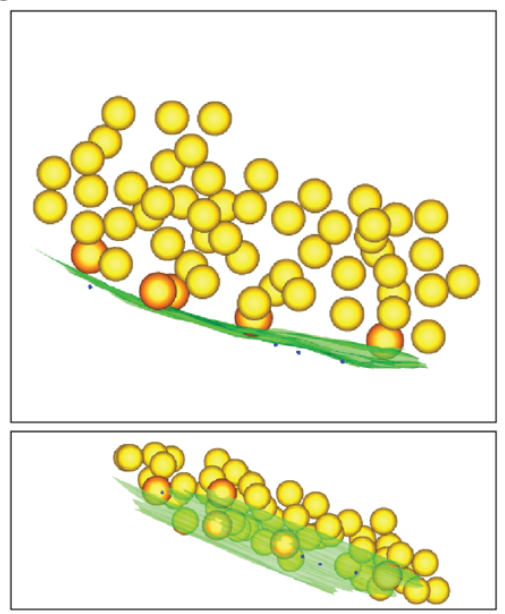

$\mathrm{F}$

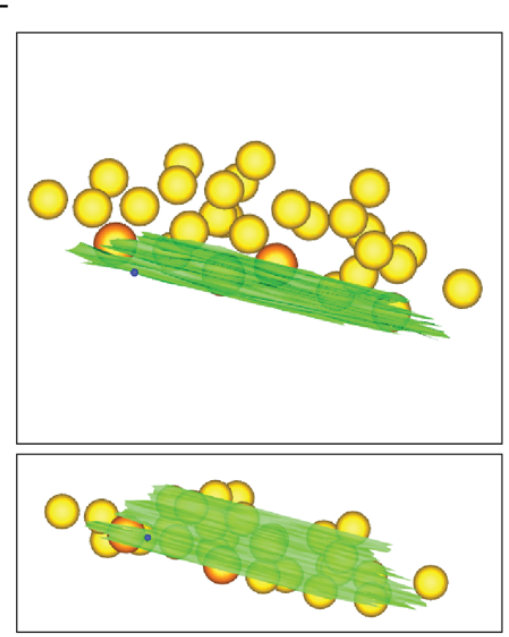

Figure S3: $\alpha 2 \delta 1$-His localization in tomograms from cryofixed excitatory hippocampal neurons. (A-F) Individual tomograms of synapses from cryo-fixed hippocampal neurons expressing $\alpha 2 \delta 1$-HIS (active zone $=$ green, $\mathrm{SVs}=$ yellow, docked $\mathrm{SV}=$ orange, gold particle $=$ blue). 
A

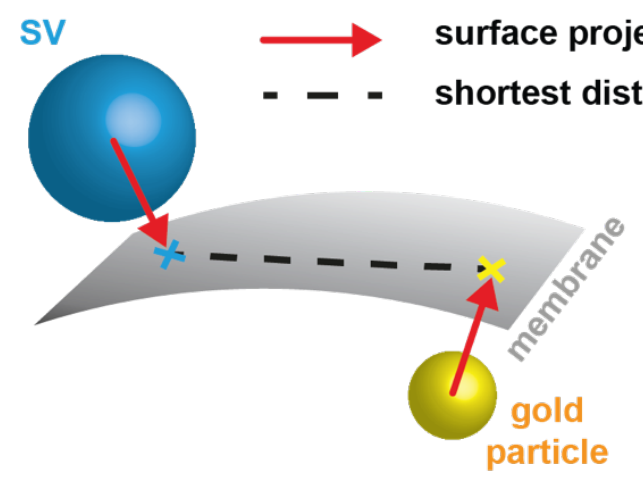

B

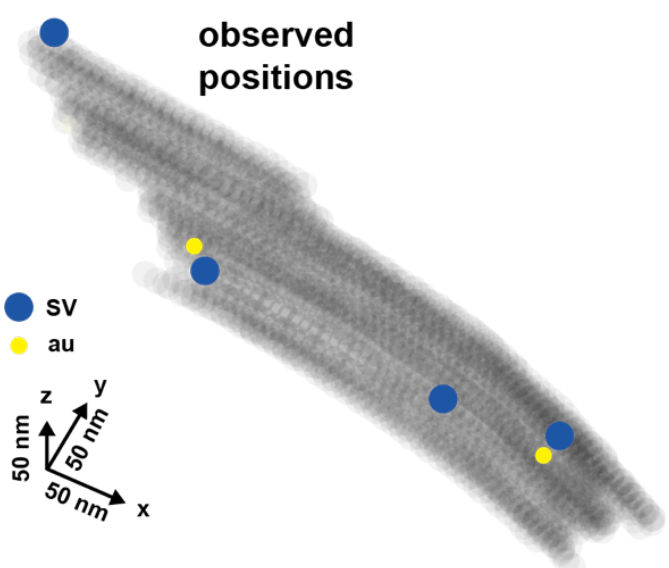

C

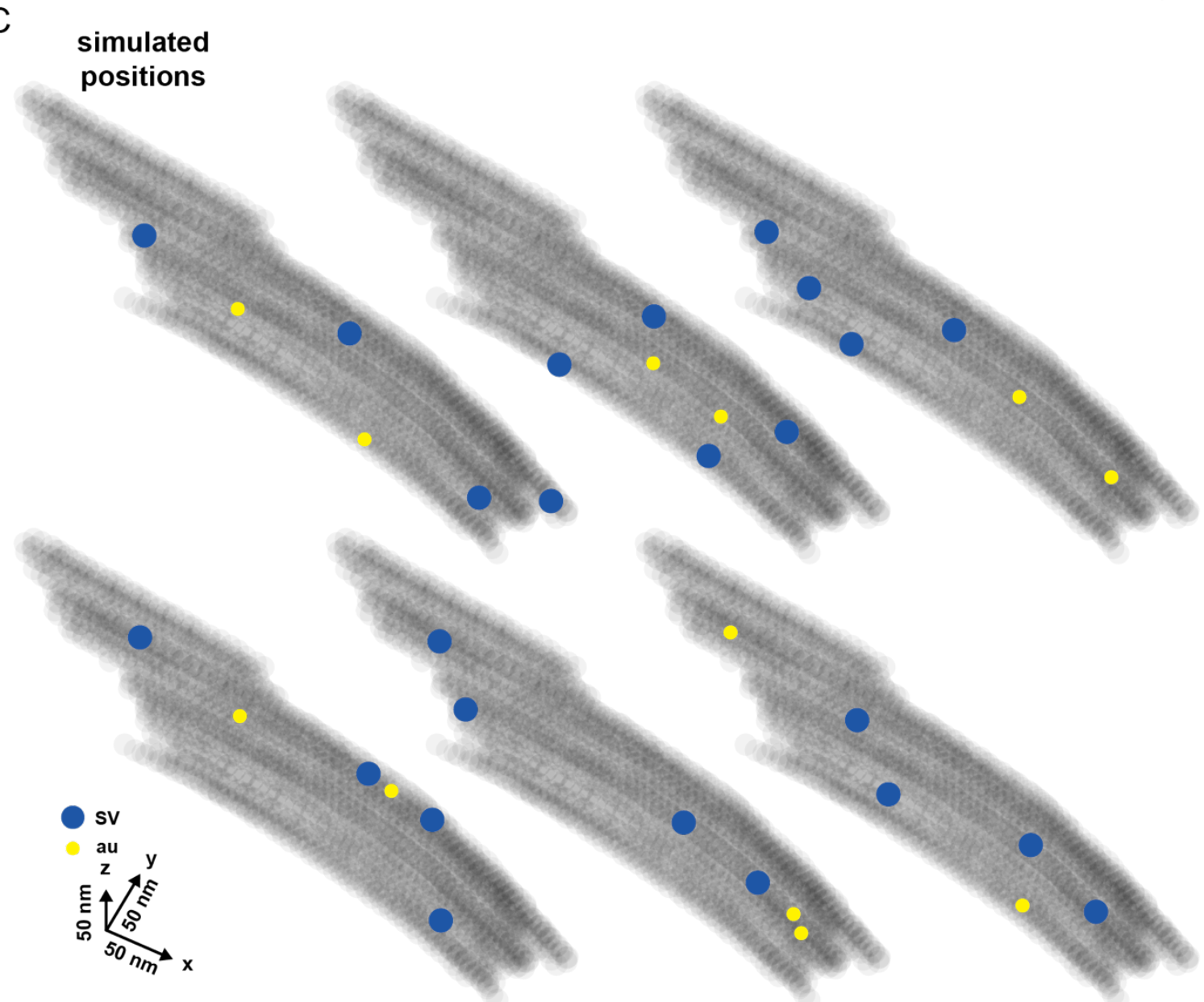

Figure S4: Analysis of $\alpha 2 \delta 1-H i s$ localization in tomograms from cryofixed excitatory hippocampal neurons.

(A) Graphic of the analysis strategy to determine the distance between the gold particle and docked SV from tomogram data. (B) Reconstruction of the observed and (C) randomized position of gold particles and docked SVs from tomograms. 
A
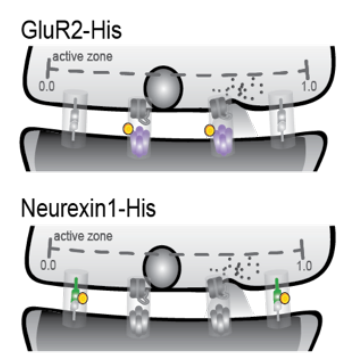

Neuroligin-His

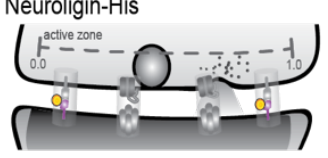

B
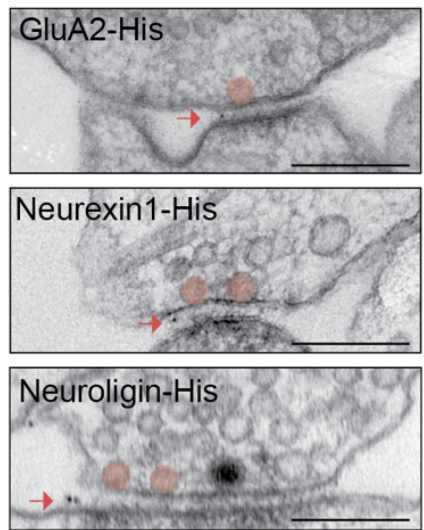
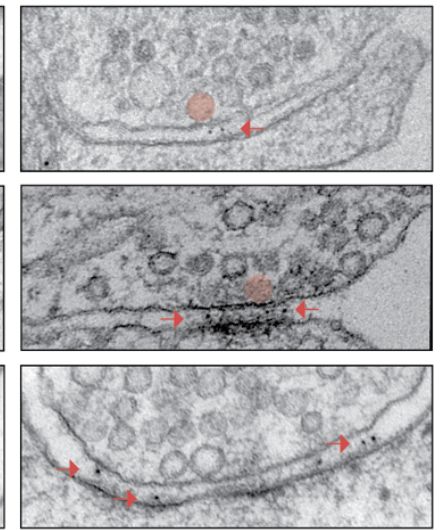

C

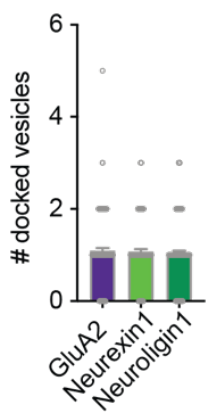

$\mathrm{F}$

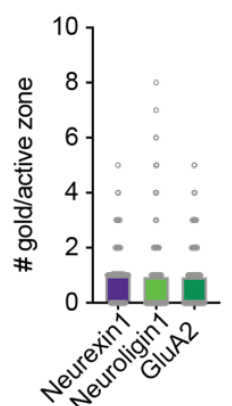

I
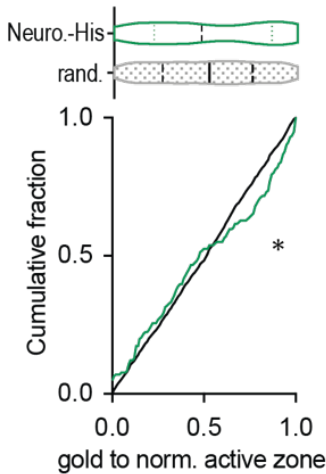

D

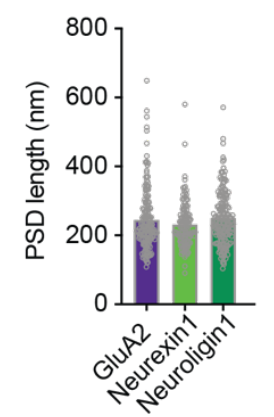

G

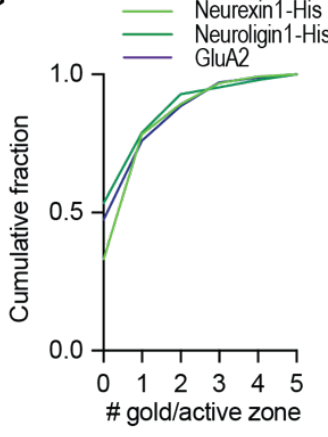

$\mathrm{E}$

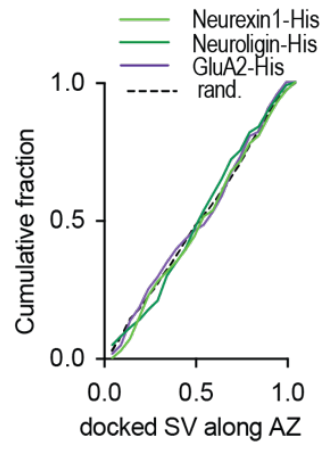

$\mathrm{H}$

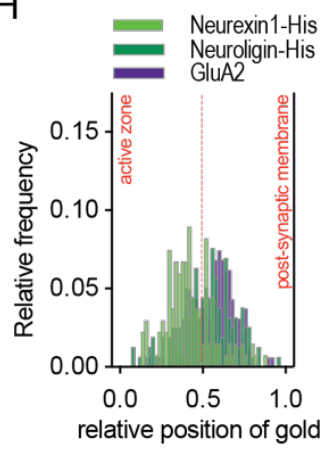

$\mathrm{J}$
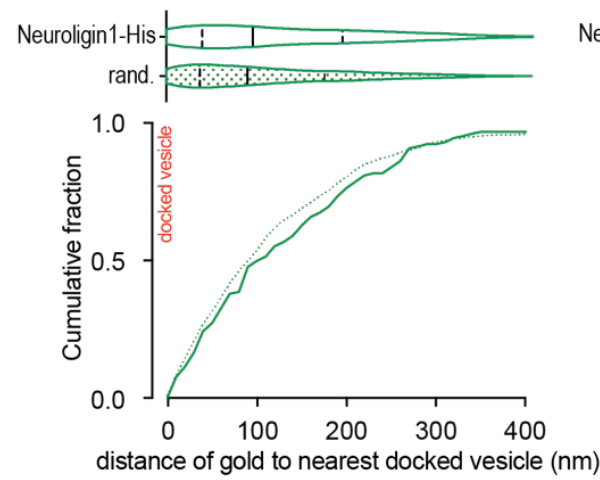

K
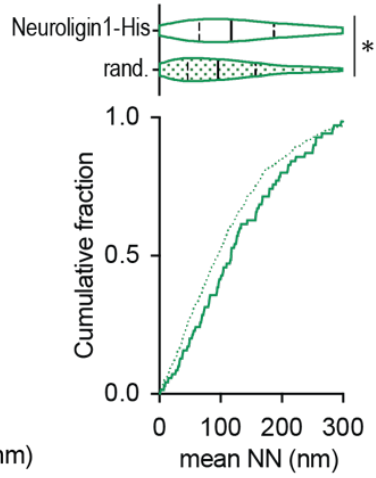

Figure S5: Neuroligin1 does not associate with docked SV.

(A) Graphic for the ultrastructural parameters analyzed in electron micrographs for GluA2-His, neurexin-His, and neuroligin-His expressing neurons. (B) Representative electron micrographs of cryofixed primary hippocampal neurons expressing GluA2-HIS, neurexin1-His, or neuroligin1-His. 
(C) Summary graph of docked SV number per AZ. (D) Summary graph of the PSD length. (E) Cumulative probability of docked SV distribution at the AZ. (F) Summary graph of gold particles per AZ. (G) Cumulative probability plot of gold particles per AZ. h) Relative frequency of gold particles in the synaptic cleft $(0=$ active zone membrane; $1=$ post-synaptic membrane). (I) Violin, and cumulative probability plots of gold the particle distribution at the normalized AZ for neuroligin-His expressing neurons compared to randomized data. $(\mathbf{J})$ Violin, and cumulative probability plots of the nearest distance between gold participles and the next docked SV compared to randomized distances. (K) Violin, and cumulative probability plots of the measured data and null model data of mean nearest neighbor distance (NND) of gold particles to docked SVs.

Data for bar graphs are individual values and means \pm SEM. Data for violin plots are medians (solid lines) and quartiles (dashed lines). Statistical significance for C, D, and F was assessed by KruskalWallis test, for I, J, and $\mathrm{K}$ by Mann-Whitney test, and for the cumulative distribution plots in I, J, and $\mathrm{K}$

test. $* \mathrm{p}<0.05$. 
A

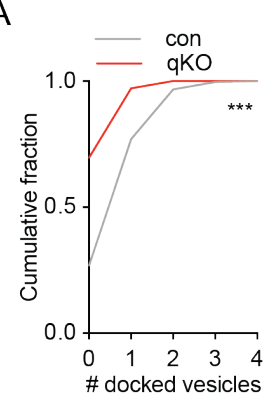

$\mathrm{F}$

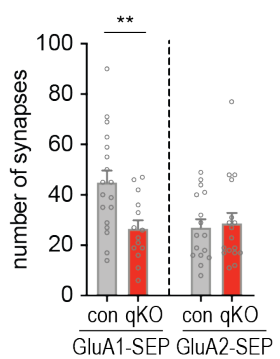

$\mathrm{K}$

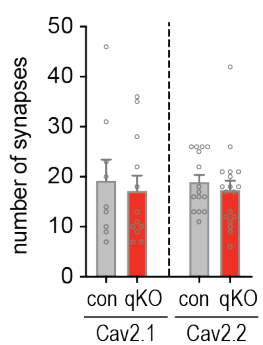

B

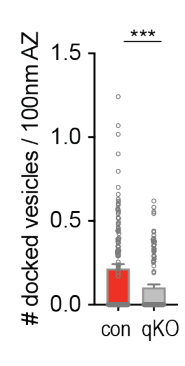

G

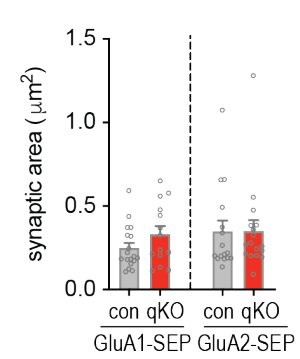

L

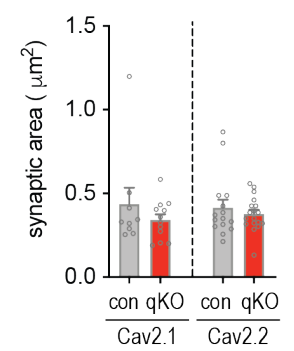

C

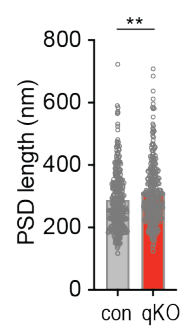

$\mathrm{H}$

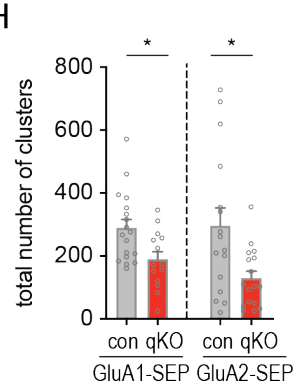

M

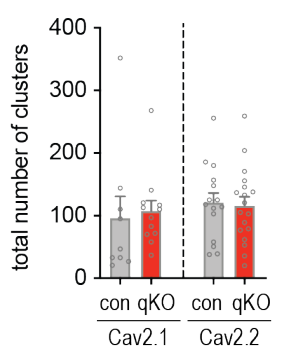

D
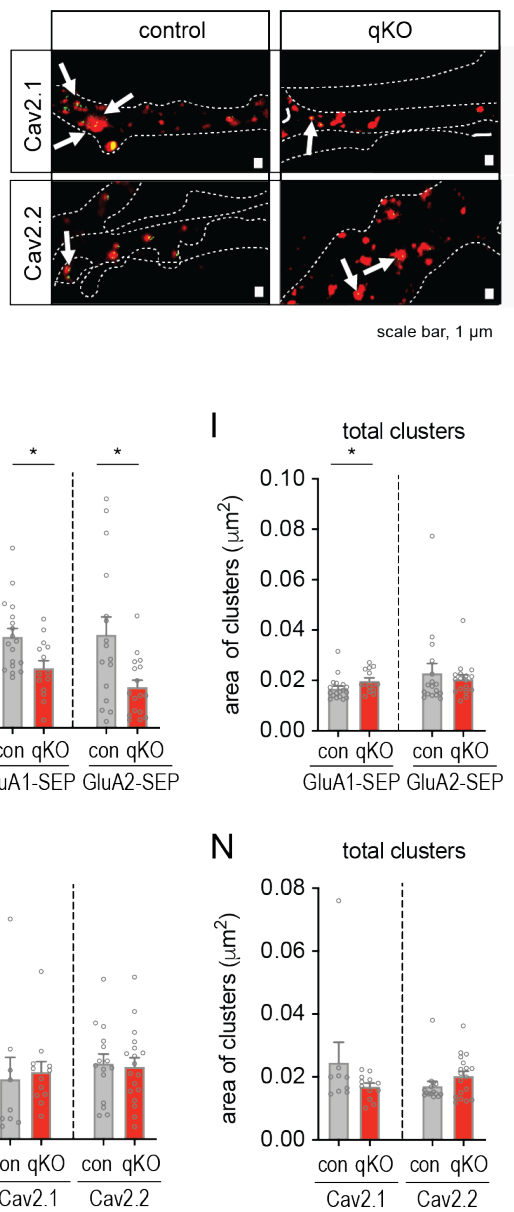

$\mathrm{E}$
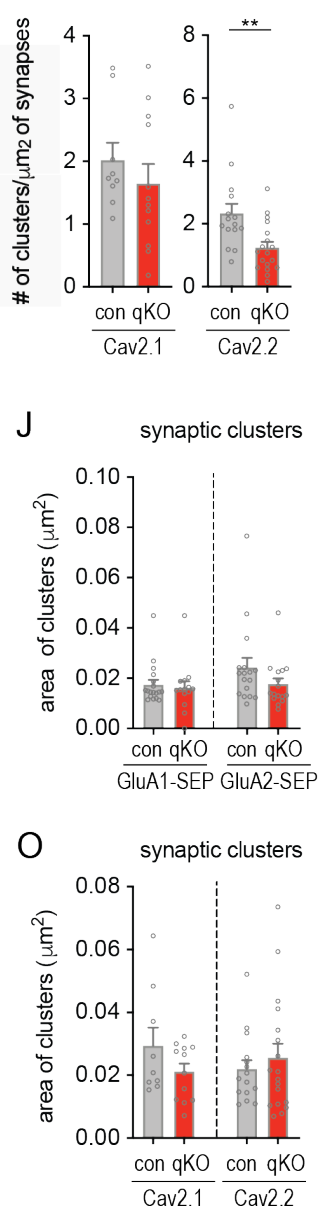

Figure S6: The deletion of RIM/RBP results in a loss of docked SV and a strong reduction in $\mathrm{Ca}^{2+}$-channels.

(A-O) All experiments were conducted in RIM/RBP deficient neurons ( $\mathrm{qKO}$ ) and their respective control. (A) Cumulative probability plot of the number of docked SV. (B) Summary graph of the number of docked SV per 100nm AZ. (C) Summary graph of the PSD length. (D) Synapse expressing Cav2.1-GFP or Cav2.2-GFP (green; dSTORM) and Homer (red). Scale bars $1 \mu \mathrm{m}$. (E) Summary graphs of the number of Cav2.1 and Cav2.2 clusters per synapse area. (F and K) Summary graphs of synapse number of the respective AMPA or $\mathrm{Ca}^{2+}$-channel subunit. ( $\mathbf{G}$ and $\mathbf{L}$ ) Summary graphs of the synaptic area of the respective AMPA or $\mathrm{Ca}^{2+}$-channel subunit. (H and M) Summary graphs of the total number of clusters of the respective AMPA or $\mathrm{Ca}^{2+}$-channel subunit. (I and N) Summary graphs of the area of all clusters for the respective AMPA or $\mathrm{Ca}^{2+}$-channel subunit. ( $\mathbf{J}$ and $\mathbf{O}$ ) Summary graphs of the area of synaptic clusters for the respective AMPA or $\mathrm{Ca}^{2+}$-channel subunit.

Data are individual values and means \pm SEM. Statistical significance for B, C, E, F, G, H, I, J, K, L, $\mathrm{M}, \mathrm{N}$, and $\mathrm{O}$ was assessed by Mann-Whitney test and cumulative distribution plots in a by Kolmogorov-Smirnov test. $* \mathrm{p}<0.05, * * \mathrm{p}<0.01$. 
A

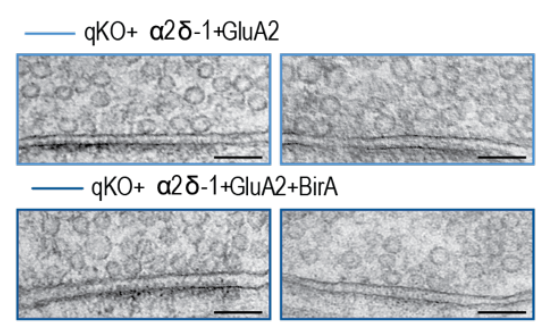

D

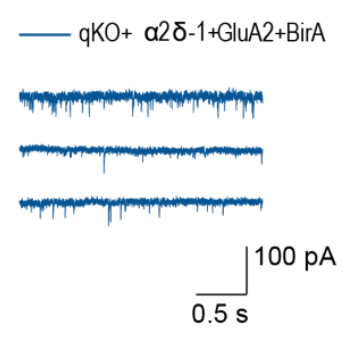

$E$

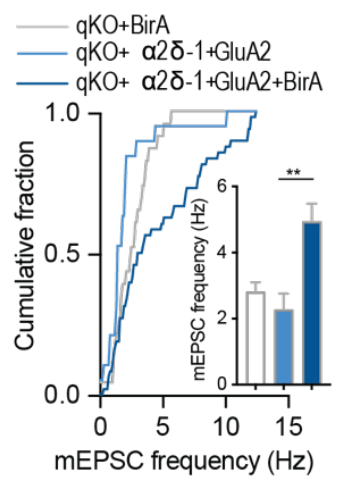

B

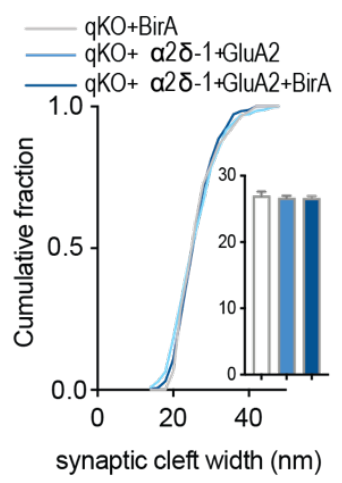

$\mathrm{F}$

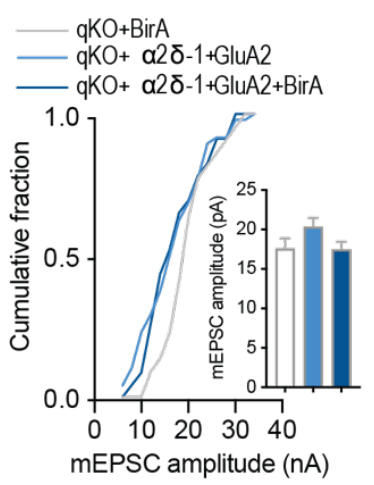

C

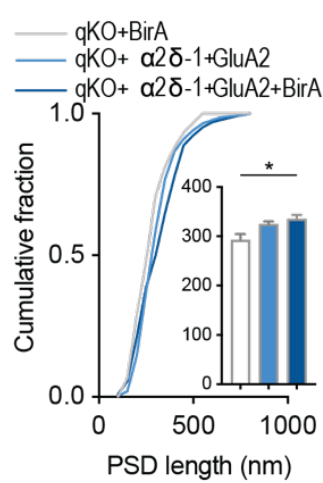

G

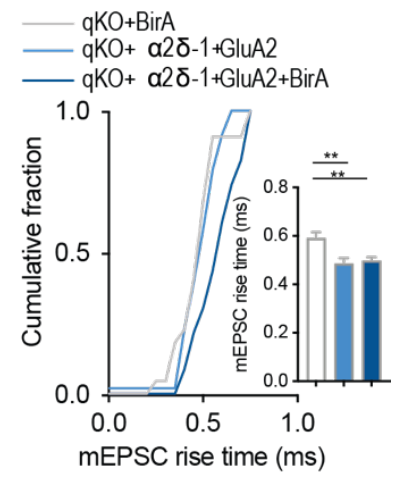

$\mathrm{H}$

I

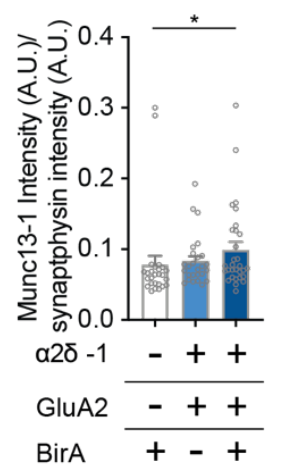

Figure S7: The artificial alignment of $\alpha 2 \delta 1$ and GluA2 partially rescues mEPSC frequency and Munc13-1 protein levels.

(A) Representative electron micrographs of cryofixed primary hippocampal neurons from $\mathrm{qKO}$ mice expressing $\alpha 2 \delta 1$-AP and GluA2-mSA or $\alpha 2 \delta 1$-AP, GluA2-mSA, and BirA. Scale bars $100 \mathrm{~nm}$ (B) Cumulative probability plot and bar graph of the synaptic cleft width. (C) Cumulative probability plot and bar graph of the PSD length. (D) Example traces of miniature postsynaptic currents (mEPSCs). (E) Cumulative probability plot, and bar graph of mEPSC frequency. (F) Cumulative probability plot, and bar graph of mEPSC amplitude. (G) Cumulative probability plot, and bar graph of mEPSC rise time. (H) Example images of Munc13-1 and synaptophysin immunostainings in neuronal cultures obtained from qKO mice. Scale bars $5 \mu \mathrm{m}$. (I) Munc13-1 immunofluorescence intensities normalized to synaptophysin intensities.

Data are means \pm SEM. Statistical significance for B, C, E, F, G, and I was assessed by KruskalWallis test. ${ }^{*} \mathrm{p}<0.05,{ }^{* *} \mathrm{p}<0.01$. 
Table S1.

\section{Figure 1}

\begin{tabular}{|c|c|c|c|c|c|c|c|c|c|c|c|c|}
\hline & & \multicolumn{3}{|c|}{ control } & \multicolumn{3}{|c|}{ a2d1-His } & & & & \multicolumn{2}{|c|}{ statistic } \\
\hline Fig. & Parameter & mean & SEM & $\mathrm{n}$ & mean & SEM & $\mathrm{n}$ & mean & SEM & $\mathrm{n}$ & $\mathrm{p}$ & test \\
\hline \multirow{2}{*}{$1 \mathrm{C}$} & \multirow{2}{*}{ \# gold/AZ } & \multirow{2}{*}{0,1867} & \multirow{2}{*}{0,3217} & \multirow{2}{*}{225} & \multirow{2}{*}{1,495} & \multirow{2}{*}{0,0936} & \multirow{2}{*}{196} & & & & $<0,0001$ & $\begin{array}{c}\text { Mann-Whitney } \\
\text { test }\end{array}$ \\
\hline & & & & & & & & & & & $<0,0001$ & $\begin{array}{l}\text { Kolmogorov- } \\
\text { Smirnov test }\end{array}$ \\
\hline
\end{tabular}

\begin{tabular}{|c|c|c|c|c|c|c|c|c|c|c|c|c|}
\hline Fig. & Parameter & mean & SEM & $\mathrm{n}$ & mean & SEM & $\mathrm{n}$ & mean & SEM & $\mathrm{n}$ & $\mathrm{p}$ & test \\
\hline \multirow[b]{2}{*}{$1 \mathrm{D}$} & \multirow{2}{*}{$\begin{array}{c}\text { relative } \\
\text { position of } \\
\text { gold }\end{array}$} & \multirow[b]{2}{*}{0,5257} & \multirow[b]{2}{*}{0,0227} & \multirow[b]{2}{*}{50} & \multirow[b]{2}{*}{0,4302} & \multirow[b]{2}{*}{0,0077} & \multirow[b]{2}{*}{293} & & & & & \\
\hline & & & & & & & & & & & & \\
\hline
\end{tabular}

\begin{tabular}{|c|c|c|c|c|c|c|c|}
\hline Fig. & Parameter & median & $\mathrm{n}$ & median & $\mathrm{n}$ & $\mathrm{p}$ & test \\
\hline \multirow{2}{*}{$1 \mathrm{E}$} & \multirow{2}{*}{$\begin{array}{c}\text { distance og } \\
\text { gold to nearest } \\
\text { docked SV }\end{array}$} & \multirow{2}{*}{91,67} & \multirow{2}{*}{38} & \multirow{2}{*}{46,49} & \multirow{2}{*}{282} & 0,0019 & $\begin{array}{c}\text { Mann-Whitney } \\
\text { test }\end{array}$ \\
\hline & & & & & & 0,0003 & $\begin{array}{l}\text { Kolmogorov- } \\
\text { Smirnov test }\end{array}$ \\
\hline
\end{tabular}

\begin{tabular}{|c|c|c|c|c|c|c|c|c|c|}
\hline & & \multicolumn{2}{|c|}{ control } & \multicolumn{2}{|c|}{ a2d1-His } & \multicolumn{2}{|c|}{ a2d1-His simulated } & \multicolumn{2}{|c|}{ statistic } \\
\hline Fig. & Parameter & median & $\mathrm{n}$ & median & $\mathrm{n}$ & median & $\mathrm{n}$ & $\mathrm{p}$ & test \\
\hline $1 \mathrm{G}$ & distance of & & & 2246 & 10 & 424 & 1007 & 0,0002 & $\begin{array}{c}\text { Mann-Whitney } \\
\text { test }\end{array}$ \\
\hline 10 & docked SV & & & $22,+0$ & 19 & 42,4 & 1301 & 0,0043 & $\begin{array}{l}\text { Kolmogorov- } \\
\text { Smirnov test }\end{array}$ \\
\hline
\end{tabular}




\section{Table S1.}

\section{Figure 2}

\begin{tabular}{|c|c|c|c|c|c|c|c|c|c|c|c|c|}
\hline & & & & & \multicolumn{3}{|c|}{ a2d1-His } & \multicolumn{3}{|c|}{ a2d1-His simulated } & \multicolumn{2}{|c|}{ statistic } \\
\hline Fig. & Parameter & mean & SEM & $\mathrm{n}$ & mean & SEM & $\mathrm{n}$ & mean & SEM & $\mathrm{n}$ & $\mathrm{p}$ & test \\
\hline \multirow{2}{*}{$2 B$} & \multirow{2}{*}{$\begin{array}{c}\text { \# docked } \\
\text { SV/100nm AZ }\end{array}$} & & & & \multirow{2}{*}{0,4813} & \multirow{2}{*}{0,019} & \multirow{2}{*}{196} & \multirow{2}{*}{0,3385} & \multirow{2}{*}{0,0199} & \multirow{2}{*}{204} & $<0,0001$ & $\begin{array}{c}\text { Mann-Whitney } \\
\text { test } \\
\end{array}$ \\
\hline & & & & & & & & & & & $<0,0001$ & $\begin{array}{l}\text { Kolmogorov- } \\
\text { Smirnov test }\end{array}$ \\
\hline
\end{tabular}

\begin{tabular}{|c|c|c|c|c|c|c|c|c|c|c|c|c|}
\hline Fig. & Parameter & mean & SEM & $\mathrm{n}$ & mean & SEM & $\mathrm{n}$ & mean & SEM & $\mathrm{n}$ & $\mathrm{p}$ & test \\
\hline 2C & $\begin{array}{c}\text { distance of } \\
\text { gold to nearest } \\
\text { docked SV }\end{array}$ & & & & & & & & & & $<0,0001$ & $\begin{array}{c}\text { Mann-Whitney } \\
\text { test }\end{array}$ \\
\cline { 5 - 9 } & & & & & & & & & & & &
\end{tabular}


bioRxiv preprint doi: https://doi.org/10.1101/2020.12.25.424391; this version posted December 25, 2020. The copyright holder for this

preprint (which was not certified by peer review) is the author/funder, who has granted bioRxiv a license to display the preprint in perpetuity. It is made available under aCC-BY-N.ND 4.0 International license.

Figure 3

\begin{tabular}{|c|c|c|c|c|c|c|c|c|c|c|}
\hline & & & & & & & & & & istic \\
\hline Fig. & Parameter & median & $\mathrm{n}$ & median & $\mathrm{n}$ & mean & SEM & $\mathrm{n}$ & $\mathrm{p}$ & test \\
\hline \multirow{2}{*}{$3 \mathrm{C}$} & \multirow{2}{*}{$\begin{array}{l}\text { gold to norm. } \\
\text { active zone }\end{array}$} & \multirow{2}{*}{0,5095} & \multirow{2}{*}{161} & \multirow{2}{*}{0,5187} & \multirow{2}{*}{2000} & & & & 0,8964 & $\begin{array}{c}\text { Mann-Whitney } \\
\text { test }\end{array}$ \\
\hline & & & & & & & & & 0,0259 & $\begin{array}{l}\text { Kolmogorov- } \\
\text { Smirnov test }\end{array}$ \\
\hline
\end{tabular}

\begin{tabular}{|c|c|c|c|c|c|c|c|c|c|c|}
\hline & & & & & & & & & & istic \\
\hline Fig. & Parameter & median & $\mathrm{n}$ & median & $\mathrm{n}$ & mean & SEM & $\mathrm{n}$ & $\bar{p}$ & test \\
\hline \multirow[b]{2}{*}{$3 \mathrm{D}$} & \multirow{2}{*}{$\begin{array}{l}\text { distance of } \\
\text { gold to nearest } \\
\text { docked SV }\end{array}$} & \multirow[b]{2}{*}{45,65} & \multirow[b]{2}{*}{147} & \multirow[b]{2}{*}{71,13} & \multirow[b]{2}{*}{1470} & & & & 0,0206 & $\begin{array}{c}\text { Mann-Whitney } \\
\text { test }\end{array}$ \\
\hline & & & & & & & & & 0,0036 & $\begin{array}{l}\text { Kolmogorov- } \\
\text { Smirnov test }\end{array}$ \\
\hline
\end{tabular}

\begin{tabular}{|c|c|c|c|c|c|c|c|c|c|c|}
\hline & & & & & & & & & & stic \\
\hline Fig. & Parameter & median & $\mathrm{n}$ & median & $\mathrm{n}$ & mean & SEM & $\mathrm{n}$ & $\mathrm{p}$ & test \\
\hline \multirow[b]{2}{*}{$3 \mathrm{E}$} & \multirow[b]{2}{*}{$\begin{array}{l}\text { mean NND } \\
(\mathrm{nm})\end{array}$} & \multirow[b]{2}{*}{52,65} & \multirow[b]{2}{*}{84} & \multirow[b]{2}{*}{73,98} & \multirow[b]{2}{*}{840} & & & & 0,0222 & $\begin{array}{c}\text { Mann-Whitney } \\
\text { test }\end{array}$ \\
\hline & & & & & & & & & 0,005 & $\begin{array}{l}\text { Kolmogorov- } \\
\text { Smirnov test }\end{array}$ \\
\hline
\end{tabular}

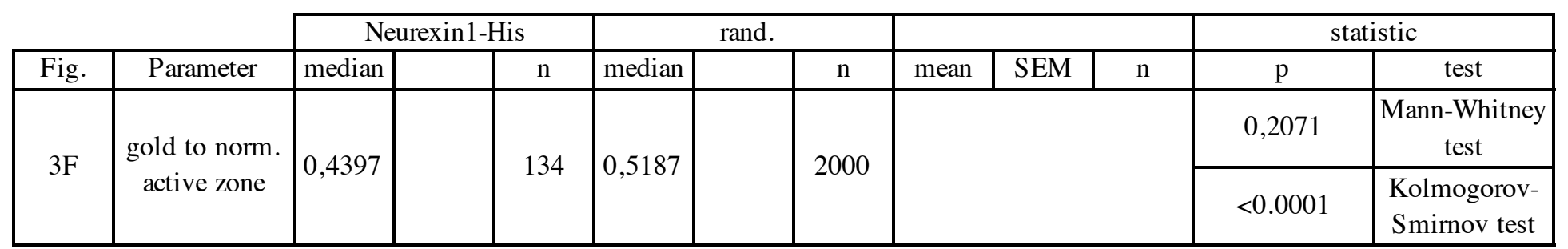

\begin{tabular}{|c|c|c|c|c|c|c|c|c|c|c|}
\hline & & & & & & & & & \multicolumn{2}{|c|}{ statistic } \\
\hline Fig. & Parameter & median & $\mathrm{n}$ & median & $\mathrm{n}$ & mean & SEM & $\mathrm{n}$ & $\mathrm{p}$ & test \\
\hline \multirow{2}{*}{$3 \mathrm{G}$} & \multirow{2}{*}{$\begin{array}{c}\text { distance of } \\
\text { gold to nearest } \\
\text { docked SV }\end{array}$} & \multirow{2}{*}{97,22} & \multirow{2}{*}{120} & \multirow{2}{*}{79,55} & \multirow{2}{*}{1200} & & & & 0,0043 & $\begin{array}{c}\text { Mann-Whitney } \\
\text { test }\end{array}$ \\
\hline & & & & & & & & & 0,0226 & $\begin{array}{l}\text { Kolmogorov- } \\
\text { Smirnov test }\end{array}$ \\
\hline
\end{tabular}

\begin{tabular}{|c|c|c|c|c|c|c|c|c|c|c|}
\hline & & & & & & & & & & stic \\
\hline Fig. & Parameter & median & $\mathrm{n}$ & median & $\mathrm{n}$ & mean & SEM & $\mathrm{n}$ & $\mathrm{p}$ & test \\
\hline \multirow{2}{*}{$3 \mathrm{H}$} & \multirow{2}{*}{$\begin{array}{c}\text { mean NND } \\
(\mathrm{nm})\end{array}$} & \multirow{2}{*}{106,3} & \multirow{2}{*}{77} & \multirow{2}{*}{84,6} & \multirow{2}{*}{770} & & & & 0,0082 & $\begin{array}{c}\text { Mann-Whitney } \\
\text { test }\end{array}$ \\
\hline & & & & & & & & & 0,0393 & $\begin{array}{l}\text { Kolmogorov- } \\
\text { Smirnov test }\end{array}$ \\
\hline
\end{tabular}


bioRxiv preprint doi: https://doi.org/10.1101/2020.12.25.424391; this version posted December 25, 2020. The copyright holder for this

preprint (which was not certified by peer review) is the author/funder, who has granted bioRxiv a license to display the preprint in perpetuity. It is made available under aCC-BY-NC-ND 4.0 International license.

Figure 4

\begin{tabular}{|c|c|c|c|c|c|c|c|c|c|c|c|c|}
\hline & & cont & 1, Glu $A$ & His & & , GluA2 & & & & & \multicolumn{2}{|c|}{ statistic } \\
\hline Fig. & Parameter & mean & SEM & $\mathrm{n}$ & mean & SEM & $\mathrm{n}$ & mean & SEM & $\mathrm{n}$ & $\mathrm{p}$ & test \\
\hline \multirow[b]{2}{*}{ 4B } & \multirow[b]{2}{*}{ \# gold/AZ } & \multirow[b]{2}{*}{0,8693} & \multirow[b]{2}{*}{0,087} & \multirow[b]{2}{*}{176} & \multirow[b]{2}{*}{0,454} & \multirow[b]{2}{*}{0,0765} & \multirow[b]{2}{*}{163} & & & & $<0.0001$ & $\begin{array}{c}\text { Mann-Whitney } \\
\text { test }\end{array}$ \\
\hline & & & & & & & & & & & $<0.0001$ & $\begin{array}{l}\text { Kolmogorov- } \\
\text { Smirnov test }\end{array}$ \\
\hline
\end{tabular}

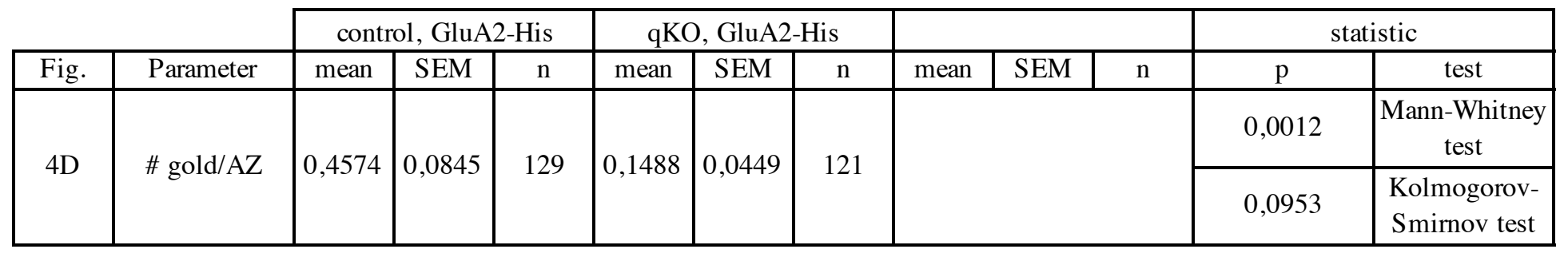

\begin{tabular}{|c|c|c|c|c|c|c|c|c|c|c|c|c|}
\cline { 2 - 11 } \multicolumn{2}{c|}{} & \multicolumn{3}{c|}{ control } & \multicolumn{3}{c|}{ qKO } & \multicolumn{3}{c|}{ statistic } \\
\hline Fig. & Parameter & mean & SEM & $\mathrm{n}$ & mean & SEM & $\mathrm{n}$ & mean & SEM & $\mathrm{n}$ & $\mathrm{p}$ & test \\
\hline 4E & $\begin{array}{c}\text { synaptic cleft } \\
\text { width (nm) }\end{array}$ & 25,59 & 0,3352 & 176 & 29,59 & 0,4253 & 163 & & & & $<0.0001$ & $\begin{array}{c}\text { Mann-Whitney } \\
\text { test }\end{array}$ \\
\hline
\end{tabular}

\begin{tabular}{|c|c|c|c|c|c|c|c|c|c|c|c|c|}
\hline Fig. & Parameter & mean & SEM & $\mathrm{n}$ & mean & SEM & $\mathrm{n}$ & mean & SEM & $\mathrm{n}$ & $\mathrm{p}$ & test \\
\hline $4 \mathrm{G}$ & $\begin{array}{c}\text { \# clusters/ } \\
\text { um2 of } \\
\text { synapses } \\
\text { GluA1 }\end{array}$ & 2,423 & 0,2719 & 18 & 1,422 & 0,2482 & 14 & & & & 0,0247 & $\begin{array}{c}\text { Mann-Whitney } \\
\text { test }\end{array}$ \\
\hline
\end{tabular}

\begin{tabular}{|c|c|c|c|c|c|c|c|c|c|c|c|c|}
\hline Fig. & Parameter & mean & SEM & $\mathrm{n}$ & mean & SEM & $\mathrm{n}$ & mean & SEM & $\mathrm{n}$ & $\mathrm{p}$ & test \\
\hline $4 \mathrm{H}$ & $\begin{array}{c}\text { \# clusters per } \\
\text { um2 of } \\
\text { synapses } \\
\text { GluA2 }\end{array}$ & 2,808 & 0,3994 & 17 & 1,663 & 0,2653 & 17 & & & & $<0.0001$ & $\begin{array}{c}\text { Mann-Whitney } \\
\text { test }\end{array}$ \\
\hline
\end{tabular}

\begin{tabular}{|c|c|c|c|c|c|c|c|c|c|c|c|c|}
\hline Fig. & Parameter & mean & SEM & $\mathrm{n}$ & mean & SEM & $\mathrm{n}$ & mean & SEM & $\mathrm{n}$ & $\mathrm{p}$ & test \\
\hline 4J & $\begin{array}{c}\text { mEPSC } \\
\text { amplitude } \\
(\mathrm{pA})\end{array}$ & 30,67 & 2,748 & 34 & 17,79 & 0,9576 & 36 & & & & $<0.0001$ & $\begin{array}{c}\text { Mann-Whitney } \\
\text { test }\end{array}$ \\
\hline
\end{tabular}

\begin{tabular}{|c|c|c|c|c|c|c|c|c|c|c|c|c|}
\hline Fig. & Parameter & mean & SEM & $\mathrm{n}$ & mean & SEM & $\mathrm{n}$ & mean & SEM & $\mathrm{n}$ & $\mathrm{p}$ & test \\
\hline $4 \mathrm{~K}$ & $\begin{array}{c}\text { mEPSC rise } \\
\text { time (ms) }\end{array}$ & 0,4157 & 0,0113 & 34 & 0,5332 & 0,0142 & 36 & & & & $<0.0001$ & $\begin{array}{c}\text { Mann-Whitney } \\
\text { test }\end{array}$ \\
\hline
\end{tabular}


bioRxiv preprint doi: https://doi.org/10.1101/2020.12.25.424391; this version posted December 25, 2020. The copyright holder for this

preprint (which was not certified by peer review) is the author/funder, who has granted bioRxiv a license to display the preprint in perpetuity. It is made available wnder aCC-BY-ND 4.0 International license.

Figure 5

\begin{tabular}{|c|c|c|c|c|c|c|c|c|c|c|c|c|}
\hline & & & $\mathrm{KO}+\mathrm{Bi}$ & & $\mathrm{qKO}$ & $\mathrm{a} 2 \mathrm{~d} 1+$ & $\mathrm{uA} 2$ & $\mathrm{qKO}+\mathrm{a}^{2}$ & $\mathrm{~d} 1+\mathrm{Glu}$ & $+\mathrm{Bir} A$ & & stic \\
\hline Fig. & Parameter & mean & SEM & $\mathrm{n}$ & mean & SEM & $\mathrm{n}$ & mean & SEM & $\mathrm{n}$ & $\mathrm{p}$ & test \\
\hline \multirow{4}{*}{$5 \mathrm{C}$} & \multirow{4}{*}{$\begin{array}{c}\text { EPSC } \\
\text { amplitude } \\
\text { (nA) }\end{array}$} & 0,0748 & 0,0355 & 24 & 0,0311 & 0,0091 & 25 & 0,9656 & 0,2893 & 52 & $<0,0001$ & $\begin{array}{c}\text { Kruskal-Wallis } \\
\text { test }\end{array}$ \\
\hline & & \multicolumn{9}{|c|}{ a2d1 GluA2 vs. a2d1 GluA2 + BirA } & $<0,0001$ & *** \\
\hline & & \multicolumn{9}{|c|}{ a2d1 GluA2 vs. BirA } & $>0,9999$ & ns. \\
\hline & & \multicolumn{9}{|c|}{ a2d1 GluA2 + BirA vs. BirA } & 0,0002 & $* * *$ \\
\hline
\end{tabular}

\begin{tabular}{|c|c|c|c|c|c|c|c|c|c|c|c|c|}
\hline & & & $\mathrm{KO}+\mathrm{Bi}$ & & $\mathrm{qKO}+$ & $\mathrm{a} 2 \mathrm{~d} 1+$ & uA2 & $\mathrm{qKO}+\mathrm{a}^{2}$ & 11+Glu & + BirA & & istic \\
\hline Fig. & Parameter & mean & SEM & $\mathrm{n}$ & mean & SEM & $\mathrm{n}$ & mean & SEM & $\mathrm{n}$ & $\mathrm{p}$ & test \\
\hline \multirow{4}{*}{$5 \mathrm{E}$} & \multirow{4}{*}{$\mathrm{RRP}(\mathrm{nC})$} & 0,0426 & 0,0098 & 23 & 0,0057 & 0,0027 & 22 & 0,1427 & 0,027 & 43 & $<0,0001$ & $\begin{array}{c}\text { Kruskal-Wallis } \\
\text { test }\end{array}$ \\
\hline & & \multicolumn{9}{|c|}{ a2d1 GluA2 vs. a2d1 GluA2 + BirA } & $<0,0001$ & $* * *$ \\
\hline & & \multicolumn{9}{|c|}{ a2d1 GluA2 vs. BirA } & 0,0595 & ns. \\
\hline & & \multicolumn{9}{|c|}{ a2d1 GluA2 + BirA vs. BirA } & 0,3023 & ns. \\
\hline
\end{tabular}

\begin{tabular}{|c|c|c|c|c|c|c|c|c|c|c|c|c|}
\hline & & & $\mathrm{O}+\mathrm{Bi}$ & & $\mathrm{qKO}+$ & $\mathrm{a} 2 \mathrm{~d} 1+$ & luA2 & $\mathrm{qKO}+\mathrm{a}$ & $\mathrm{d} 1+\mathrm{Glu} A$ & $+\mathrm{BirA}$ & & istic \\
\hline Fig. & Parameter & mean & SEM & $\mathrm{n}$ & mean & SEM & $\mathrm{n}$ & mean & SEM & $\mathrm{n}$ & $\mathrm{p}$ & test \\
\hline \multirow{4}{*}{$5 \mathrm{G}$} & \multirow{4}{*}{$\begin{array}{c}\text { \# docked } \\
\text { SVs/AZ }\end{array}$} & 0,5254 & 0,074 & 59 & 0,4045 & 0,0325 & 356 & 1,078 & 0,0596 & 232 & $<0,0001$ & $\begin{array}{c}\text { Kruskal-Wallis } \\
\text { test }\end{array}$ \\
\hline & & \multicolumn{9}{|c|}{ BirA vs. $\mathrm{a} 2 \mathrm{~d} 1+$ GluA2 } & 0,3143 & ns. \\
\hline & & \multicolumn{9}{|c|}{ BirA vs. $\mathrm{a} 2 \mathrm{~d} 1+\mathrm{GluA} 2+\mathrm{BirA}$} & $<0,0001$ & **** \\
\hline & & \multicolumn{9}{|c|}{ a2d1 GluA2 vs. A2d1 + GluA2 + BirA" } & $<0,0001$ & $* * *$ \\
\hline
\end{tabular}

\begin{tabular}{|c|c|c|c|c|c|c|c|c|c|c|}
\hline & & & $\mathrm{qKO}+$ & $\mathrm{a} 2 \mathrm{~d} 1+\mathrm{c}$ & $\mathrm{uA} 2$ & $\mathrm{qKO}+\mathrm{a} 2$ & $11+$ GluA & BirA & & stic \\
\hline Fig. & Parameter & & mean & SEM & $\mathrm{n}$ & mean & SEM & $\mathrm{n}$ & $\mathrm{p}$ & test \\
\hline \multirow{5}{*}{$5 \mathrm{I}$} & \multirow{5}{*}{$\begin{array}{c}\text { SynGCaMP6f } \\
\text { deltaF/F0 }\end{array}$} & & & & 11 & & & 13 & 0,0184 & 2way ANOVA \\
\hline & & \multicolumn{2}{|r|}{0,0476} & 0,0242 & 11 & 0,0766 & 0,0531 & 13 & & \\
\hline & & \multicolumn{2}{|r|}{0,0718} & 0,0261 & 11 & 0,0928 & 0,0522 & 13 & & \\
\hline & & \multicolumn{2}{|r|}{0,0806} & 0,034 & 11 & 0,2065 & 0,0648 & 13 & & \\
\hline & & \multicolumn{2}{|r|}{0,1493} & 0,0827 & 11 & 0,6688 & 0,1395 & 13 & & \\
\hline
\end{tabular}


bioRxiv preprint doi: https://doi.org/10.1101/2020.12.25.424391; this version posted December 25, 2020. The copyright holder for this

preprint (which was not certified by peer review) is the author/funder, who has granted bioRxiv a license to display the preprint in perpetuity. It is made available 4 nder aCC-BY-NG-ND 4.0 International license.

Figure ${ }^{1}$

\begin{tabular}{|c|c|c|c|c|c|c|c|c|c|}
\hline & & \multicolumn{3}{|c|}{ control } & \multicolumn{3}{|c|}{ a2d1-His } & \multicolumn{2}{|c|}{ statistic } \\
\hline Fig. S & Parameter & mean & SEM & $n$ & mean & SEM & $n$ & $\mathrm{p}$ & test \\
\hline $1 \mathrm{~B}$ & $\begin{array}{c}\text { EPSC } \\
\text { amplitude } \\
(\mathrm{nA})\end{array}$ & 4,548 & 0,6435 & 40 & 3,746 & 0,6236 & 34 & 0,3892 & $\begin{array}{c}\text { Mann-Whitney } \\
\text { test }\end{array}$ \\
\hline
\end{tabular}

\begin{tabular}{|c|c|c|c|c|c|c|c|c|c|c|c|}
\hline Fig. S & Parameter & mean & SEM & $\mathrm{n}$ & mean & SEM & $\mathrm{n}$ & & & $\mathrm{p}$ & test \\
\hline 1B & $\begin{array}{c}\text { EPSC charge } \\
(\mathrm{nC})\end{array}$ & 39,15 & 7,172 & 40 & 30,83 & 6,257 & 34 & & & Mann-Whitney \\
test
\end{tabular}

\begin{tabular}{|c|c|c|c|c|c|c|c|c|c|c|c|}
\hline Fig. S & Parameter & mean & SEM & $\mathrm{n}$ & mean & SEM & $\mathrm{n}$ & & & $\mathrm{p}$ & test \\
\hline 1C & PPR & 1,121 & 0,0553 & 40 & 1,239 & 0,0639 & 34 & & & 0,1168 & $\begin{array}{c}\text { Mann-Whitney } \\
\text { test }\end{array}$ \\
\hline
\end{tabular}

\begin{tabular}{|c|c|c|c|c|c|c|c|c|c|c|c|}
\hline Fig. S & Parameter & mean & SEM & $\mathrm{n}$ & mean & SEM & $\mathrm{n}$ & & & test \\
\hline 1E & RRP (nC) & 0,2066 & 0,0514 & 22 & 0,259 & 0,0874 & 17 & & & Mann-Whitney \\
& & & & & & & & & & 0,1168 \\
\hline
\end{tabular}

\begin{tabular}{|c|c|c|c|c|c|c|c|c|c|}
\hline Fig. S & Parameter & mean & SEM & $\mathrm{n}$ & mean & SEM & $\mathrm{n}$ & $\mathrm{p}$ & test \\
\hline $1 \mathrm{~F}$ & PVR (\%) & 7,473 & 1,808 & 22 & 8,485 & 2,419 & 17 & 0,8998 & $\begin{array}{c}\text { Mann-Whitney } \\
\text { test }\end{array}$ \\
\hline
\end{tabular}


bioRxiv preprint doi: https://doi.org/10.1101/2020.12.25.424391; this version posted December 25, 2020. The copyright holder for this preprint (which was not certified by peer review) is the author/funder, who has granted bioRxiv a license to display the preprint in perpetuity. It is made available _under aCC-BY-NG-ND 4.0 International license.

Figure S2

\begin{tabular}{|c|c|c|c|c|c|c|c|c|c|c|c|c|}
\hline & & & control & & & a2d1-His & & $\mathrm{a} 2 \mathrm{~d} 1$ & His $(5 \mathrm{~m}$ & im) & & \\
\hline Fig. S & Parameter & mean & SEM & $\mathrm{n}$ & mean & SEM & $\mathrm{n}$ & mean & SEM & $\mathrm{n}$ & $\mathrm{p}$ & test \\
\hline \multirow{4}{*}{$2 \mathrm{C}$} & \multirow{4}{*}{ \# docked SVs } & 1,338 & 0,0564 & 225 & 1,49 & 0,0585 & 196 & 1,054 & 0,053 & 204 & $<0,0001$ & $\begin{array}{l}\text { Kruskal- } \\
\text { Wallis test }\end{array}$ \\
\hline & & \multicolumn{9}{|c|}{ control vs. a2d1-His } & 0,1326 & ns. \\
\hline & & \multicolumn{9}{|c|}{ a2d1-His vs. a2d1-His (5ms stim) } & $<0,0001$ & $* * *$ \\
\hline & & \multicolumn{9}{|c|}{ control vs. a2d1-His (5ms stim) } & 0,0019 & $* *$ \\
\hline
\end{tabular}

\begin{tabular}{|c|c|c|c|c|c|c|c|c|c|c|c|c|}
\hline \multirow{4}{*}{$2 \mathrm{D}$} & \multirow{4}{*}{$\begin{array}{l}\text { PSD length } \\
(\mathrm{nm})\end{array}$} & 237,6 & 4,316 & 225 & 245,8 & 5,047 & 196 & 240,4 & 5,403 & 204 & 0,369 & $\begin{array}{c}\text { Kruskal- } \\
\text { Wallis test }\end{array}$ \\
\hline & & \multicolumn{9}{|c|}{ control vs. a2d1-His } & 0,6815 & ns. \\
\hline & & \multicolumn{9}{|c|}{ a2d1-His vs. a2d1-His (5ms stim) } & 0,6288 & ns. \\
\hline & & \multicolumn{9}{|c|}{ control vs. a2d1-His (5ms stim) } & $>0,9999$ & ns. \\
\hline
\end{tabular}

\begin{tabular}{|c|c|c|c|c|c|c|c|c|c|c|c|c|}
\hline \multirow{4}{*}{$2 \mathrm{E}$} & \multirow{4}{*}{$\begin{array}{c}\text { dockedS V/nor } \\
\text { m. AZ size }\end{array}$} & 0,4524 & 0,0155 & 293 & 0,4879 & 0,0161 & 292 & 0,468 & 0,0176 & 215 & 0,0898 & $\begin{array}{c}\text { Kruskal- } \\
\text { Wallis test }\end{array}$ \\
\hline & & \multicolumn{9}{|c|}{ control vs. a2d1-His } & 0,8095 & ns. \\
\hline & & \multicolumn{9}{|c|}{ a2d1-His vs. a2d1-His (5ms stim) } & $>0.9999$ & ns. \\
\hline & & \multicolumn{9}{|c|}{ control vs. a2d1-His (5ms stim) } & $>0.9999$ & ns. \\
\hline
\end{tabular}

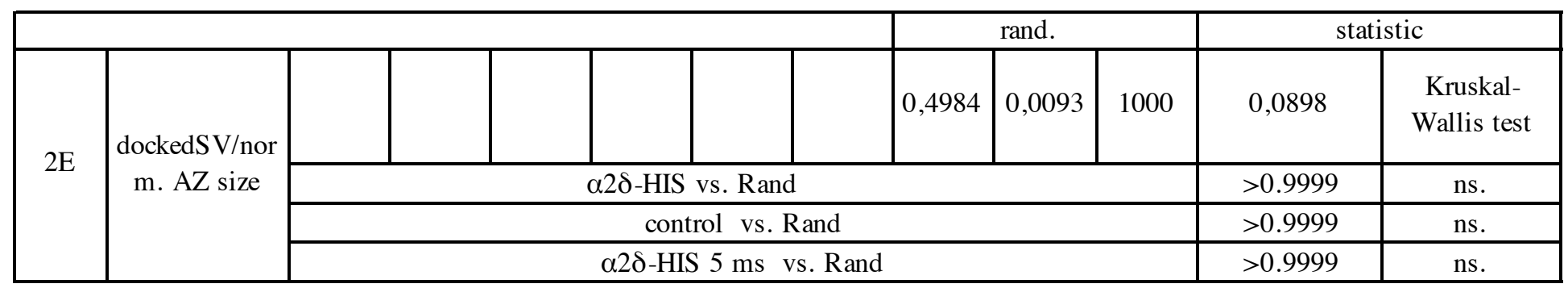

\begin{tabular}{|c|c|c|c|c|c|c|c|c|c|c|c|c|}
\hline \multirow[b]{2}{*}{ Fig. S } & \multirow[b]{2}{*}{ Parameter } & \multicolumn{3}{|c|}{ control } & \multicolumn{3}{|c|}{ a2d1-His } & \multicolumn{3}{|c|}{ a2d1-His (5ms stim) } & \multicolumn{2}{|c|}{ statistic } \\
\hline & & mean & SEM & $\mathrm{n}$ & mean & SEM & $\mathrm{n}$ & mean & SEM & $\mathrm{n}$ & $\mathrm{p}$ & test \\
\hline \multirow{5}{*}{$2 \mathrm{G}$} & \multirow{5}{*}{ \# gold/AZ } & \multirow{2}{*}{0,1867} & \multirow{2}{*}{0,0322} & \multirow{2}{*}{225} & \multirow{2}{*}{1,495} & \multirow{2}{*}{0,0936} & \multirow{2}{*}{196} & \multirow{2}{*}{1,069} & \multirow{2}{*}{0,0841} & \multirow{2}{*}{204} & $<0,0001$ & $\begin{array}{c}\text { Kruskal- } \\
\text { Wallis test }\end{array}$ \\
\hline & & & & & & & & & & & $<0,0001$ & $\begin{array}{l}\text { Kolmogrov- } \\
\text { Smirnov test }\end{array}$ \\
\hline & & \multicolumn{9}{|c|}{ control vs. a2d1-His } & $<0,0001$ & $* * *$ \\
\hline & & \multicolumn{9}{|c|}{ a2d1-His vs. a2d1-His (5ms stim) } & 0,0014 & $* *$ \\
\hline & & \multicolumn{9}{|c|}{ control vs. a2d1-His (5ms stim) } & $<0,0001$ & $* * *$ \\
\hline
\end{tabular}

\begin{tabular}{|c|c|c|c|c|c|c|c|c|c|c|c|c|}
\hline Fig. S & Parameter & mean & SEM & $\mathrm{n}$ & mean & SEM & $\mathrm{n}$ & mean & SEM & $\mathrm{n}$ & $\mathrm{p}$ & test \\
\hline $2 \mathrm{H}$ & $\begin{array}{c}\text { relative } \\
\text { position of } \\
\text { gold }\end{array}$ & 0,526 & 0,023 & 50 & & & & 0,4697 & 0,0091 & 212 & \\
\hline
\end{tabular}


bioRxiv preprint doi: https://doi.org/10.1101/2020.12.25.424391; this version posted December 25, 2020. The copyright holder for this preprint (which was not certified by peer review) is the author/funder, who has granted bioRxiv a license to display the preprint in perpetuity. It is made available _under aCC-BY-NG-ND 4.0 International license.

Figure S2

\begin{tabular}{|c|c|c|c|c|c|c|c|c|c|c|c|c|}
\hline & & & control & & & $\mathrm{a} 2 \mathrm{~d} 1-\mathrm{Hi}$ & & $\mathrm{a} 2 \mathrm{~d} 1$ & His $(5 \mathrm{~m}$ & tim) & & \\
\hline \multirow{4}{*}{$2 \mathrm{I}$} & \multirow{4}{*}{$\begin{array}{c}\text { gold/norm. } \\
\text { AZ size }\end{array}$} & 0,4495 & 0,0411 & 50 & 0,449 & 0,0182 & 293 & 0,5025 & 0,0223 & 212 & 0,7381 & $\begin{array}{l}\text { Kruskal- } \\
\text { Wallis test }\end{array}$ \\
\hline & & \multicolumn{9}{|c|}{ control vs. a2d1-His } & $>0,9999$ & $* * *$ \\
\hline & & \multicolumn{9}{|c|}{ a2d1-His vs. a2d1-His (5ms stim) } & $>0,9999$ & $* *$ \\
\hline & & \multicolumn{9}{|c|}{ control vs. a2d1-His (5ms stim) } & $>0,9999$ & $* * *$ \\
\hline
\end{tabular}

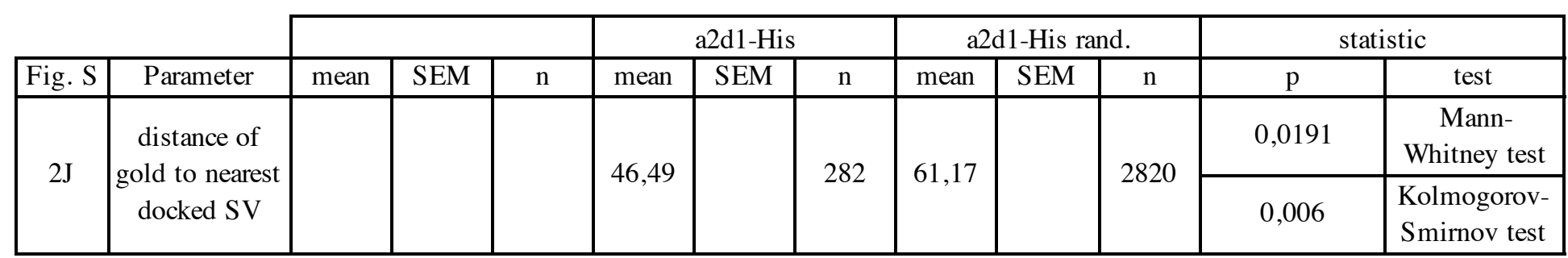

\begin{tabular}{|c|c|c|c|c|c|c|c|c|c|c|c|c|c|}
\cline { 2 - 11 } \\
\cline { 2 - 11 }
\end{tabular}


bioRxiv preprint doi: https://doi.org/10.1101/2020.12.25.424391; this version posted December 25, 2020. The copyright holder for this preprint (which was not certified by peer review) is the author/funder, who has granted bioRxiv a license to display the preprint in perpetuity. It is made available _under aCC-BY-NG=ND 4.0 International license.

Figure S5

\begin{tabular}{|c|c|c|c|c|c|c|c|c|c|c|c|c|}
\hline & & & SluA2-H & & & urexin1- & & & roligin1 & & & \\
\hline Fig. S & Parameter & mean & SEM & $\mathrm{n}$ & mean & SEM & $\mathrm{n}$ & mean & SEM & $\mathrm{n}$ & $\mathrm{p}$ & test \\
\hline \multirow{4}{*}{$5 \mathrm{C}$} & \multirow{4}{*}{ \# docked SVs } & 1,097 & 0,0554 & 175 & 1,077 & 0,0563 & 130 & 1,039 & 0,0537 & 180 & 0,6719 & $\begin{array}{l}\text { Kruskal- } \\
\text { Wallis test }\end{array}$ \\
\hline & & \multicolumn{9}{|c|}{ Neurexin1 vs. Neuroligin1 } & $>0,9999$ & ns. \\
\hline & & \multicolumn{9}{|c|}{ Neurexin1 vs. GluA2 } & $>0,9999$ & ns. \\
\hline & & \multicolumn{9}{|c|}{ Neuroligin1 vs. GluA2 } & $>0,9999$ & ns. \\
\hline
\end{tabular}

\begin{tabular}{|c|c|c|c|c|c|c|c|c|c|c|c|c|}
\hline \multirow{4}{*}{$5 \mathrm{D}$} & \multirow{4}{*}{$\begin{array}{l}\text { PSD length } \\
\quad(\mathrm{nm})\end{array}$} & 245,3 & 6,743 & 175 & 231,1 & 5,718 & 130 & 250,4 & 5,718 & 180 & 0,0621 & $\begin{array}{c}\text { Kruskal- } \\
\text { Wallis test }\end{array}$ \\
\hline & & \multicolumn{9}{|c|}{ Neurexin1 vs. Neuroligin1 } & 0,068 & ns. \\
\hline & & \multicolumn{9}{|c|}{ Neurexin1 vs. GluA2 } & $>0,9999$ & ns. \\
\hline & & \multicolumn{9}{|c|}{ Neuroligin1 vs. GluA2 } & 0,3461 & ns. \\
\hline
\end{tabular}

\begin{tabular}{|c|c|c|c|c|c|c|c|c|c|c|c|c|}
\hline $5 \mathrm{E}$ & $\begin{array}{c}\text { dockedSV } \\
\text { along AZ }\end{array}$ & 0,4979 & 0,0206 & 190 & 0,5163 & 0,0237 & 140 & 0,4987 & 0,0198 & 187 & & \\
\hline
\end{tabular}

\begin{tabular}{|c|c|c|c|c|c|c|c|c|c|c|c|c|}
\hline \multirow{4}{*}{$5 \mathrm{~F}, \mathrm{G}$} & \multirow{4}{*}{$\begin{array}{l}\text { \# gold/active } \\
\text { zone }\end{array}$} & 0,92 & 0,0856 & 175 & 1,031 & 0,0913 & 130 & 0,9347 & 0,1 & 180 & 0,0633 & $\begin{array}{c}\text { Kruskal- } \\
\text { Wallis test }\end{array}$ \\
\hline & & \multicolumn{9}{|c|}{ Neurexin1 vs. Neuroligin1 } & 0,0585 & ns. \\
\hline & & \multicolumn{9}{|c|}{ Neurexin1 vs. GluA2 } & 0,3416 & ns. \\
\hline & & \multicolumn{9}{|c|}{ Neuroligin1 vs. GluA2 } & $>0,9999$ & ns. \\
\hline
\end{tabular}

\begin{tabular}{|c|c|c|c|c|c|c|c|c|c|c|c|c|}
\hline $5 \mathrm{H}$ & $\begin{array}{l}\text { relative } \\
\text { position of } \\
\text { gold }\end{array}$ & 0,5559 & 0,0109 & 161 & 0,4246 & 0,0127 & 134 & 0,0526 & 0,0128 & 158 & & \\
\hline & & & roligin1 & & $\mathrm{Neu}$ & roligin1 & and. & & & & & \\
\hline Fig. & Parameter & median & & $\mathrm{n}$ & median & & $n$ & mean & SEM & $\mathrm{n}$ & $\mathrm{p}$ & test \\
\hline \multirow{2}{*}{$5 \mathrm{I}$} & \multirow{2}{*}{$\begin{array}{l}\text { gold to norm. } \\
\text { active zone }\end{array}$} & \multirow{2}{*}{0,4755} & & \multirow{2}{*}{156} & \multirow{2}{*}{0,5187} & & \multirow{2}{*}{2000} & & & & 0,5141 & $\begin{array}{c}\text { Mann- } \\
\text { Whitney test }\end{array}$ \\
\hline & & & & & & & & & & & 0,0248 & $\begin{array}{l}\text { Kolmogorov- } \\
\text { Smirnov test }\end{array}$ \\
\hline
\end{tabular}

\begin{tabular}{|c|c|c|c|c|c|c|c|c|c|c|}
\hline & & $\mathrm{Nel}$ & & Neu & & & & & & \\
\hline Fig. $\mathrm{S}$ & Parameter & median & $\mathrm{n}$ & median & $\mathrm{n}$ & mean & SEM & $\mathrm{n}$ & $\mathrm{p}$ & test \\
\hline \multirow{2}{*}{$5 \mathrm{~J}$} & \multirow{2}{*}{$\begin{array}{l}\text { gold to norm. } \\
\text { active zone }\end{array}$} & \multirow{2}{*}{94,39} & \multirow{2}{*}{133} & \multirow{2}{*}{88,54} & \multirow{2}{*}{1370} & & & & 0,172 & $\begin{array}{c}\text { Mann- } \\
\text { Whitney test }\end{array}$ \\
\hline & & & & & & & & & 0,4227 & $\begin{array}{l}\text { Kolmogorov- } \\
\text { Smirnov test }\end{array}$ \\
\hline
\end{tabular}

\begin{tabular}{|c|c|c|c|c|c|c|c|c|c|c|}
\hline & & $\mathrm{Nel}$ & & Neu & & & & & & \\
\hline Fig. $\mathrm{S}$ & Parameter & median & $\mathrm{n}$ & median & $\mathrm{n}$ & mean & SEM & $\mathrm{n}$ & $\mathrm{p}$ & test \\
\hline \multirow{2}{*}{$5 \mathrm{~K}$} & \multirow{2}{*}{$\begin{array}{l}\text { gold to norm. } \\
\text { active zone }\end{array}$} & \multirow{2}{*}{117,8} & \multirow{2}{*}{70} & \multirow{2}{*}{95,94} & \multirow{2}{*}{700} & & & & 0,0482 & $\begin{array}{c}\text { Mann- } \\
\text { Whitney test }\end{array}$ \\
\hline & & & & & & & & & 0,1824 & $\begin{array}{l}\text { Kolmogorov- } \\
\text { Smirnov test }\end{array}$ \\
\hline
\end{tabular}


bioRxiv preprint doi: https://doi.org/10.1101/2020.12.25.424391; this version posted December 25, 2020 . The copyright holder for this preprint (which was not certified by peer review) is the author/funder, who has granted bioRxiv a license to display the preprint in perpetuity. It is made available-under aCC-BY-NG-ND 4.0 International license.

Figure $\$ 6$

\begin{tabular}{|c|c|c|c|c|c|c|c|c|c|c|c|c|}
\hline & & \multicolumn{3}{|c|}{ control } & \multicolumn{3}{|c|}{$\mathrm{qKO}$} & & & & \multicolumn{2}{|c|}{ statistic } \\
\hline Fig. S & Parameter & mean & SEM & $\mathrm{n}$ & mean & SEM & $\mathrm{n}$ & mean & SEM & $\mathrm{n}$ & $\mathrm{p}$ & test \\
\hline $6 \mathrm{~A}$ & $\begin{array}{c}\text { \# docked } \\
\text { vesicles }\end{array}$ & 0,9967 & 0,0449 & 305 & 0,331 & 0,0313 & 282 & & & & $<0.0001$ & $\begin{array}{l}\text { Kolmogorov- } \\
\text { Smirnov test }\end{array}$ \\
\hline
\end{tabular}

\begin{tabular}{|c|c|c|c|c|c|c|c|c|c|c|c|c|}
\hline Fig. S & Parameter & mean & SEM & $\mathrm{n}$ & mean & SEM & $\mathrm{n}$ & mean & SEM & $\mathrm{n}$ & $\mathrm{p}$ & test \\
\hline 6B & $\begin{array}{c}\text { \# docked } \\
\text { vesicles/100n } \\
\mathrm{m} \mathrm{AZ}\end{array}$ & 0,3711 & 0,0171 & 305 & 0,1032 & 0,0103 & 282 & & & & $<0.0001$ & $\begin{array}{c}\text { Mann-Whitney } \\
\text { test }\end{array}$ \\
\hline
\end{tabular}

\begin{tabular}{|c|c|c|c|c|c|c|c|c|c|c|}
\hline 6C & $\begin{array}{c}\text { PSD length } \\
(\mathrm{nm})\end{array}$ & 288,8 & 5,445 & 305 & 311,5 & 5,924 & 282 & & $\begin{array}{c}\text { Mann-Whitney } \\
\text { test }\end{array}$ \\
\hline
\end{tabular}

\begin{tabular}{|c|c|c|c|c|c|c|c|c|c|c|c|c|}
\hline & & \multicolumn{3}{|c|}{ control } & \multicolumn{3}{|c|}{$\mathrm{qKO}$} & & & & \multicolumn{2}{|c|}{ statistic } \\
\hline Fig. S & Parameter & mean & SEM & $\mathrm{n}$ & mean & SEM & $\mathrm{n}$ & mean & SEM & $\mathrm{n}$ & $\mathrm{p}$ & test \\
\hline $6 \mathrm{E}$ & $\begin{array}{c}\text { \# clusters per } \\
\text { um2 of } \\
\text { synapses } \\
\text { Cav2.1 }\end{array}$ & 2,017 & 0,2811 & 9 & 1,649 & 0,3064 & 12 & & & & 0,2188 & $\begin{array}{c}\text { Mann-Whitney } \\
\text { test }\end{array}$ \\
\hline
\end{tabular}

\begin{tabular}{|c|c|c|c|c|c|c|c|c|c|c|c|c|}
\hline Fig. S & Parameter & mean & SEM & $\mathrm{n}$ & mean & SEM & $\mathrm{n}$ & mean & SEM & $\mathrm{n}$ & $\mathrm{p}$ & test \\
\hline 6E & $\begin{array}{c}\text { \# clusters per } \\
\text { um2 of } \\
\text { synapses } \\
\text { Cav2.2 }\end{array}$ & 2,323 & 0,3173 & 15 & 1,24 & 0,1853 & 18 & & & & \\
& & & & & & & & & & \\
Mann-Whitney \\
test
\end{tabular}

\begin{tabular}{|c|c|c|c|c|c|c|c|c|c|c|c|c|}
\hline Fig. S & Parameter & mean & SEM & $\mathrm{n}$ & mean & SEM & $\mathrm{n}$ & mean & SEM & $\mathrm{n}$ & $\mathrm{p}$ & test \\
\hline 6F & $\begin{array}{c}\text { number of } \\
\text { synapses } \\
\text { GluA1 }\end{array}$ & 44,89 & 4,751 & 18 & 26,57 & 3,396 & 14 & & & & 0,0092 & $\begin{array}{c}\text { Mann-Whitney } \\
\text { test }\end{array}$ \\
\hline
\end{tabular}

\begin{tabular}{|c|c|c|c|c|c|c|c|c|c|c|c|c|}
\hline Fig. S & Parameter & mean & SEM & $\mathrm{n}$ & mean & SEM & $\mathrm{n}$ & mean & SEM & $\mathrm{n}$ & $\mathrm{p}$ & test \\
\hline 6F & $\begin{array}{c}\text { number of } \\
\text { synapses } \\
\text { GluA2 }\end{array}$ & 27,06 & 3,331 & 16 & 28,71 & 4,167 & 17 & & & & 0,8518 & $\begin{array}{c}\text { Mann-Whitney } \\
\text { test }\end{array}$ \\
\hline
\end{tabular}

\begin{tabular}{|c|c|c|c|c|c|c|c|c|c|c|c|c|}
\hline Fig. S & Parameter & mean & SEM & $\mathrm{n}$ & mean & SEM & $\mathrm{n}$ & mean & SEM & $\mathrm{n}$ & $\mathrm{p}$ & test \\
\hline 6G & $\begin{array}{c}\text { Synaptic area } \\
\text { (um2) GluA1 }\end{array}$ & 0,25 & 0,0305 & 18 & 0,3322 & 0,0488 & 14 & & & & 0,183 \\
$\begin{array}{c}\text { Mann-Whitney } \\
\text { test }\end{array}$ \\
\hline
\end{tabular}

\begin{tabular}{|c|c|c|c|c|c|c|c|c|c|c|c|c|}
\hline Fig. S & Parameter & mean & SEM & $\mathrm{n}$ & mean & SEM & $\mathrm{n}$ & mean & SEM & $\mathrm{n}$ & $\mathrm{p}$ & test \\
\hline 6G & $\begin{array}{c}\text { Synaptic area } \\
\text { (um2) GluA2 }\end{array}$ & 0,3492 & 0,0637 & 16 & 0,351 & 0,0641 & 17 & & & 0,4228 & $\begin{array}{c}\text { Mann-Whitney } \\
\text { test }\end{array}$ \\
\hline
\end{tabular}

\begin{tabular}{|c|c|c|c|c|c|c|c|c|c|c|c|c|}
\hline Fig. S & Parameter & mean & SEM & $\mathrm{n}$ & mean & SEM & $\mathrm{n}$ & mean & SEM & $\mathrm{n}$ & $\mathrm{p}$ & test \\
\hline $6 \mathrm{H}$ & $\begin{array}{c}\text { total number } \\
\text { of clusters } \\
\text { GluA1 }\end{array}$ & 289,4 & 26,42 & 18 & 189,4 & 24,38 & 14 & & & & 0,0101 & $\begin{array}{c}\text { Mann-Whitney } \\
\text { test }\end{array}$ \\
\hline
\end{tabular}


bioRxiv preprint doi: https://doi.org/10.1101/2020.12.25.424391; this version posted December 25, 2020. The copyright holder for this preprint (which was not certified by peer review) is the author/funder, who has granted bioRxiv a license to display the preprint in perpetuity. It is made available-under aCC-BY-NG-ND 4.0 International license.

Figure $S 6$

\begin{tabular}{|c|c|c|c|c|c|c|c|c|c|c|c|c|}
\hline Fig. S & Parameter & mean & SEM & $\mathrm{n}$ & mean & SEM & $\mathrm{n}$ & mean & SEM & $\mathrm{n}$ & $\mathrm{p}$ & test \\
\hline $6 \mathrm{H}$ & $\begin{array}{c}\text { total number } \\
\text { od clusters } \\
\text { GluA2 }\end{array}$ & 295,8 & 56,88 & 16 & 129,1 & 22,61 & 17 & & & & 0,0212 & $\begin{array}{c}\text { Mann-Whitney } \\
\text { test }\end{array}$ \\
\hline
\end{tabular}

\begin{tabular}{|c|c|c|c|c|c|c|c|c|c|c|c|c|}
\hline Fig. S & Parameter & mean & SEM & $\mathrm{n}$ & mean & SEM & $\mathrm{n}$ & mean & SEM & $\mathrm{n}$ & $\mathrm{p}$ & test \\
\hline 6I & $\begin{array}{c}\text { Area of } \\
\text { clusters (um2) } \\
\text { total GluA1 }\end{array}$ & 0,0168 & 0,0011 & 18 & 0,0198 & 0,0012 & 14 & & & & 0,0336 & $\begin{array}{c}\text { Mann-Whitney } \\
\text { test }\end{array}$ \\
\hline
\end{tabular}

\begin{tabular}{|c|c|c|c|c|c|c|c|c|c|c|c|c|}
\hline Fig. S & Parameter & mean & SEM & $\mathrm{n}$ & mean & SEM & $\mathrm{n}$ & mean & SEM & $\mathrm{n}$ & $\mathrm{p}$ & test \\
\hline 6I & $\begin{array}{c}\text { Area of } \\
\text { clusters (um2) } \\
\text { total GluA2 }\end{array}$ & 0,0229 & 0,0038 & 16 & 0,0205 & 0,0017 & 17 & & & & 0,1677 & $\begin{array}{c}\text { Mann-Whitney } \\
\text { test }\end{array}$ \\
\hline
\end{tabular}

\begin{tabular}{|c|c|c|c|c|c|c|c|c|c|c|c|c|}
\hline Fig. S & Parameter & mean & SEM & $\mathrm{n}$ & mean & SEM & $\mathrm{n}$ & mean & SEM & $\mathrm{n}$ & $\mathrm{p}$ & test \\
\hline 6J & $\begin{array}{c}\text { Area of } \\
\text { clusters (um2) } \\
\text { synaptic } \\
\text { GluA1 }\end{array}$ & 0,0175 & 0,0019 & 18 & 0,0161 & 0,0027 & 14 & & & & & \\
\hline
\end{tabular}

\begin{tabular}{|c|c|c|c|c|c|c|c|c|c|c|c|c|}
\hline Fig. S & Parameter & mean & SEM & $\mathrm{n}$ & mean & SEM & $\mathrm{n}$ & mean & SEM & $\mathrm{n}$ & $\mathrm{p}$ & test \\
\hline 6J & $\begin{array}{c}\text { Area of } \\
\text { clusters (um2) } \\
\text { synaptic } \\
\text { GluA2 }\end{array}$ & 0,0242 & 0,0039 & 16 & 0,0177 & 0,0023 & 17 & & & & & \\
\hline
\end{tabular}

\begin{tabular}{|c|c|c|c|c|c|c|c|c|c|c|c|c|}
\hline Fig. S & Parameter & mean & SEM & $\mathrm{n}$ & mean & SEM & $\mathrm{n}$ & mean & SEM & $\mathrm{n}$ & $\mathrm{p}$ & test \\
\hline $6 \mathrm{~K}$ & $\begin{array}{c}\text { number of } \\
\text { synapses } \\
\text { Cav2.1 }\end{array}$ & 19,22 & 4,209 & 9 & 17,17 & 3,072 & 12 & & & & 0,6883 & $\begin{array}{c}\text { Mann-Whitney } \\
\text { test }\end{array}$ \\
\hline
\end{tabular}

\begin{tabular}{|c|c|c|c|c|c|c|c|c|c|c|c|c|}
\hline Fig. S & Parameter & mean & SEM & $\mathrm{n}$ & mean & SEM & $\mathrm{n}$ & mean & SEM & $\mathrm{n}$ & $\mathrm{p}$ & test \\
\hline $6 \mathrm{~K}$ & $\begin{array}{c}\text { number of } \\
\text { synapses } \\
\text { Cav2.2 }\end{array}$ & 18,93 & 1,456 & 15 & 17,33 & 1,896 & 18 & & & & 0,3641 & $\begin{array}{c}\text { Mann-Whitney } \\
\text { test }\end{array}$ \\
\hline
\end{tabular}

\begin{tabular}{|c|c|c|c|c|c|c|c|c|c|c|c|c|}
\hline Fig. S & Parameter & mean & SEM & $\mathrm{n}$ & mean & SEM & $\mathrm{n}$ & mean & SEM & $\mathrm{n}$ & $\mathrm{p}$ & test \\
\hline 6L & $\begin{array}{c}\text { Synaptic area } \\
\text { (um2) Cav2.1 }\end{array}$ & 0,4354 & 0,0305 & 9 & 0,3431 & 0,034 & 12 & & & & 0,7544 & $\begin{array}{c}\text { Mann-Whitney } \\
\text { test }\end{array}$ \\
\hline
\end{tabular}

\begin{tabular}{|c|c|c|c|c|c|c|c|c|c|c|c|c|}
\hline Fig. S & Parameter & mean & SEM & $\mathrm{n}$ & mean & SEM & $\mathrm{n}$ & mean & SEM & $\mathrm{n}$ & $\mathrm{p}$ & test \\
\hline 6L & $\begin{array}{c}\text { Synaptic area } \\
\text { (um2) Cav2.2 }\end{array}$ & 0,4156 & 0,0482 & 15 & 0,3781 & 0,0241 & 18 & & & & 0,9219 & $\begin{array}{c}\text { Mann-Whitney } \\
\text { test }\end{array}$ \\
\hline
\end{tabular}

\begin{tabular}{|c|c|c|c|c|c|c|c|c|c|c|c|c|}
\hline Fig. S & Parameter & mean & SEM & $\mathrm{n}$ & mean & SEM & $\mathrm{n}$ & mean & SEM & $\mathrm{n}$ & $\mathrm{p}$ & test \\
\hline $6 \mathrm{M}$ & $\begin{array}{c}\text { total number } \\
\text { of clusters } \\
\text { Cav2.1 }\end{array}$ & 95,78 & 35,11 & 9 & 107,3 & 16,96 & 12 & & & & 0,199 & $\begin{array}{c}\text { Mann-Whitney } \\
\text { test }\end{array}$ \\
\hline
\end{tabular}


bioRxiv preprint doi: https://doi.org/10.1101/2020.12.25.424391; this version posted December 25, 2020. The copyright holder for this

preprint (which was not certified by peer review) is the author/funder, who has granted bioRxiv a license to display the preprint in perpetuity. It is made available _under aCC-BY-NG-ND 4.0 International license.

Figure S6

\begin{tabular}{|c|c|c|c|c|c|c|c|c|c|c|c|c|}
\hline Fig. S & Parameter & mean & SEM & $\mathrm{n}$ & mean & SEM & $\mathrm{n}$ & mean & SEM & $\mathrm{n}$ & $\mathrm{p}$ & test \\
\hline $6 \mathrm{M}$ & $\begin{array}{c}\text { total number } \\
\text { of clusters } \\
\text { Cav2.2 }\end{array}$ & 120,7 & 15,57 & 15 & 116,1 & 14,16 & 18 & & & & & \\
\hline
\end{tabular}

\begin{tabular}{|c|c|c|c|c|c|c|c|c|c|c|c|c|}
\hline Fig. S & Parameter & mean & SEM & $\mathrm{n}$ & mean & SEM & $\mathrm{n}$ & mean & SEM & $\mathrm{n}$ & $\mathrm{p}$ & test \\
\hline $6 \mathrm{~N}$ & $\begin{array}{c}\text { Area of } \\
\text { clusters (um2) } \\
\text { total Cav2.1 }\end{array}$ & 0,0246 & 0,0065 & 9 & 0,0169 & 0,0011 & 12 & & & 0,3451 & $\begin{array}{c}\text { Mann-Whitney } \\
\text { test }\end{array}$ \\
\hline
\end{tabular}

\begin{tabular}{|c|c|c|c|c|c|c|c|c|c|c|c|c|}
\hline Fig. S & Parameter & mean & SEM & $\mathrm{n}$ & mean & SEM & $\mathrm{n}$ & mean & SEM & $\mathrm{n}$ & $\mathrm{p}$ & test \\
\hline $6 \mathrm{~N}$ & $\begin{array}{c}\text { Area of } \\
\text { clusters (um2) } \\
\text { total Cav2.2 }\end{array}$ & 0,0171 & 0,0016 & 15 & 0,0203 & 0,0016 & 18 & & & 0,1896 & $\begin{array}{c}\text { Mann-Whitney } \\
\text { test }\end{array}$ \\
\hline
\end{tabular}

\begin{tabular}{|c|c|c|c|c|c|c|c|c|c|c|c|c|}
\hline Fig. S & Parameter & mean & SEM & $\mathrm{n}$ & mean & SEM & $\mathrm{n}$ & mean & SEM & $\mathrm{n}$ & $\mathrm{p}$ & test \\
\hline 60 & $\begin{array}{c}\text { Area of } \\
\text { clusters (um2) } \\
\text { synaptic } \\
\text { Cav2.1 }\end{array}$ & 0,0294 & 0,0057 & 9 & 0,0211 & 0,0026 & 12 & & & & 0,3824 & $\begin{array}{c}\text { Mann-Whitney } \\
\text { test }\end{array}$ \\
\hline
\end{tabular}

\begin{tabular}{|c|c|c|c|c|c|c|c|c|c|c|c|c|}
\hline Fig. S & Parameter & mean & SEM & $\mathrm{n}$ & mean & SEM & $\mathrm{n}$ & mean & SEM & $\mathrm{n}$ & $\mathrm{p}$ & test \\
\hline $6 \mathrm{O}$ & $\begin{array}{c}\text { Area of } \\
\text { clusters (um2) } \\
\text { synaptic } \\
\text { Cav2.2 }\end{array}$ & 0,022 & 0,0029 & 15 & 0,0256 & 0,0044 & 18 & & & & 0,9858 & $\begin{array}{c}\text { Mann-Whitney } \\
\text { test }\end{array}$ \\
\hline
\end{tabular}


bioRxiv preprint doi: https://doi.org/10.1101/2020.12.25.424391; this version posted December 25, 2020. The copyright holder for this preprint (which was not certified by peer review) is the author/funder, who has granted bioRxiv a license to display the preprint in perpetuity. It is made available _under aCC-BY-NG-ND 4.0 International license.

Figure S7

\begin{tabular}{|c|c|c|c|c|c|c|c|c|c|c|c|c|}
\hline & & & $\mathrm{KO}+\mathrm{Bi}$ & & qKO & $\mathrm{a} 2 \mathrm{~d} 1+$ & $\mathrm{uA} 2$ & $\mathrm{qKO}+\mathrm{a}$ & $\mathrm{d} 1+\mathrm{GluA}$ & + BirA & & stic \\
\hline Fig. S & Parameter & mean & SEM & $\mathrm{n}$ & mean & SEM & $\mathrm{n}$ & mean & SEM & $\mathrm{n}$ & $\mathrm{p}$ & test \\
\hline \multirow{4}{*}{ 7B } & \multirow{4}{*}{$\begin{array}{l}\text { synaptic cleft } \\
\text { width (nm) }\end{array}$} & 26,93 & 0,6821 & 59 & 26,67 & 0,3291 & 340 & 26,62 & 0,3147 & 232 & $<0,0001$ & $\begin{array}{c}\text { Kruskal-Wallis } \\
\text { test }\end{array}$ \\
\hline & & \multicolumn{9}{|c|}{ BirA vs. a $2 \mathrm{~d} 1+$ GluA2 } & 0,3143 & ns. \\
\hline & & \multicolumn{9}{|c|}{ BirA vs. a2d1 + GluA2 + BirA } & $<0,0001$ & **** \\
\hline & & \multicolumn{9}{|c|}{ a2d1 GluA2 vs. A2d1 + GluA2 + BirA" } & $<0,0001$ & $* * *$ \\
\hline
\end{tabular}

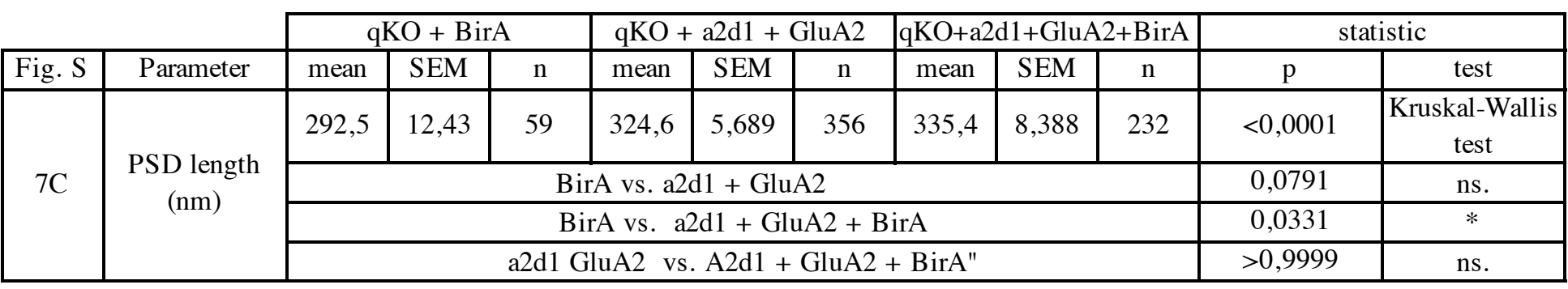

\begin{tabular}{|c|c|c|c|c|c|c|c|c|c|c|c|c|}
\hline & & & $\mathrm{KO}+\mathrm{Bi}$ & & $\mathrm{qKO}$ & $\mathrm{a} 2 \mathrm{~d} 1+$ & $\mathrm{uA} 2$ & $\mathrm{qKO}+\mathrm{a}$ & $\mathrm{d} 1+\mathrm{GluA}$ & BirA & & stic \\
\hline Fig. S & Parameter & mean & SEM & $\mathrm{n}$ & mean & SEM & $\mathrm{n}$ & mean & SEM & $\mathrm{n}$ & $\mathrm{p}$ & test \\
\hline \multirow{4}{*}{$7 \mathrm{E}$} & \multirow{4}{*}{$\begin{array}{c}\text { mEPSC } \\
\text { frequency }(\mathrm{Hz})\end{array}$} & 3,331 & 0,4451 & 23 & 2,268 & 0,4982 & 19 & 4,941 & 0,5387 & 48 & 0,0051 & $\begin{array}{c}\text { Kruskal-Wallis } \\
\text { test }\end{array}$ \\
\hline & & \multicolumn{9}{|c|}{ BirA vs. a2d1 + GluA2 } & 0,0043 & ** \\
\hline & & \multicolumn{9}{|c|}{ BirA vs. a2d1 + GluA2 + BirA } & 0,3871 & ns. \\
\hline & & \multicolumn{9}{|c|}{ a2d1 GluA2 vs. a2d1 + GluA2 + BirA } & 0,3613 & ns. \\
\hline
\end{tabular}

\begin{tabular}{|c|c|c|c|c|c|c|c|c|c|c|c|c|}
\hline Fig. S & Parameter & mean & SEM & $\mathrm{n}$ & mean & SEM & $\mathrm{n}$ & mean & SEM & $\mathrm{n}$ & $\mathrm{p}$ & test \\
\hline \multirow{4}{*}{$7 \mathrm{~F}$} & \multirow{4}{*}{$\begin{array}{c}\text { mEPSC } \\
\text { amplitude } \\
\text { (nA) }\end{array}$} & 17,6 & 1,29 & 23 & 20,37 & 1,103 & 22 & 17,48 & 0,9581 & 48 & 0,1262 & $\begin{array}{c}\text { Kruskal-Wallis } \\
\text { test }\end{array}$ \\
\hline & & \multicolumn{9}{|c|}{ BirA vs. a2d $1+$ GluA2 } & 0,1557 & ns. \\
\hline & & \multicolumn{9}{|c|}{ BirA vs. $\mathrm{a} 2 \mathrm{~d} 1+\mathrm{GluA} 2+\mathrm{BirA}$} & 0,306 & ns. \\
\hline & & \multicolumn{9}{|c|}{ a2d1 GluA2 vs. a2d1 + GluA2 + BirA } & $>0,9999$ & ns. \\
\hline
\end{tabular}

\begin{tabular}{|c|c|c|c|c|c|c|c|c|c|c|c|c|}
\hline Fig. S & Parameter & mean & SEM & $\mathrm{n}$ & mean & SEM & $\mathrm{n}$ & mean & SEM & $\mathrm{n}$ & $\mathrm{p}$ & test \\
\hline \multirow{4}{*}{$7 \mathrm{G}$} & \multirow{4}{*}{$\begin{array}{c}\text { mEPSC rise } \\
\text { time (ms) }\end{array}$} & 0,5905 & 0,0246 & 23 & 0,4846 & 0,0241 & 22 & 0,4967 & 0,0153 & 48 & 0,0044 & $\begin{array}{c}\text { Kruskal-Wallis } \\
\text { test }\end{array}$ \\
\hline & & \multicolumn{9}{|c|}{ BirA vs. a2d1 + GluA2 } & $>0,9999$ & ns. \\
\hline & & \multicolumn{9}{|c|}{ BirA vs. $\mathrm{a} 2 \mathrm{~d} 1+\mathrm{GluA} 2+\mathrm{BirA}$} & 0,007 & $* *$ \\
\hline & & \multicolumn{9}{|c|}{ a2d1 GluA2 vs. a2d1 + GluA2 + BirA } & 0,0165 & $*$ \\
\hline
\end{tabular}

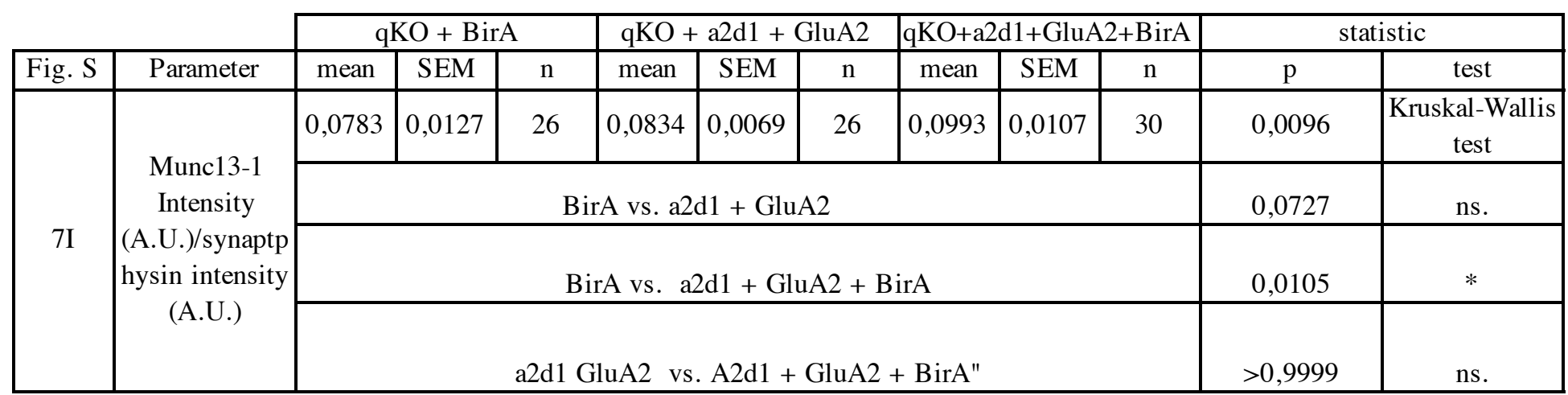

